Aus der Abteilung Neurologie

(Prof. Dr. med. M. Bähr)

im Zentrum Neurologische Medizin

der Medizinischen Fakultät der Universität Göttingen

\title{
14-3-3-Isoformen im Liquor cerebrospinalis bei Patienten mit verschiedenen molekularen Subtypen der sporadischen Creutzfeldt-Jakob-Krankheit
}

\author{
INAUGURAL-DISSERTATION \\ zur Erlangung des Doktorgrades \\ der Medizinischen Fakultät \\ der Georg-August-Universität zu Göttingen
}

vorgelegt von

Swati Jategaonkar

aus

Bangalore, Indien

Göttingen 2011 
Dekan:

I. Berichterstatterin:

II. Berichterstatter/in:

III. Berichterstatter/in:

Tag der mündlichen Prüfung:
Prof. Dr. med. C. Frömmel

Prof. Dr. med. Zerr

Priv.-Doz. Dr. med. Schulz-Schaeffer

09.05.2012 


\section{Inhaltsverzeichnis}

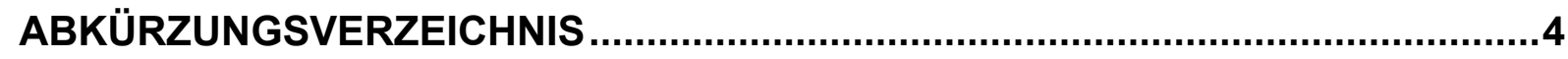

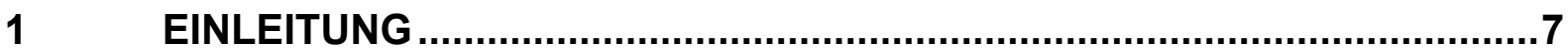

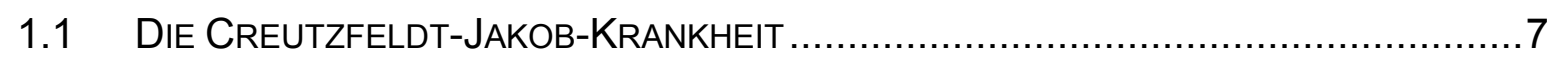

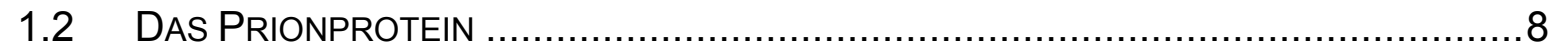

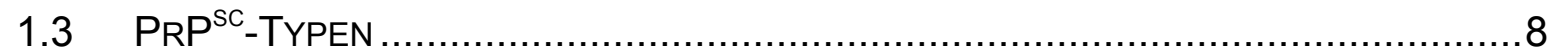

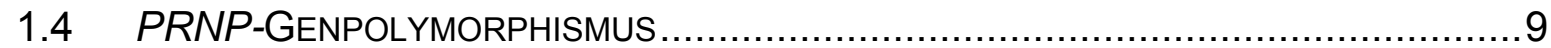

1.5 SUBTYPEN DER SPORADISCHEN CREUTZFELDT-JAKOB-KRANKHEIT .....................9

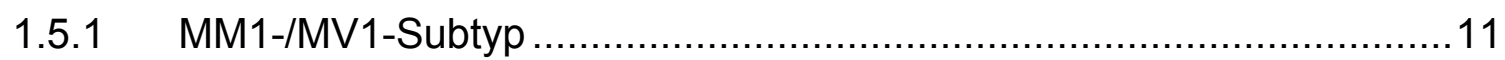

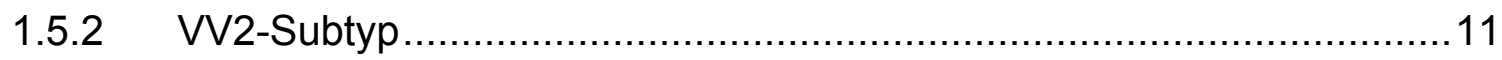

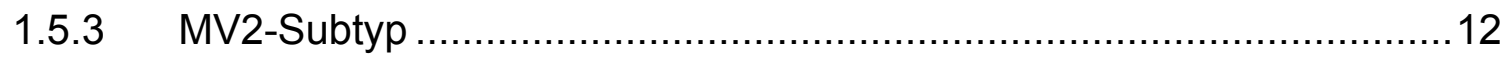

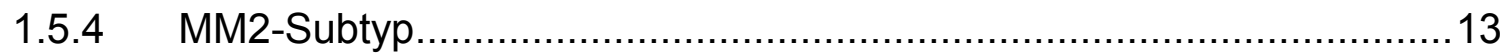

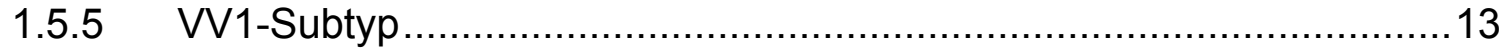

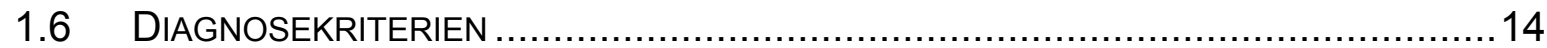

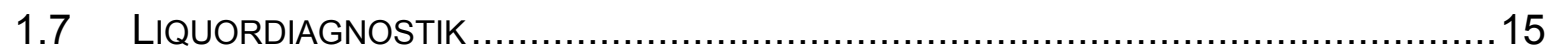

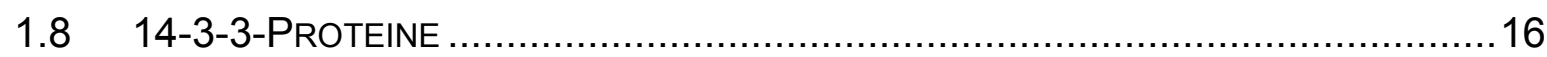

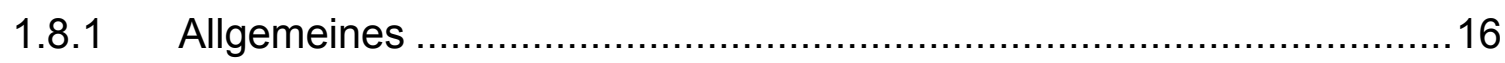

1.8.2 14-3-3-Protein und Creutzfeldt-Jakob-Krankheit...............................18

1.8.3 Isoformen des 14-3-3-Proteins.......................................................

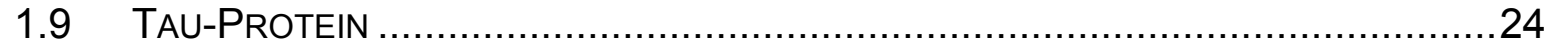

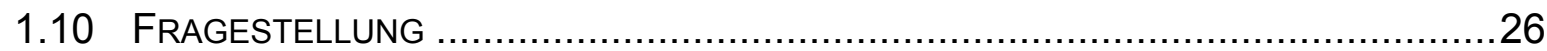

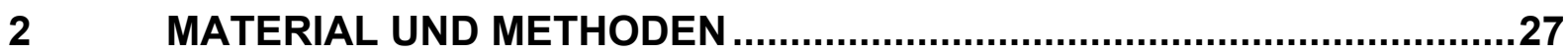

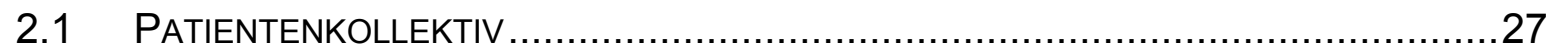

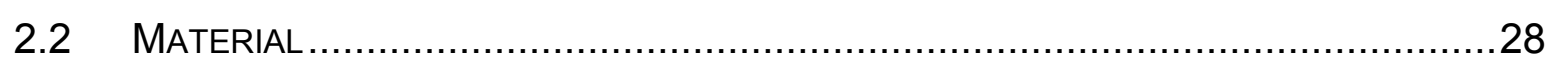

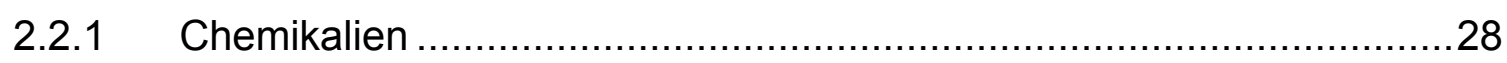

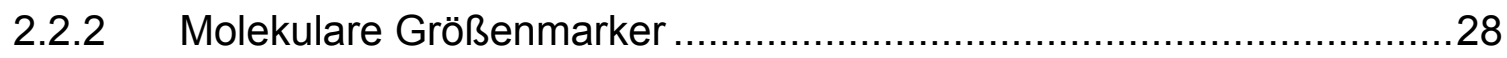

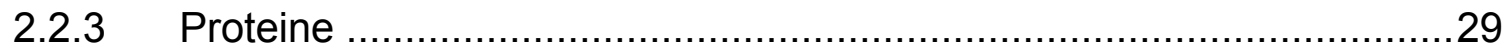

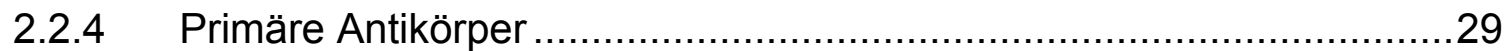

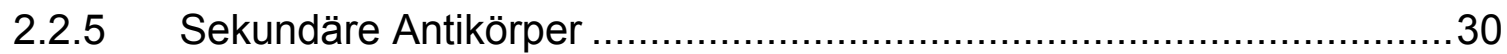

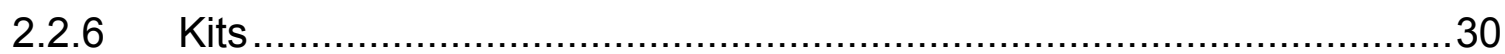

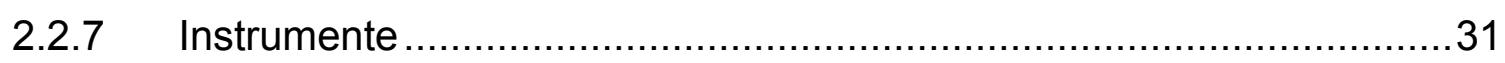

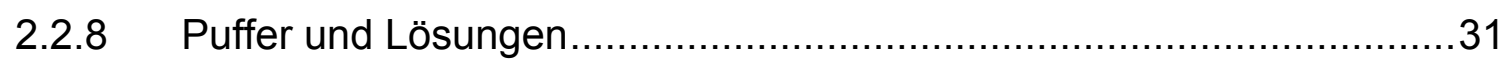


2.3 METHODEN

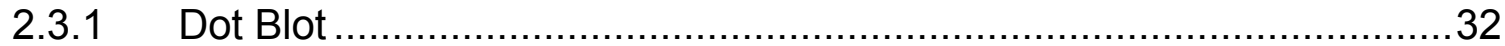

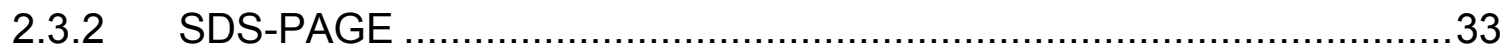

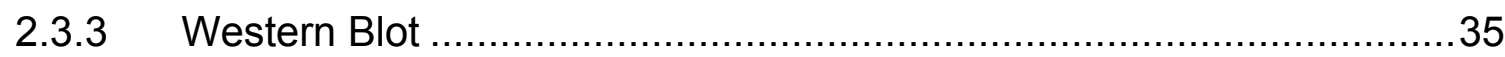

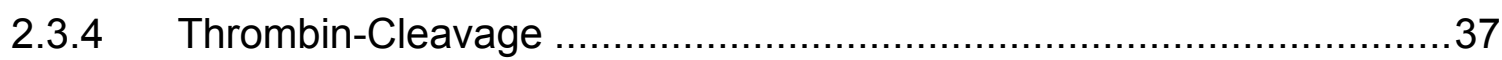

2.3.5 Tau-Proteinbestimmung im Liquor ................................................38

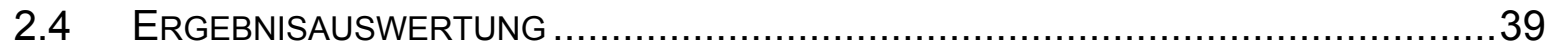

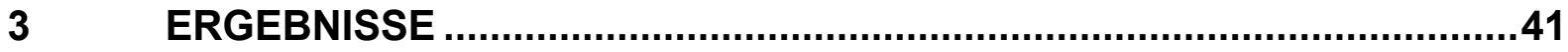

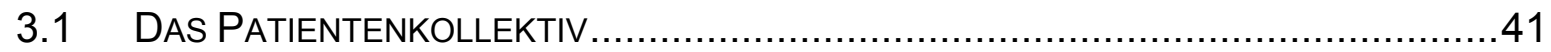

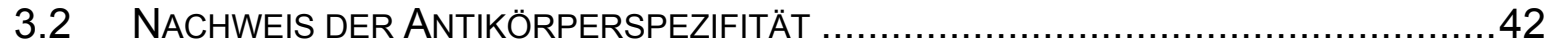

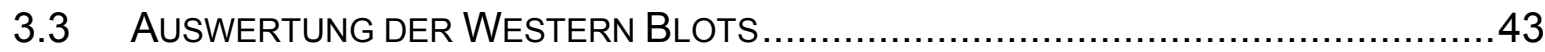

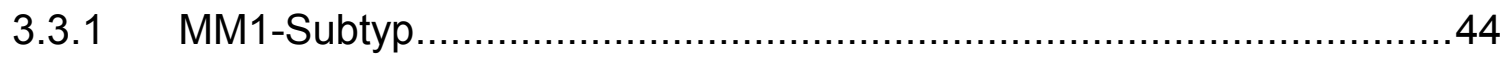

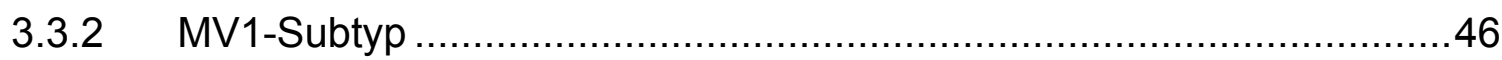

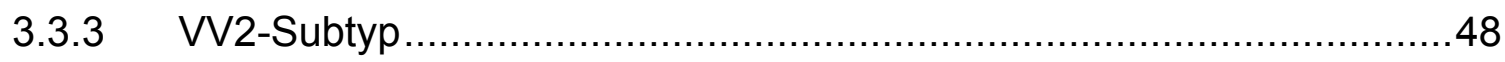

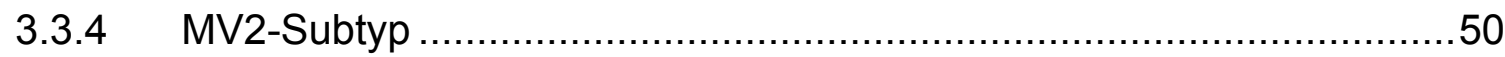

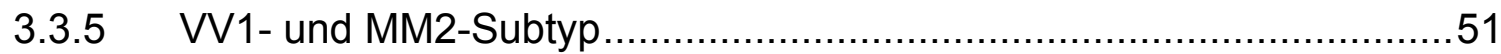

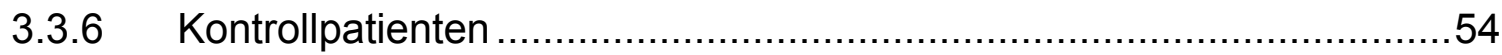

3.3.7 Zusammenfassung des qualitativen Nachweises der 14-3-3Isoformen für die einzelnen sCJK-Subtypen ......................................55

3.4 KORRELATION DER 14-3-3-ISOFORMEN MIT DEN BANDENSTÄRKEN IM

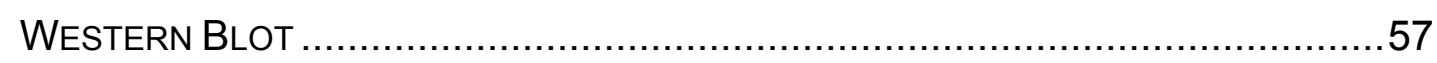

3.5 NACHWEIS VON TAU-PROTEIN IM LIQUOR VON SCJK-PATIENTEN ......................63

3.6 ERGEBNIS DER KORRELATION DER BANDENINTENSITÄTEN FÜR 14-3-3PROTEIN MIT DER HÖHE DES TAU-PROTEINS IM LIQUOR CEREBRosPINALIS ........64

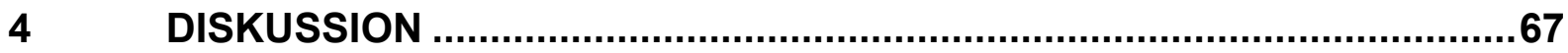

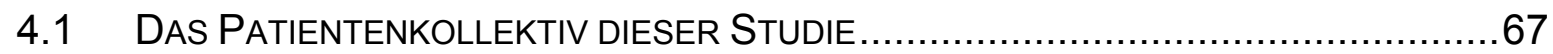

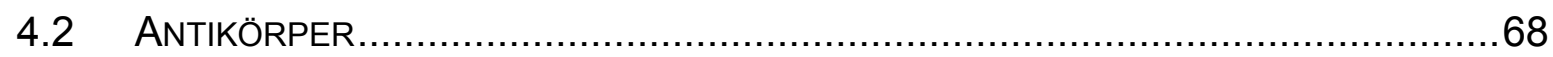

4.3 VORHANDENSEIN VON 14-3-3-ISOFORMEN IM LIQUOR VON SCJK-

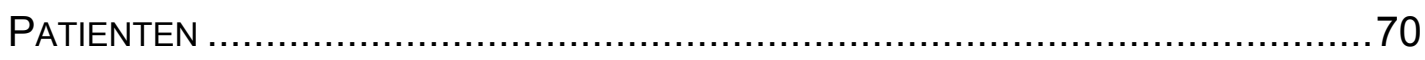

4.4 DifFERENZIERUNG DER SCJK-SUBTYPEN ANHAND DES 14-3-3-

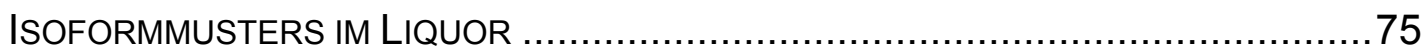

4.5 ISOFORMMUSTER DES KONTROLLKOLLEKTIVS - 14-3-3-B ALS DIFFERENZIERUNGSMARKER 
4.6 Rolle des TAu-PROTEINS IM LIQUOR VON SCJK-PATIENTEN ........................77

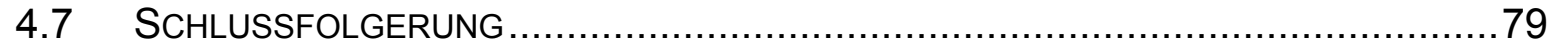

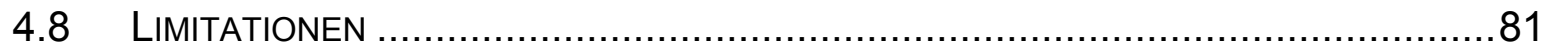

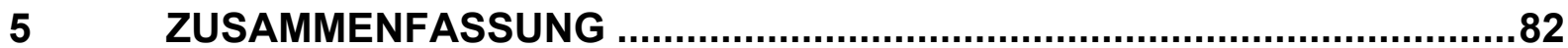

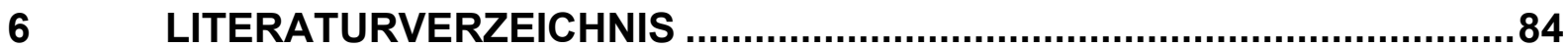




\section{Abkürzungsverzeichnis}

A

Abb.

AD

$\mathrm{Ag}$

APS

BLOTTO

BSE

${ }^{\circ} \mathrm{C}$

CJK

CMRT

CSF

CWD

${ }_{\text {dd }} \mathrm{H}_{2} \mathrm{O}$

DEAE

dl

ECL

EEG

ELISA

engl.

et al.

FFI

$g$

g

GSS

GST

HRP

HSE

IBL

iCJK

$\lg G$

$\mathrm{kDa}$

I
Ampere

Abbildung

Alzheimer-Demenz

Antigen

Ammoniumperoxidisulfat

Bovine lacto transfer technic optimizer

Bovine spongiforme Enzephalopathie

Grad Celsius

Creutzfeldt-Jakob-Krankheit

Kraniales Magnetresonanztomogramm

Cerebrospinal fluid

Chronic wasting disease

Doppelt destilliertes Wasser

Diethylaminoethyl

Deziliter

Enzyme-linked Chemilumineszenz

Elektroenzephalogramm

Enzyme-linked immunosorbent assay

Englisch

Et alii

Letale familiäre Insomnie

Erdbeschleunigung

Gramm

Gerstmann-Sträussler-Scheinker-Syndrom

Glutathion-S-Transferase

Horseradish-peroxidase

Herpes-simplex-Enzephalitis

Immunolaboratories Japan

latrogene Creutzfeldt-Jakob-Krankheit

Immunglobulin G

Kilo-Dalton

Liter 


\begin{tabular}{|c|c|}
\hline LB & Lewy Bodies \\
\hline M & Methionin \\
\hline$\mu g$ & Mikrogramm \\
\hline$\mu \mathrm{l}$ & Mikroliter \\
\hline $\mathrm{ml}$ & Milliliter \\
\hline $\mathrm{mm}$ & Millimeter \\
\hline $\mathrm{mM}$ & Millimolar \\
\hline MSA & Multisystematrophie \\
\hline MW & Mittelwert \\
\hline $\mathrm{n}$ & Anzahl \\
\hline $\mathrm{ng}$ & Nanogramm \\
\hline $\mathrm{nm}$ & Nanometer \\
\hline NSE & Neuronen-spezifische-Enolase \\
\hline Pat. & Patient \\
\hline PBS & Phosphate-buffered saline \\
\hline PCR & Polymerase chain reaction \\
\hline PD & Morbus Parkinson \\
\hline pg & Pikogramm \\
\hline PRNP & Prionproteingen \\
\hline $\operatorname{PrP}^{c}$ & Zelluläres Prionprotein \\
\hline $\operatorname{PrP} \mathrm{P}^{\mathrm{sc}}$ & Scrapie-Variante des Prionproteins \\
\hline PSWC & Periodische Sharp-Wave-Komplexe \\
\hline PVDF & Polyvinyldifluorid \\
\hline RP-HPLC & Reversed phase high-performance liquid chromatography \\
\hline RT & Raumtemperatur \\
\hline SC & Santa Cruz Biotechnology \\
\hline sCJK & Sporadische Creutzfeldt-Jakob-Krankheit \\
\hline SD & Standardabweichung \\
\hline SDS & Sodium dodecylsulfate \\
\hline SDS-PAGE & Sodium dodecylsulfate polyacrylamide gel electrophoresis \\
\hline S.J. & Swati Jategaonkar \\
\hline Tab. & Tabelle \\
\hline TSE & Transmissible spongiforme Enzephalopathien \\
\hline U.H. & Uta Heinemann \\
\hline
\end{tabular}




$\begin{array}{ll}\text { V } & \text { Valin } \\ \text { vCJK } & \text { Variante der Creutzfeldt-Jakob-Krankheit } \\ \text { v/v } & \text { Volume/volume } \\ \text { WB } & \text { Western Blot } \\ \text { WHO } & \text { World Health Organisation } \\ \alpha & \text { Alpha } \\ \beta & \text { Beta } \\ \delta & \text { Delta } \\ \varepsilon & \text { Epsilon } \\ \gamma & \text { Gamma } \\ \eta & \text { Eta } \\ \sigma & \text { Sigma } \\ \tau & \text { Tau } \\ \zeta & \text { Zeta }\end{array}$




\section{Einleitung}

\subsection{Die Creutzfeldt-Jakob-Krankheit}

Die Creutzfeldt-Jakob-Krankheit (CJK) wurde erstmal 1920 und 1921 von Creutzfeldt und Jakob als "eine eigenartige Erkrankung des Zentralnervensystems" (Creutzfeldt 1920, S. 1; Jakob 1921, S. 147) beschrieben. Es handelt sich um eine Form der seltenen neurodegenerativen, transmissiblen spongiformen Enzephalopathien (TSE), die durch neuronalen Untergang, Astrozytose und spongiforme Veränderungen des Gehirns gekennzeichnet sind. Sie kommen sowohl bei Mensch als auch Tier vor. 1982 wurde von Prusiner der Begriff Prionerkrankung ([engl.] prion: proteinaceous infectious particle) definiert (Prusiner 1982). Zu TSEs gehören neben der sporadischen CJK (sCJK) u. a. das Gerstmann-Sträussler-Scheinker-Syndrom (GSS), letale familiäre Insomnie (FFI), variante Creutzfeldt-Jakob-Krankheit (vCJK), ebenso wie die bovine spongiforme Enzephalopathie (BSE), chronic wasting disease (CWD) und Scrapie.

Die Creutzfeldt-Jakob-Krankheit ist mit einer Inzidenz von 1-2/1 Millionen Einwohner weltweit selten und tritt beim Menschen in $84 \%$ der Fälle sporadisch, sowie in etwa $10 \%$ der Fälle familiär auf (Ladogana et al. 2005). Daneben sind iatrogene Formen (iCJK), sowie die mit BSE-assoziierte Variante der CJK (vCJK) bekannt (Brown et al. 2000, Will et al. 1996). Die sporadische Creutzfeldt-Jakob-Krankheit tritt im mittleren und hohen Alter auf, typischerweise zwischen der sechsten und siebten Lebensdekade (Ladogana et al. 2005) und endet nach einer durchschnittlichen Überlebensdauer von 7 Monaten (Pocchiari et al. 2004) stets letal bei einer weltweiten Mortalitätsrate von 1,39 auf eine Millionen Einwohner (Ladogana et al. 2005). Die definitive Diagnose der SCJK kann bislang nur postmortem durch den Nachweis des pathologischen Prionproteins im Gehirn gestellt werden (Budka et al. 1995, Kretzschmar et al. 1996). Es wurden jedoch klinische Diagnosekriterien etabliert, die eine prämortale Diagnose der $\mathrm{sCJK}$ wahrscheinlich machen (WHO 1998). Eine kausale Therapie der Creutzfeldt-Jakob-Krankheit ist bis zum heutigen Zeitpunkt nicht bekannt. 


\subsection{Das Prionprotein}

Verantwortlich für das Auftreten der CJK sind die sogenannten Prionen, die aus Ablagerungen einer abnormen Isoform des zellulären Prionproteins $\left(\operatorname{PrP}^{\mathrm{c}}\right)$, bekannt als Scrapie-Variante $\left(\mathrm{PrP}^{\mathrm{sc}}\right)$, bestehen (Prusiner et al. 1984). Das $\mathrm{PrP}^{\mathrm{sc}}$ unterscheidet sich vom physiologischen, zellulären Prionprotein $\left(\operatorname{PrP}^{\mathrm{c}}\right)$ durch eine hohe Anzahl an $\beta$-Faltblättern in der Tertiärstruktur, verminderter Löslichkeit in Detergenzien, erhöhter Aggregationstendenz und einer relativ höheren Resistenz gegenüber Proteolyse (Meyer et al. 1986, Oesch et al. 1985). Das zelluläre Prionprotein ( $\operatorname{PrP}^{\mathrm{C}}$ ) hingegen hat eine Tertiärstruktur reich an $\alpha$-Helices. Die Funktion des physiologisch in Neuronen stark exprimierten Glykoproteins $\mathrm{PrP}^{\mathrm{C}}$ ist noch unklar. Möglicherweise spielt es eine Rolle bei der synaptischen Übertragung (Parchi und Gambetti 1995). Die posttranslationale Konformationsänderung von $\alpha$-Helices in $\beta$-Faltblätter ist entscheidend in der Entstehung von $\mathrm{PrP}^{\mathrm{sc}}$ und somit in der Pathogenese von Prionkrankheiten (Pan et al. 1993). Hypothesen zur Ätiologie der sporadischen Form der CJK beinhalten die horizontale Transmission, d.h. Infektion, die zunächst als Zeichen einer viralen Ätiologie interpretiert wurde (Gajdusek und Gibbs 1968, Gibbs und Gajdusek 1971), somatische Mutationen des offenen Leserahmens ([engl.] open reading frame, ORF) des Prionproteingens (PRNP) und spontane Konversion der $\alpha$ Helices in $\beta$-Faltblätter (Prusiner 1989). Auch nicht-zufällige, altersabhängige Abnormalitäten des Prionproteinmetabolismus werden ursächlich diskutiert.

Die sporadische Form der Creutzfeldt-Jakob-Krankheit zeigt eine große phänotypische Heterogenität. Sie beruht erstens auf wirtsunabhängigen Eigenschaften des $\operatorname{PrP}^{\mathrm{sc}}$ und zweitens auf wirtsabhängigen molekulargenetischen Faktoren (Parchi et al. 1996). Beide Variablen tragen zur Einteilung der sCJKPatienten in sechs Subtypen bei.

\section{$1.3 \operatorname{PrP}^{\mathrm{sc}}$-Typen}

Bei der sporadischen CJK sind zwei PrP ${ }^{\mathrm{sc}}$-Typen beschrieben (Typ 1 und Typ 2), die unterschiedlich stark glykosylierte (di-, mono- und unglykosylierte) Isoformen aufweisen (Parchi et al. 1996). Die zwei $\mathrm{PrP}^{\mathrm{sc}}$-Typen unterscheiden sich in ihrer 
elektrophoretischen Mobilität und lassen sich anhand des Verhältnisses unterschiedlich stark glykosylierter $\mathrm{PrP}^{\mathrm{sc}}$-Isoformen differenzieren. Die relative molekulare Masse der bei der Elektrophorese schnellsten und damit unglykosylierten Isoform liegt beim PrP ${ }^{\mathrm{sc}}$ Typ 1 bei $21 \mathrm{kDa}$, beim Typ 2 bei $19 \mathrm{kDa}$. Das pathologische Prionprotein $\mathrm{PrP}^{\mathrm{sc}}$ akkumuliert bereits, bevor histopathologische Läsionen im Gehirn sichtbar sind (Parchi et al. 1996). Es wurde jedoch gezeigt, dass nicht ausschließlich die Menge, sondern der Typ des $\mathrm{PrP}^{\mathrm{sc}}$ den Progress der Krankheit bestimmt. So ist der Grad an Zelldysfunktion mit nachfolgender Symptomatik beim $\operatorname{PrP}^{\mathrm{sc}}$ Typ 1 deutlich schwerer als beim Typ 2 (Parchi et al. 1996), verbunden mit einer erhöhten Sensitivität für 14-3-3-Protein im Liquor und für periodische Sharp-Wave-Komplexe (PSWC) im EEG (Heinemann et al. 2007).

\subsection{PRNP-Genpolymorphismus}

Das Prionprotein ist beim Menschen auf dem kurzen Arm des Chromosoms 20 als PRNP-Gen codiert (Sparkes et al. 1986). Das Codon-129 des PRNP-Gens zeigt einen häufigen Polymorphismus kodierend für die Aminosäuren Methionin (M) oder Valin (V) (Owen et al. 1990), der mittels Polymerasekettenreaktion (PCR) und anschließender Sequenzierung der kodierenden Region bestimmt werden kann (Windl et al. 1996). In der kaukasischen Bevölkerung findet man Häufigkeiten von Codon-129-Polymorphismen von etwa $37 \%$ für MM, 51\% für MV und $12 \%$ für VV (Parchi et al. 1999). In der Population der Patienten mit sporadischer CJK sind jedoch circa 90\% homozygot für Methionin oder Valin, was eine erhöhte Anfälligkeit für sCJK bei Homozygoten, insbesondere für Methionin-Homozygotie, an Codon-129 vermuten lässt (Ladogana et al. 2005).

\subsection{Subtypen der sporadischen Creutzfeldt-Jakob-Krankheit}

Der PrP ${ }^{\text {sc }}$-Typ und der Genotyp an Codon-129 des PRNP-Gens beeinflussen gravierend den Phänotyp der sporadischen Creutzfeldt-Jakob-Krankheit und sind nicht als voneinander unabhängige Faktoren zu betrachten. So findet man in circa 95\% der Patienten mit sCJK, die homozygot für Methionin (MM) sind, den PrP ${ }^{\mathrm{sc}}$-Typ 1 , bei Patienten, die homozygot für Valin (VV) oder heterozygot (MV) sind, in circa 
86\% der Fälle PrP ${ }^{\mathrm{sc}}$-Typ 2 (Parchi et al. 1999). Tabelle 1 zeigt die Verteilung der PRNP-Genotypen in der kaukasischen Bevölkerung und in sCJKPatientenkollektiven, sowie den Zusammenhang von $\mathrm{PrP}^{\mathrm{sc}}-$ Typen und PRNPGenotypen.

\begin{tabular}{|lccc|}
\hline Codon-129 & MM & MV & VV \\
\hline Kaukasisches Kollektiv $(n=544)$ & 37 & 51 & 12 \\
sCJK Kollektiv $\left(n=300 / n=992^{*}\right)$ & $71.6 / 66^{*}$ & $11.7 / 18^{*}$ & $16.7 / 16^{*}$ \\
PrP $^{\text {sc }}$ Typ $1(n=214)$ & 94.9 & 3.7 & 1.4 \\
PrP $^{\text {sc }}$ Typ 2 $(n=86)$ & 14.0 & 31.4 & 54.6 \\
\hline
\end{tabular}

Tabelle 1: $\quad$ PRNP Genotypen und PrPsc-Typen bei sCJK, Angaben in \% * = Angaben aus Heinemann et al. 2007

(modifiziert nach Parchi et al. 1999)

Anhand des Codon-129-Polymorphismus und der PrP ${ }^{\mathrm{sc}}$-Typen wurden von Parchi et al. (1999) sechs verschiedene Subtypen (MM1, MM2, MV1, MV2, VV1, VV2) definiert, die sich unter anderem in der Symptomatik, im Alter bei Krankheitsbeginn, Krankheitsdauer, neuropathologischem Läsionsprofil, Sensitivität von EEG, 14-3-3Western Blot (WB) und cMRT (kraniales Magnetresonanztomogramm) unterscheiden (Heinemann et al. 2007, Parchi et al. 1999). Tabelle 2 zeigt die Verteilung der sechs Subtypen von neuropathologisch gesicherten sCJK-Patienten anhand klinischer und apparativer Parameter.

\begin{tabular}{|c|c|c|c|c|c|c|c|c|}
\hline & $\begin{array}{c}\text { MM1 } \\
(n=153)\end{array}$ & $\begin{array}{c}\text { MM2 } \\
(n=12)\end{array}$ & $\begin{array}{c}\text { MV1 } \\
(n=12)\end{array}$ & $\begin{array}{c}\text { MV2 } \\
(n=26)\end{array}$ & $\begin{array}{l}\text { V1 } \\
(n=7)\end{array}$ & $\begin{array}{c}\text { V22 } \\
(n=33)\end{array}$ & PrP1 & PrP2 \\
\hline $\begin{array}{l}\text { Mittleres } \\
\text { Alter* }\end{array}$ & $\begin{array}{c}67.5 \\
(31-86)\end{array}$ & $\begin{array}{c}67 \\
(60-82)\end{array}$ & $\begin{array}{c}61 \\
(53-79)\end{array}$ & $\begin{array}{c}64 \\
(53-75)\end{array}$ & $\begin{array}{c}44.2 \\
(19-55)\end{array}$ & $\begin{array}{c}65.1 \\
(40-81)\end{array}$ & $\begin{array}{c}67 \\
(19-86)\end{array}$ & $\begin{array}{c}63 \\
(40-82)\end{array}$ \\
\hline $\begin{array}{l}\text { Krankheits- } \\
\text { dauer \# }\end{array}$ & $\begin{array}{c}4.4 \\
(1.1-38.5)\end{array}$ & $\begin{array}{c}14 \\
(3-24)\end{array}$ & $\begin{array}{c}4.6 \\
(2.1-20.4)\end{array}$ & $\begin{array}{c}12 \\
(4-27)\end{array}$ & $\begin{array}{c}17.4 \\
(8.3-24.7)\end{array}$ & $\begin{array}{c}6.4 \\
(2.2-15.7)\end{array}$ & $\begin{array}{c}4.43 \\
(1.1-38.5)\end{array}$ & $\begin{array}{c}10 \\
(2.2-32.1)\end{array}$ \\
\hline $\begin{array}{l}\text { Positives } \\
14-3-3\end{array}$ & $\begin{array}{c}99 \% \\
(135 / 136)\end{array}$ & $\begin{array}{l}92 \% \\
(11 / 12)\end{array}$ & $\begin{array}{l}92 \% \\
(11 / 12)\end{array}$ & $\begin{array}{l}76 \% \\
(20 / 26)\end{array}$ & $\begin{array}{c}100 \% \\
(7 / 7)\end{array}$ & $\begin{array}{l}97 \% \\
(30 / 31)\end{array}$ & $\begin{array}{c}98 \% \\
(158 / 161)\end{array}$ & $\begin{array}{l}86 \% \\
(60 / 70)\end{array}$ \\
\hline $\begin{array}{l}\text { Typisches } \\
\text { EEG }\end{array}$ & $\begin{array}{c}73 \% \\
(107 / 147)\end{array}$ & $\begin{array}{l}42 \% \\
(5 / 12)\end{array}$ & $\begin{array}{l}64 \% \\
(7 / 11)\end{array}$ & $\begin{array}{l}8 \% \\
(2 / 26)\end{array}$ & $\begin{array}{l}17 \% \\
(1 / 6)\end{array}$ & $\begin{array}{c}4 \% \\
(1 / 27)\end{array}$ & $\begin{array}{c}69 \% \\
(115 / 167)\end{array}$ & $\begin{array}{l}13 \% \\
(8 / 62)\end{array}$ \\
\hline $\begin{array}{l}\text { Typisches } \\
\text { MRT }\end{array}$ & $\begin{array}{l}51 \% \\
(36 / 71)\end{array}$ & $\begin{array}{c}13 \% \\
(1 / 8)\end{array}$ & $\begin{array}{c}71 \% \\
(5 / 7)\end{array}$ & $\begin{array}{c}90 \% \\
(18 / 20)\end{array}$ & $\begin{array}{c}33 \% \\
(2 / 6)\end{array}$ & $\begin{array}{l}63 \% \\
(17 / 27)\end{array}$ & $\begin{array}{l}50 \% \\
(43 / 86)\end{array}$ & $\begin{array}{l}54 \% \\
(32 / 59)\end{array}$ \\
\hline
\end{tabular}

Tabelle 2: $\quad$ Subtypenverteilung von sCJK-Patienten anhand klinischer und apparativer Parameter * in Jahren, \# in Monaten (nach Heinemann et al. 2007) 


\subsubsection{MM1-/MV1-Subtyp}

Der MM1-Subtyp ist mit $60-70 \%$ die beim Menschen am häufigsten vorkommende Form der sporadischen Creutzfeldt-Jakob-Krankheit und wird zusammen mit dem Subtyp MV1 als „klassische“ sCJK beschrieben (Gambetti et al. 2003). Die beiden Subtypen MM1 und MV1 zeigen sehr ähnliche klinische Merkmale und neuropathologische Läsionsprofile. Sie gehen mit einer kurzen Krankheitsdauer und rapide fortschreitendem Krankheitsprozess einher, wobei früh progressive Demenz, Myoklonien, periodische Sharp-Wave-Komplexe (PSWC) im EEG und positiver Nachweis von 14-3-3 im Western Blot mit einer Sensitivität von circa 95\% charakteristisch für diese beiden Subtypen sind (Castellani et al. 2004, Parchi et al. 1996). Im 14-3-3-ELISA ([engl.] enzyme-linked immunosorbent assay) konnten bei den klassischen sCJK-Subtypen hohe Konzentrationen (MM1: Median 2384 pg/ml, MV1: $2401 \mathrm{pg} / \mathrm{ml}$ ) an 14-3-3 im Liquor nachgewiesen werden (Gmitterova et al. 2009). Neuropathologisch lässt sich eine spongiforme Degeneration, Astrogliose und neuronaler Zelluntergang im zerebralen, v. a. okzipitalen Kortex, im Neostriatum, Thalamus und Zerebellum nachweisen, wohingegen die Hippokampusregion, der Hypothalamus und die Kerne des Hirnstamms ausgespart sind. Immunhistochemisch ergibt sich eine feine, gepunktete Färbung des $\mathrm{PrP}^{\mathrm{sc}}$ vom sogenannten synaptischen bzw. retikulären Typ sowohl für den Subtyp MM1 als auch MV1 (Gambetti et al. 2003, Parchi et al. 1996 und 1999).

\subsubsection{VV2-Subtyp}

Der VV2-Subtyp, früher als zerebelläre oder ataktische Form der sCJK bezeichnet, ist mit circa 16\% aller Fälle der zweithäufigste Subtyp der sporadischen CreutzfeldtJakob-Krankheit (Parchi et al. 1999). Symptome bei Krankheitsbeginn, wie die ehemalige Bezeichnung schon besagt, sind Ataxie sowie weitere zerebelläre Symptome. Ein Myoklonus zeigt sich anfangs nicht, tritt jedoch im Laufe der Erkrankung zunehmend auf, genauso wie progressive Demenz und Pyramidenbahnzeichen. Kortikale Symptome wie Apraxie und Aphasie wurden hingegen nicht beobachtet (Parchi et al. 1996). Das Gehirn der VV2-Patienten ist besonders in den subkortikalen Schichten und den Hirnstammkernen von spongiformen Veränderungen, Astrogliose und Neuronenverlust betroffen. Der zerebelläre Kortex ist weitgehend atroph (Parchi et al. 1999). Die 
immunhistochemische Färbung von $\operatorname{PrP}^{\mathrm{sc}}$ zeigt bei diesem Subtyp, neben einem synaptischen Muster und laminärer Verteilung von $\mathrm{PrP}^{\mathrm{sc}}$ in tiefen kortikalen Schichten, zusätzlich fokale plaqueartige Aggregate ohne PrP-Amyloid und ein diagnostisch wegweisendes Färbungsmuster im Kleinhirn (Gambetti et al. 2003). Das EEG zeigt bei diesem Patientenkollektiv nur selten das typische Bild der PSWC, jedoch in circa zwei Drittel der Fälle typische hyperintense Areale im cMRT (Heinemann et al. 2007). Die Sensitivität von 14-3-3-Western Blots ist mit $97 \%$ (Heinemann et al. 2007) und $80 \%$ (Castellani et al. 2004) in der Literatur unterschiedlich hoch angegeben. In der Studie von Gmitterova et al. konnte bei dem VV2-Subtyp die höchste 14-3-3-Konzentration (Median $3437 \mathrm{pg} / \mathrm{ml}$ ) im Liquor nachgewiesen werden (Gmitterova et al. 2009).

\subsubsection{MV2-Subtyp}

Der dritthäufigste Subtyp mit einer Häufigkeit von circa 10\% ist der MV2-Subtyp, auch als Kuru-Plaques-Variante bekannt (Krasnianski et al. 2006b, Parchi et al. 1999). Der MV2-Subtyp hat im Gegensatz zum MM1-Subtyp einen protrahierten, eher atypischen Krankheitsverlauf und muss daher differentialdiagnostisch von der varianten Creutzfeldt-Jakob-Krankheit (vCJK) abgegrenzt werden (Krasnianski et al. 2006b). Bei Krankheitsbeginn präsentieren sich die Patienten häufig mit den Symptomen Demenz und Ataxie und entwickeln im Verlauf mehrheitlich psychiatrische sowie extrapyramidalmotorische Störungen (Krasnianski et al. 2006b). Das histopathologische Profil des MV2-Subtyps ist durch Kuru-Plaques charakterisiert, die PrP-Amyloid enthalten (Gambetti et al. 2003). Das PrP ${ }^{\mathrm{sc}}$ Färbemuster entspricht dem des VV2-Subtyps, wobei die Ablagerungen noch fokaler und plaqueartiger sind (Parchi et al. 1999). Die apparative Diagnostik beim MV2Subtyp ergibt eine geringe Sensitivität für das EEG, jedoch eine Sensitivität von $90 \%$ für das cMRT. Die in verschiedenen Studien differierend beschriebenen Sensitivitäten von 30, 57 bzw. 76\% (Castellani et al. 2004, Krasnianski et al. 2006b, Zerr et al. 2000b) für positives 14-3-3 im Liquor sind signifikant niedriger als beim klassischen sCJK-Typ (Krasnianski et al. 2006b). Die mittlere Konzentration im 14-33-ELISA lag bei diesem Subtyp lediglich bei 719 pg/ml (Gmitterova et al. 2009). 


\subsubsection{MM2-Subtyp}

Der mit circa 4\% aller sCJK-Patienten sehr seltene MM2-Subtyp ist charakterisiert durch eine lange Krankheitsdauer, progressive Demenz und frühe neuropsychologische Symptome, wie Aphasie oder Apraxie (Krasnianski et al. 2006a). Er kann klinisch und histopathologisch weiter in eine thalamische und kortikale Variante unterteilt werden (Parchi et al. 1999), je nach Lokalisation der Läsionen und den daraus resultierenden dominierenden Symptomen. Typisch für den MM2-Subtyp ist eine grob-spongiforme Degeneration mit großen Vakuolen, wobei das Zerebellum meist nicht betroffen ist (Gambetti et al. 2003). Die PrP ${ }^{s c}$ Immunhistochemie zeigt eine Färbung besonders am Rand der Vakuolen, wobei insgesamt die Menge an $\mathrm{PrP}^{\mathrm{sc}}$ geringer ist als bei anderen Formen (Parchi et al. 1999). Sowohl der thalamische als auch der kortikale MM2-Subtyp zeigen eine hohe Sensitivität für den Nachweis der Proteine 14-3-3 und S100b, einem weiteren neurodegenerativen Marker, im Liquor der Patienten. Die 14-3-3-Konzentration im Liquor lag dennoch mit einem Median von $537 \mathrm{pg} / \mathrm{ml}$ deutlich unterhalb der anderen Subtypen (Gmitterova et al. 2009). Typische EEG- und MRT-Phänomene sind nur in $42 \%$ bzw. 13\% nachweisbar (Krasnianski et al. 2006a).

\subsubsection{VV1-Subtyp}

Der mit circa 1\% Häufigkeit verschwindend seltene VV1-Subtyp wird auch als EarlyOnset-Typ bezeichnet, da er signifikant jüngere Patienten (mittleres Alter 44 Jahre vs. 65 bei allen anderen Subtypen der SCJK) betrifft (Meissner et al. 2005). Der VV1Typ geht mit einer verlängerten Krankheitsdauer (im Mittel 21 Monate vs. 6 Monate bei anderen sCJK-Subtypen) einher und präsentiert sich initial mit Persönlichkeitsveränderungen, langsam progredienter Demenz, sowie fokalen neurologischen Defiziten (Meissner et al. 2005). Auffällig ist in der Histopathologie die Dissoziation zwischen den schwerwiegenden spongiformen Veränderungen im Neokortex mit Aussparung von Hirnstamm und Zerebellum und der sehr schwachen, synaptoformen Färbung von $\operatorname{PrP}^{\mathrm{sc}}$ (Gambetti et al. 2003). EEG und cMRT haben beim VV1-Subtyp eine geringe Sensitivität, 14-3-3 hingegen konnte in einer Studie von Meissner et al. (2005) beim gesamten Patientenkollektiv, bestehend aus neun Patienten, nachgewiesen werden. Der Median der 14-3-3-Konzentration im Liquor bei diesem Subtyp lag bei 1245 pg/ml (Gmitterova et al. 2009). 


\subsection{Diagnosekriterien}

Die definitive Diagnose einer sporadischen Creutzfeldt-Jakob-Krankheit kann bislang nur postmortal durch neuropathologischen Nachweis bestimmter Hirnläsionen und des immunhistochemisch gefärbten Prionproteins $\mathrm{PrP}^{\mathrm{sc}} \mathrm{im}$ Gehirn erfolgen (Budka et al. 1995, Kretzschmar et al. 1996). In den letzten Jahren wurden jedoch große Fortschritte hinsichtlich der klinischen Charakterisierung verschiedener CJKPhänotypen und apparativer Diagnostik gemacht, so dass folgende Kriterien für die Diagnose einer Creutzfeldt-Jakob-Krankheit (definitiv, wahrscheinlich, möglich), unabhängig von den beschriebenen Subtypen und nach Ausschluss anderer Differentialdiagnosen, vorgeschlagen wurden:

\begin{tabular}{|l|l|l|}
\hline I & & Progressive Demenz \\
\hline II & A & Myoklonus \\
\hline & B & Sehstörungen/zerebelläre Symptome \\
\hline & C & Pyramidale/extrapyramidale Symptome \\
\hline & D & Akinetischer Mutismus \\
\hline III & A & $\begin{array}{l}\text { Typisches EEG (periodische bi-/triphasische Sharp-Wave- } \\
\text { Komplexe) }\end{array}$ \\
\hline & B & Positiver Nachweis für 14-3-3 im Liquor mittels Western Blot \\
\hline Mögliche sCJK & C & Positiver MRT-Befund (siehe unten) \\
\hline Wahrscheinliche sCJK & I und 2 von II und mindestens 1 von III \\
\hline Definitive sCJK & Neuropathologisch gesicherte Fälle \\
\hline
\end{tabular}

Tabelle 3: Diagnosekriterien der sporadischen CJK

(WHO 1998, Zerr et al. 2000a, Zerr et al. 2009)

Neuere Studien (Kallenberg et al. 2006, Zerr et al. 2009) haben gezeigt, dass Patienten mit sporadischer Creutzfeldt-Jakob-Krankheit in MRT-Untersuchungen (DWI bzw. FLAIR) charakteristische Hyperintensitäten aufweisen, sodass positive MRT-Befunde, nämlich Hyperintensität in Nucleus caudatus und Putamen oder in mindestens zwei kortikalen Regionen (temporal-parietal-okzipital), Einzug in die Diagnosekriterien für sporadische Creutzfeldt-Jakob-Krankheit gehalten haben. 


\subsection{Liquordiagnostik}

Im Gegensatz zu der neuen Variante der Creutzfeldt-Jakob-Krankheit (vCJK), bei der das pathologische Prionprotein in lymphatischen Geweben nachgewiesen werden kann (Hill et al. 1997), war es bei der sporadischen CJK lange Zeit nicht möglich, $\mathrm{PrP}^{\mathrm{sc}}$ außerhalb des Gehirns zu bestimmen. Erst kürzlich ist es Atarashi et al. (2011) erstmalig gelungen, mittels der neuen Methode RT-QUIC (real-time quaking-induced conversion) PrPsc in Liquor cerebrospinalis nachzuweisen. Weitere Studien werden den diagnostischen Stellenwert dieser Methode in der prämortalen Diagnose der sCJK zeigen. Eine Hirnbiopsie ist auf Grund der Infektiosität und mangelnder Sterilisations- und Dekontaminationsmöglichkeiten (Taylor et al. 1994) mit Risiken für die Patienten verbunden, v. a. bei Behandlung mit demselben Operationsbesteck. Aus diesen Gründen sind Surrogatmarker für die Diagnose der sCJK notwendig, wobei der erhöhte bzw. erniedrigte Nachweis zerebraler Proteine im Liquor von Patienten mit Verdacht auf sporadische CJK ein sehr wertvolles diagnostisches Mittel ist (Sanchez-Juan et al. 2006). Zu diesen Surrogatmarkern gehören u. a. TauProtein, $\beta$-Amyloid, NSE (Neuronen-spezifische-Enolase), S100b und 14-3-3-Protein.

Der Nachweis der Proteine 14-3-3 im Liquor von sCJK-Patienten ist, wie bereits erwähnt, in die diagnostischen Kriterien der Weltgesundheitsorganisation (WHO 1998) eingegangen und erfolgt routinemäßig mittels Gelelektrophorese ([engl.] sodium dodecylsulfate polyacrylamide gel electrophoresis, SDS-PAGE) und Western Blot (WB). Obwohl die Methode des Western Blot und insbesondere seine subjektive Interpretation eine Standardisierung der Ergebnisse erschwert, konnte gezeigt werden, dass diese Methode gerade im Hinblick auf die Sensitivität anderen quantitativen Verfahren wie beispielsweise einem ELISA überlegen ist (Kenney et al. 2000). Die Aufnahme des 14-3-3-Western Blots in die Diagnosekriterien führte zu einer starken Zunahme der Sensitivität klinisch gestellter Diagnosen ( $97 \%$ vs. $66 \%$ ) (Brandel et al. 2000, Zerr et al. 2000a). Von einer Anwendung als ScreeningParameter bei Patienten mit Demenz wird jedoch abgeraten, da das 14-3-3-Protein ein unspezifischer Marker neuronaler Schädigung ist und auch bei anderen Krankheitsbildern mit massiver Hirnschädigung erhöht sein kann, wie z.B. Ischämie, Blutung, Enzephalitis (Van Everbroeck et al. 2003). Der Nachweis von 14-3-3 bei Verdacht auf SCJK unterstützt jedoch die Diagnosestellung in der Differenzialdiagnose der neurodegenerativen Demenzen bei einer insgesamt sehr 
hohen Sensitivität (94\% bzw. 96\%) und Spezifität (93,3\% bzw. 99\%) (Hsich et al. 1996, Zerr et al. 1998).

Die Spezifität und Sensitivität des 14-3-3-Western Blots (WB) variiert abhängig von unterschiedlichen Einflussfaktoren in den verschiedenen Studien. So konnte gezeigt werden, dass durch die Kombination von 14-3-3-WB mit dem Nachweis von $A_{\beta} 1-42$ im Liquor die Spezifität signifikant erhöht werden konnte (Van Everbroeck et al. 2003), ebenso wie der positive prädiktive Wert bei Kombination von 14-3-3-WB mit einem typischen EEG (Zerr et al. 2000a). Weiterhin konnte gezeigt werden, dass mit zunehmendem Krankheitsprogress und bei wiederholter Lumbalpunktion die Sensitivität für 14-3-3 im Liquor zunimmt, wobei es in der Literatur diesbezüglich widersprüchliche Angaben gibt und ein endgültiger Abfall im terminalen Krankheitsstadium nicht ausgeschlossen werden kann (Gmitterova et al. 2009, Mollenhauer et al. 2003, Sanchez-Juan et al. 2006 und 2007, Van Everbroeck et al. 2003). Das Alter bei Krankheitsbeginn beeinflusst ebenfalls die Sensitivität des Nachweises von 14-3-3, wobei jüngere Patienten (<40 Jahre) eine geringere Sensitivität aufweisen als Ältere (76\% vs. 95\%) (Heinemann et al. 2007). Zusätzlich wurde gezeigt, dass bei längerer, gesamter Krankheitsdauer die 14-3-3Konzentration signifikant erniedrigt waren (Gmitterova et al. 2009, Van Everbroeck et al. 2003) bzw. hohe Konzentrationen an hirnassoziierten Proteinen im Liquor mit einer kurzen Krankheitsdauer einhergehen (Sanchez-Juan et al. 2007). Auf Grund dieser Umstände, der Assoziation von protrahierter Krankheitsdauer mit einem MVPolymorphismus an Codon-129 und weiterer Untersuchungen wurde angenommen, dass der PRNP-Genotyp und damit verbunden der molekulare Subtyp der Erkrankung einen Einfluss auf die Sensitivität des 14-3-3-Western Blots hat (Sanchez-Juan et al. 2007, Van Everbroeck et al. 2005).

\subsection{4-3-3-Proteine}

\subsubsection{Allgemeines}

Das 14-3-3-Protein wurde 1968 erstmalig durch Moore und Perez als ein in großen Mengen vorhandenes, saures Hirnprotein beschrieben. Es handelt sich um eine Proteinfamilie, benannt nach ihrem Elutions- und Migrationsmuster bei der zweidimensionalen Diethylaminoethyl (DEAE)-Zellulose-Chromatographie und der 
anschließenden Gelelektrophorese. Diese Proteinfamilie liegt hauptsächlich in Form von Dimeren vor, mit einem monomerischen Molekulargewicht von ca. $30 \mathrm{kDa}$ (Boston et al. 1982a). Jedes Monomer besteht aus neun a-Helices, die einen zentralen Kanal als Bindungstasche für Peptide und andere Liganden bilden (Yaffe 2002) (s. Abb. 1).
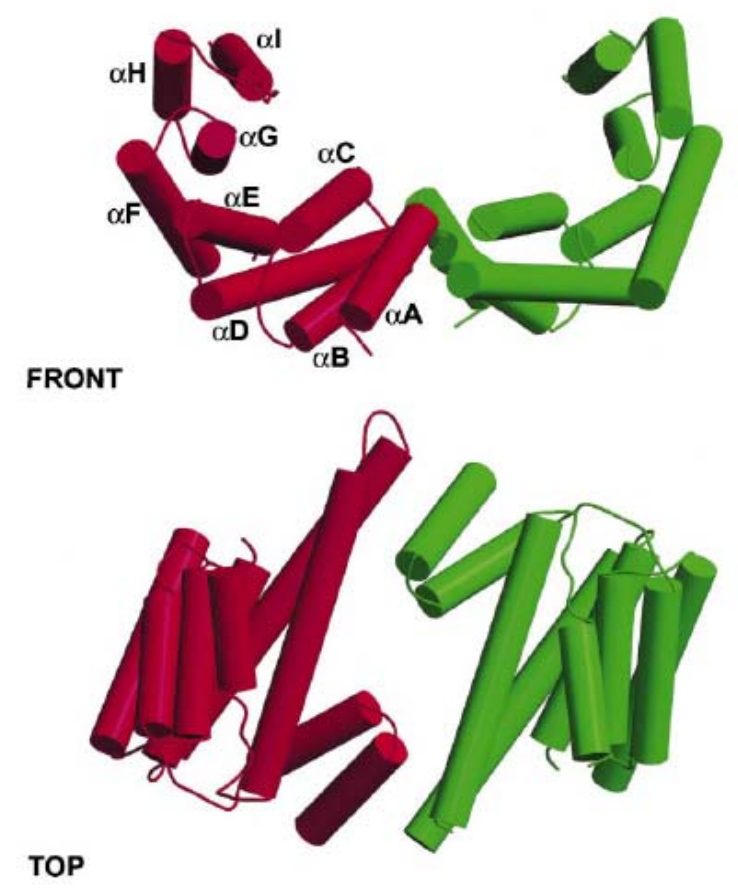

Abbildung 1: Struktur des 14-3-3-Proteins in zwei orthogonalen Ansichten.

Die neun $\alpha$-Helices $(\alpha \mathrm{A}-\alpha \mathrm{l})$ eines Monomers sind als Zylinder dargestellt.

(Yaffe 2002, S. 55)

14-3-3-Proteine liegen in insgesamt sieben Isoformen vor $(\beta, \gamma, \eta, \varepsilon, \zeta, \sigma, \tau)$ und sind in nahezu allen Geweben des Körpers vorhanden mit einer Vielzahl verschiedener Funktionen. Die Bindungstasche von 14-3-3 bindet bevorzugt Motive mit phosphoryliertem Serin (Muslin et al. 1996), wobei durch Proteomstudien gezeigt werden konnte, dass mehrere hundert Proteine als Bindungspartner von 14-3-3 fungieren, wobei die Phosphorylierung die Interaktion der Proteine stark beeinflusst (Pozuelo et al. 2004). Sie spielen durch vielfältige Mechanismen eine wichtige Rolle unter anderem in der Regulation von Zellzyklus und Zelldifferenzierung, Stressreaktion und Apoptose, sowie Transkription und Signaltransduktion (Aitken et al. 1992, Ford et al. 1994, Fu et al. 2000, Hermeking und Benzinger 2006, van Hemert et al. 2001, Xiao et al. 1995). Im Gehirn kommt der 14-3-3-Proteinfamilie eine bedeutende Rolle $\mathrm{zu}$, da sie mit $13,3 \mu \mathrm{g} / \mathrm{ml}$ circa $1 \%$ der gesamten löslichen Proteinfraktion des Gehirns ausmacht (Boston et al. 1982b). Yamauchi et al. (1981) 
konnten erstmals nachweisen, dass 14-3-3 bei der Synthese von Neurotransmittern wie Serotonin und Dopamin eine kritische Rolle spielt (Ichimura et al. 1987). In der Literatur werden bislang Knockout-Mäuse von zwei 14-3-3-Isoformen beschrieben. 14-3-3- $\gamma_{0 / 0}$-Mäuse zeigten keine phänotypischen Besonderheiten und normale Überlebensraten, sowie fehlende reaktive Hochregulierung anderer 14-3-3-Isoformen (Steinacker et al. 2005). 14-3-3- $\varepsilon_{0 / 0}$-Mäuse hingegen zeigten eine hohe perinatale Mortalität, sowie eine Ausdünnung des zerebralen Kortex und Defekte in der Hippokampusregion, die eine Rolle der 14-3-3-Isoform $\varepsilon$ bei der Hirnentwicklung und neuronalen Migration unterstützen (Toyo-oka et al. 2003). Immunhistochemische Studien zeigten das Vorhandensein von 14-3-3-Protein in unterschiedlichen Lokalisationen im Gehirn, abhängig von den 14-3-3-Isoformen, auf die später noch näher eingegangen wird. Insgesamt gesehen kommt 14-3-3 vor allem in den Neuronen der grauen Hirnsubstanz vor (Isobe et al. 1989), jedoch erfolgte später auch der Nachweis von 14-3-3-Proteinen in der weißen Hirnsubstanz (Baxter et al. 2002). Es ist vor allem intrazytoplasmatisch lokalisiert, kann jedoch auch in der Plasmamembran, in intrazellulären Organellen, wie dem Nukleolus und dem Golgiapparat (Fu et al. 2000), sowie in synaptischen Membranen (Martin et al. 1994) gefunden werden. Diese vielfältigen Lokalisationen geben Hinweise auf die Bedeutung von 14-3-3-Protein im Gehirn, jedoch sind seine exakten Funktionen, auch extrazerebral, noch unzureichend bekannt.

\subsubsection{4-3-3-Protein und Creutzfeldt-Jakob-Krankheit}

Neben den oben genannten vielfältigen Aufgaben der 14-3-3-Proteinfamilie ist die genaue Funktion, auch im Zusammenhang mit der Creutzfeldt-Jakob-Krankheit, noch ungeklärt. Erstmalig 1986 und auch in späteren Studien wurden mittels 2DGelelektrophrese zwei Proteine, p130 und p131, im Liquor von CJK-Patienten gefunden (Harrington et al. 1986, Zerr et al. 1996), welche sich später als Mitglieder der 14-3-3-Familie herausstellten (Hsich et al. 1996). Im Laufe der Jahre konnte dann gezeigt werden, dass 14-3-3, isoform-unspezifisch, als Marker für neuronalen Untergang und neurodegenerative Schädigung im Liquor cerebrospinalis einiger Patientenkollektive zu finden ist und insbesondere bei Creutzfeldt-Jakob-Patienten ein wichtiges diagnostisches Kriterium darstellt (Hsich et al. 1996, Huang et al. 2003, Saiz et al. 1999, Zerr et al. 1998). Ungewiss ist, ob dem 14-3-3-Protein, zusätzlich zu 
seinem diagnostischen Wert, eine Bedeutung in der Pathogenese von neurodegenerativen Erkrankungen zukommt. Für diese Hypothese spricht das Vorhandensein von 14-3-3 u.a. in den neurofibrillären Tangles beim Morbus Alzheimer (Layfield et al. 1996), ebenso wie in den glialen, zytoplasmatischen Einschlusskörperchen bei der Multisystematrophie (MSA) (Komori et al. 2003) und in den Lewy-Körperchen bei Morbus Parkinson, sowie bei der Demenz mit LewyKörperchen (Berg et al. 2003). Weiterhin konnte 14-3-3 auch in PrP-Amyloidplaques im Gehirn von Patienten mit einer genetischen Prionkrankheit, dem GerstmannSträussler-Scheinker-Syndrom, nachgewiesen werden (Di Fede et al. 2007). Diese Studien, sowie der Nachweis, dass 14-3-3 einen Komplex mit dem zellulären Prionprotein $\left(\mathrm{PrP}^{\mathrm{C}}\right.$ ) bildet (Satoh et al. 2005), deuten in Richtung einer möglichen Beteiligung der 14-3-3-Proteinfamilie in der Pathogenese der Creutzfeldt-JakobKrankheit. Zum jetzigen Zeitpunkt ist dieser Aspekt jedoch noch Gegenstand aktueller Forschung.

\subsubsection{Isoformen des 14-3-3-Proteins}

Wie bereits mehrfach erwähnt, handelt es sich bei den 14-3-3-Proteinen um eine Proteinfamilie, bestehend aus sieben verschiedenen Isoformen, kodiert durch unterschiedliche, stark konservierte Gene. Die sieben Isoformen sind mit griechischen Buchstaben $(\beta, \gamma, \eta, \varepsilon, \zeta, \sigma$, und $\tau)$ benannt nach ihrem Elutionsprofil in der Umkehrphase-Hochleistungsflüssigkeitschromatographie ([engl.] reversed phase high-performance liquid chromatography, RP-HPLC) (Ichimura et al. 1988, Martin et al. 1993). Bei den zunächst mit $\alpha$ und $\delta$ bezeichneten Isoformen konnte gezeigt werden, dass es sich um die phosphorylierten Formen der Isoformen 14-3-3- $\beta$ und $-\zeta$ handelt (Aitken et al. 1995). Die sieben Isoformen sind sehr homologe Proteine, die sich in ihrer Aminosäuresequenz nur wenig unterscheiden und insbesondere in der Region der Bindungstasche stark konserviert sind (s. Abb. 2). 


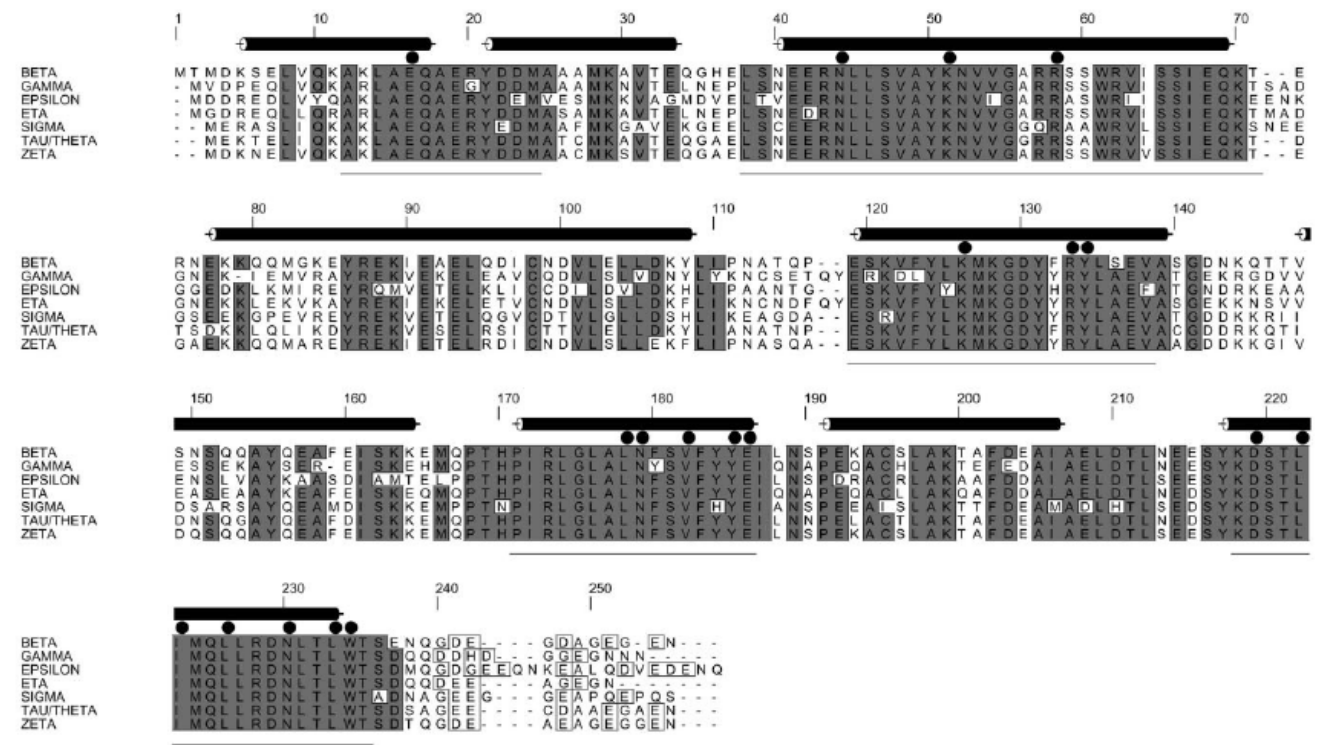

Abbildung 2: Lineare Sequenzierung von humanen 14-3-3-Isofomen. Aminosäuren konserviert in mindestens 6 der 7 Isoformen sind grau unterlegt.

(Yaffé, 2002, S. 54)

Die größten Unterschiede zwischen den Isoformen weisen die divergierenden Aminosäuren am C-Terminus der Proteine auf, die in Abbildung 2 mit kleinen Kästchen markiert sind.

Bezüglich der Frage, warum es eine derart große Isoformvielfalt bei den 14-3-3Proteinen gibt, obwohl diese sehr homolog sind und sehr ähnliche Bindungsmuster mit anderen Proteinen aufweisen, sind einige Aspekte hinsichtlich der Funktion und Lokalisation der einzelnen Isoformen bereits bekannt, viele Fragen jedoch noch offen. Es konnte zum Beispiel gezeigt werden, dass einzelne 14-3-3-Isoformen, wie z. B. $\varepsilon, \zeta$ oder $\tau$, neben Homodimeren auch Heterodimere aus zwei verschiedenen Isoformen bilden können (Jones et al. 1995). An diese Heterodimere können einige Liganden gleichermaßen binden, was die spezifische Bindung einer einzelnen Isoform mit bestimmten Liganden in Frage stellt. Auf der anderen Seite wurde eine signifikant höhere Affinität von manchen Isoformen zu einigen Liganden, beispielsweise von 14-3-3- $\zeta$ und $-\eta$ zu CDC25B, einer Zellzyklusphosphatase, nachgewiesen (Mils et al. 2000, Vincenz und Dixit 1996), was wiederum für eine spezifische Funktion zumindest einzelner 14-3-3-Isoformen spricht. Jones et al. formulieren darüber hinaus die Möglichkeit, dass aus der Bildung verschiedener Heterodimere dennoch spezifische Funktionen als Adapterproteine in Signaltransduktionswegen resultieren könnten (Jones et al. 1995). 
Die 14-3-3-Isoformen variieren in ihrem Verteilungsmuster in den Geweben des menschlichen Körpers. So wurde die 14-3-3-Isoform $\tau$ (tau) zunächst in hoher Konzentration in T-Zellen nachgewiesen (Nielsen 1991), 14-3-3- $\sigma$ (sigma) hingegen hauptsächlich in epithelialen Zellen (Leffers et al. 1993, Prasad et al. 1992), wobei dieser Isoform insbesondere beim Kolonkarzinom tumorsuppressive Eigenschaften zugeschrieben werden. Im Gehirn ist 14-3-3, wie bereits eingangs erwähnt, in sehr hoher Konzentration zu finden, wobei die Expression der Isoformen unterschiedlich stark ausgeprägt ist. Eine Reihe von Studien, die das Vorhandensein und die Lokalisation der einzelnen Isoformen im Gehirn und auch im Liquor cerebrospinalis untersucht haben, zeigen differierende Ergebnisse. Di Fede et al. (2007) konnten mittels immunhistochemischer Färbung von Hirnschnitten und Western-Blot-Analyse von Hirnhomogenaten gesunder Kontrollen, GSS- und CJK-Patienten alle Isoformen nachweisen. Sie konnten zeigen, dass die $\zeta$ (zeta)-Isoform am stärksten exprimiert wird, gefolgt von 14-3-3- $\varepsilon$ (epsilon). 14-3-3- $\tau$ (tau), $-\beta$ (beta) und $-\eta$ (eta) zeigten eine Bandenintensität zu etwa gleichen Anteilen. Die 14-3-3-Isoform $\gamma$ (gamma) war nur mit einer Intensität von 9\% und 14-3-3- $\sigma$ (sigma) verschwindend gering nur mit 0.4\% nachweisbar (s. Abb. 3). Dieses Expressionsmuster der 14-3-3-Isoformen war identisch in verschiedenen untersuchten Hirnarealen, was auf ein homogenes Verteilungsmuster der 14-3-3-Proteine hinweist. Im Gegensatz zu den gesunden Kontrollen und Patienten mit Gerstmann-Sträussler-Scheinker-Syndrom fiel die immunhistochemische Färbung jedoch bei Patienten mit sporadischer CreutzfeldtJakob-Krankheit generalisiert weniger stark aus (Di Fede et al. 2007).

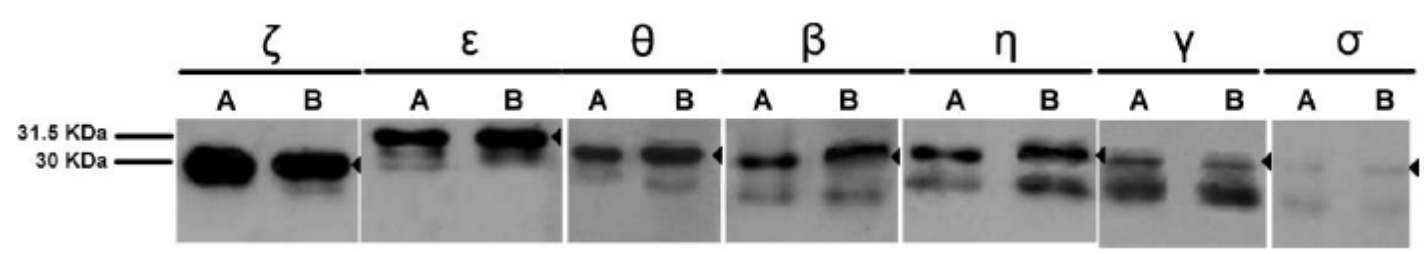

Abbildung 3: Western-Blot-Analyse von Hirnhomogenaten eines Patienten mit GerstmannSträussler-Scheinker-Syndrom (GSS) F198S (A) und einer Kontrollperson (B) mit Antikörpern gegen 14-3-3-Isoformen. Patient und Kontrollperson zeigen beide ähnliche Isoformmuster, charakterisiert durch abnehmende Expressionsstärke: $\zeta>\varepsilon>\tau=\beta=\eta>\gamma>\sigma$. (Di Fede et al. 2007, S. 128) 
In einer anderen Studie hingegen konnte gezeigt werden, dass sich die Verteilungsmuster der 14-3-3-Isoformen, zumindest im Gehirn von Mäusen und Ratten, deutlich unterscheiden und sich im Zuge von Pathologien zusätzlich verändern (Baxter et al. 2002, Martin et al. 1994). Baxter et al. (2002) konnten ein ähnliches Verteilungsmuster im gesunden Rattenhirn für die 14-3-3-Isoformen $\beta, \gamma, \eta$ und $\zeta$ in bestimmten neuroanatomischen Kerngebieten der grauen Substanz nachweisen, wohingegen die $\varepsilon$-Isoform unspezifisch in der gesamten grauen Substanz gefunden wurde. 14-3-3- $\tau$ wurde, im Gegensatz zu den Ergebnissen von Di Fede et al. (2007), am geringsten immunhistochemisch markiert und war fast ausschließlich auf den Hippokampus beschränkt (Baxter et al. 2002), wobei Genexpressionsstudien 14-3-3- $\tau$ als einzige Isoform zusätzlich in der weißen Substanz nachweisen konnten (Watanabe et al. 1994). Pathologische Veränderungen bei Scrapie-infizierten Tieren waren am ausgeprägtesten im Thalamus und im Hippokampus zu finden, einhergehend mit geringerem Nachweis bzw. abgeschwächten Signalen von 14-3-3- $\beta,-\gamma,-\eta$ und $-\zeta$ in diesem Bereich, wobei der Verlust des Nachweises von 14-3-3- $\tau$ in terminalen Stadien der Erkrankung am massivsten war und auf die ausgeprägte neurodegenerative Schädigung als Ursache zurückgeführt wird (Baxter et al. 2002). Die Isoform $\sigma$ konnte in einigen Studien nicht im Hirngewebe detektiert werden (Berg et al. 2003, Martin et al. 1993), während Umahara et al. (2004) überraschend 14-3-3- $\sigma$ im Hippokampus, in Hirnhomogenaten von gesunden Kontrollen und in Pick-Bodies nachweisen konnten. Interessanterweise wurde die Isoform 14-3-3- $\eta$ auffällig häufig in denselben Neuronen lokalisiert wie das Prionprotein (Baxter et al. 2002).

Die Lokalisation und Quantität der einzelnen 14-3-3-Isoformen in bestimmten Hirnarealen werden in der Literatur, wie oben beschrieben, unterschiedlich angegeben. Sie sind jedoch möglicherweise insofern von Bedeutung, als dass sie eine Rolle spielen könnten für das Erscheinen bestimmter Isoformen im Liquor cerebrospinalis bei Patienten mit sCJK. Wie bereits eingangs erwähnt, ist 14-3-3 unter anderem ein etablierter Marker für neuronalen Untergang und sein Nachweis im Liquor ein wichtiger Parameter für die prämortale Diagnose der sCJK. Tatsächlich lässt sich 14-3-3 auch bei anderen Differentialdiagnosen, wie z. B. bei paraneoplastischen, neurologischen Dysfunktionen, vaskulärer Demenz oder viraler Enzephalitis, im Liquor nachweisen (Huang et al. 2003, Saiz et al. 1999, Van 
Everbroeck et al. 2003). Bislang wurden in mehreren Studien 14-3-3-Isoformmuster im Liquor cerebrospinalis untersucht, wobei in der Literatur unterschiedliche Angaben über das Vorhandensein und Muster der einzelnen Isoformen im Liquor von Patienten mit sporadischer Creutzfeldt-Jakob-Krankheit zu finden sind. Folgende Tabelle soll eine Synopsis über die bisherigen Studienergebnisse geben (s. Tab. 4).

\begin{tabular}{|c|c|c|c|c|c|c|}
\hline $\begin{array}{l}\text { Studien- } \\
\text { ergebnisse }\end{array}$ & $\begin{array}{l}\text { Lee, } \\
\text { Harrington } \\
1997\end{array}$ & $\begin{array}{l}\text { Saiz } \\
\text { et al. } 1999\end{array}$ & $\begin{array}{l}\text { Takahashi } \\
\text { et al. } 1999\end{array}$ & $\begin{array}{l}\text { Wiltfang } \\
\text { et al. } 1999\end{array}$ & $\begin{array}{l}\text { Wakabayashi } \\
\text { et al. } 2001\end{array}$ & $\begin{array}{l}\text { Shiga } \\
\text { et al. } 2006\end{array}$ \\
\hline $\begin{array}{l}\text { 14-3-3- } \\
\text { Isoform }\end{array}$ & Diagnose & Diagnose & Diagnose & Diagnose & Diagnose & Diagnose \\
\hline$\beta$ & CJK & CJK & & CJK & & CJK \\
\hline$\gamma$ & CJK & CJK & CJK & CJK & AIDS & CJK \\
\hline$\eta$ & & & & $\begin{array}{l}\text { CJK, AD, } \\
\text { HSE }\end{array}$ & & CJK \\
\hline$\varepsilon$ & & & CJK & CJK & AIDS & CJK \\
\hline$\zeta$ & & CJK & & & AIDS & CJK \\
\hline \multicolumn{7}{|l|}{$\sigma$} \\
\hline$\tau$ & CJK & CJK & & & & \\
\hline Antikörper & Santa Cruz & Santa Cruz & $\begin{array}{c}\text { selbst } \\
\text { hergestellt* }\end{array}$ & $\begin{array}{c}\text { Santa Cruz } \\
+ \text { selbst } \\
\text { hergestellt* }\end{array}$ & $\begin{array}{c}\text { selbst } \\
\text { hergestellt* }\end{array}$ & $\begin{array}{c}\text { Santa Cruz } \\
+ \text { selbst } \\
\text { hergestellt* }\end{array}$ \\
\hline
\end{tabular}

Tabelle 4: 14-3-3-Isoformen: Synopsis der bisherigen isoformspezifischen Studienergebnisse CSF = [engl. $]$ cerebrospinal fluid, AD = Alzheimer Demenz, HSE = Herpes-simplexEnzephalitis, LB = [engl.] Lewy Bodies, PD = [engl.] Parkinson's Disease, *im gleichen Labor selbsthergestellte Antikörper

In einzelnen Studien ist auch das Vorhandensein von Doppelbanden im Western Blot einiger 14-3-3-Isoformen beschrieben (Saiz et al. 1999, Sanchez-Valle et al. 2002), wobei die untere Bande bei ca. $22 \mathrm{kDa}$ liegt und Sanchez-Valle et al. (2002) zeigen konnten, dass es sich dabei um eine Kreuzreaktion der 14-3-3-Antikörper mit den leichten Ketten von Immunglobulinen handelt. 


\section{$1.9 \quad$ Tau-Protein}

Neben dem Surrogatmarker 14-3-3 spielt, wie bereits anfangs erwähnt, auch das Tau-Protein im Liquor von Patienten mit Creutzfeldt-Jakob-Krankheit eine Rolle. Es handelt sich bei dem Tau-Protein um ein Mikrotubuli-assoziiertes Protein, welches zahlreich in den Axonen von Neuronen vorhanden ist und in den Erhalt der axonalen Struktur und Integrität involviert ist (Maccioni und Cambiazo 1995). Es existieren sechs verschiedene Isoformen des Tau-Proteins im adulten Gehirn (Neve et al. 1986), wobei jede dieser Isoformen im gesunden Hirn an verschiedenen Stellen phosphoryliert sein kann. Hyperphosphoryliertes, aggregierendes Tau-Protein ist mit den sogenannten Tauopathien wie dem Morbus Pick assoziiert und ist ein wichtiges pathologisches Merkmal des Morbus Alzheimer (Alonso et al. 2001). Vandermeeren et al. (1993) konnten mittels ELISA quantitativ zeigen, dass sich das Tau-Protein, nicht nur in den typischen neurofibrillären Tangles (neurofibrillären Bündeln) im Gehirn, sondern auch im Liquor von Alzheimer-Patienten nachweisen lässt. Der diesem Nachweis zugrunde liegende Gedanke ist, dass bei der AlzheimerErkrankung die Schädigung der Neurone direkt zu einer Erhöhung des Tau-Protein im Liquor führt (Vigo-Pelfrey et al. 1995). Auf Grund eines ähnlichen Pathomechanismus für den Nachweis von 14-3-3 im Liquor von CJK-Patienten und auf der Suche nach weiteren sensitiven und spezifischen Biomarkern, konnten Otto et al. (1997) ebenfalls erhöhte Konzentrationen von Tau-Protein im Liquor von Patienten mit CJK nachweisen. Mittels ELISA konnte sogar ein signifikanter Unterschied in der Höhe der Tau-Proteinkonzentration bei CJK-Patienten im Gegensatz zu Patienten mit anderen Demenzen, vornehmlich Morbus Alzheimer, gefunden werden (CJK: Mittelwert 12215 pg/ml, Median 13153 pg/ml, Andere Demenzen: Mittelwert 702 pg/ml, Median 558 pg/ml) (s. Abb. 4). 


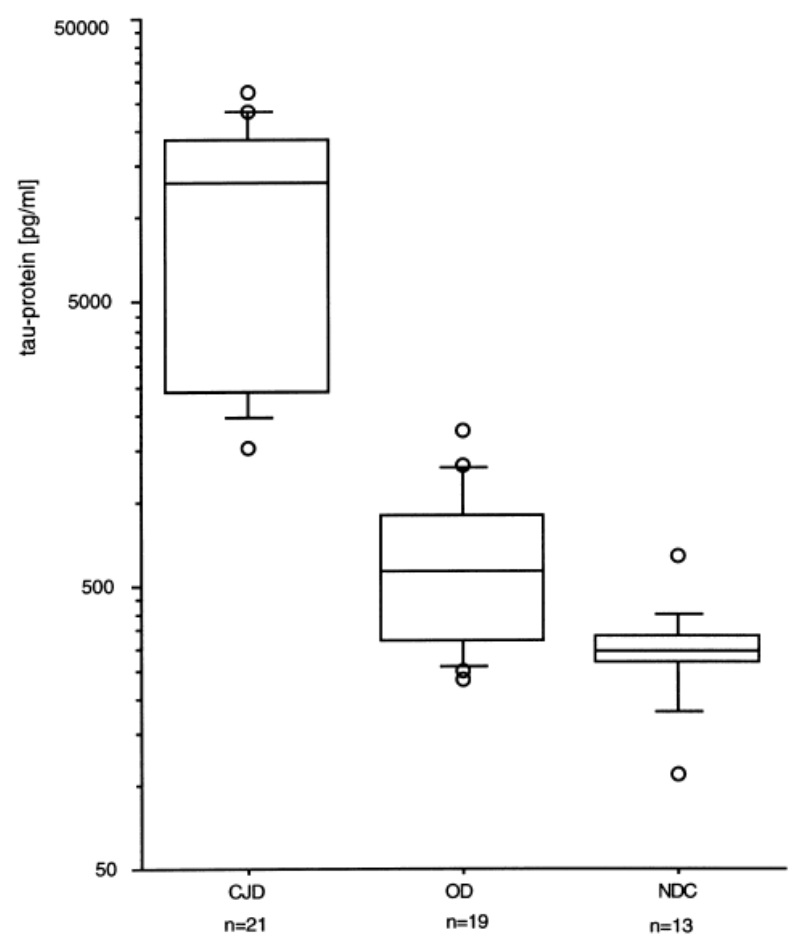

Abbildung 4: Box-Plot von Tau-Proteinkonzentration im Liquor von Patienten mit CJD ([engl.] Creutzfeldt-Jakob disease), OD ( [engl.] other dementias) und NDC ([engl.] non-demented controls), (Otto et al. 1997, S. 211)

In einer späteren Arbeit von Otto et al. (2002) konnte gezeigt werden, dass insbesondere bei den selteneren Subtypen der SCJK der Nachweis erhöhter TauProteinkonzentrationen teilweise früher möglich ist als ein positiver 14-3-3-Western Blot und umgekehrt. Des Weiteren konnte ein signifikanter Zusammenhang zwischen der Höhe des Tau-Proteins im Liquor und der 14-3-3-Banden im Western Blot gefunden werden (Otto et al. 2002). Andere Studien betonen die höhere Sensitivität durch Kombination der Liquormarker 14-3-3 und Tau-Protein (Sanchez-Juan et al. 2006) in der Diagnostik der sporadischen Creutzfeldt-Jakob-Krankheit und ihrer Subtypen. 


\section{$1.10 \quad$ Fragestellung}

In der vorliegenden Arbeit soll der Nachweis der Proteine 14-3-3 und ihrer Isoformen als Liquormarker bei sporadischer Creutzfeldt-Jakob-Krankheit im Hinblick auf die verschiedenen Subtypen untersucht werden.

In Anbetracht der bisherigen widersprüchlichen Datenlage bezüglich der einzelnen Isoformen im Liquor bei Patienten mit SCJK soll mit spezifischen Antikörpern zum einen das Vorhandensein und Muster der sieben 14-3-3-Isoformen mit der bislang zu favorisierenden Standardmethode des Western Blots untersucht werden. Motivation dieser Fragestellung ist die mögliche Detektion eines für die Creutzfeldt-JakobKrankheit spezifischen Isoformmusters, welche eine Diagnose prämortal unterstützt.

Zum anderen lässt die widersprüchliche Datenlage sowie die Heterogenität der Patienten mit sporadischer Creutzfeldt-Jakob-Krankheit vermuten, dass es unterschiedliche Isoformmuster der Proteine 14-3-3 im Liquor der verschiedenen Subtypen (MM1, MM2, MV1, MV2, VV1, VV2) geben könnte. Hintergrund dieser Vermutung ist unter anderem die unterschiedliche Sensitivität des 14-3-3-Western Blots bei den Subtypen, differierende neuropathologische Läsionsprofile und möglicherweise unterschiedliche transkriptionale Expressionsregulation, was im Verlauf der Erkrankung zur Freisetzung verschiedener 14-3-3-Isoformen in den Liquor führen könnte. In diesem Zusammenhang sollen auch die falsch-positiven Liquores von Patienten mit anderen oben erwähnten neurologischen Diagnosen auf Unterschiede im Isoformmuster von 14-3-3 im Vergleich zu CJK-Patienten hin untersucht werden. Des Weiteren würde ein Isoformmuster, das spezifisch für einen Subtyp der sCJK spricht, die Diagnose der CJK erleichtern und in Bezug auf die unterschiedlich lange mittlere Krankheitsdauer der Subtypen möglicherweise eine prognostische Aussage ermöglichen.

Als weiterer Aspekt soll untersucht werden, ob ein Zusammenhang zwischen der Höhe des Liquormarkers Tau-Protein und der Stärke der 14-3-3-Banden zu erkennen ist, zum einen in Bezug auf die verschiedenen Isoformen, zum anderen in Bezug auf die sCJK-Subtypen. 


\section{Material und Methoden}

\subsection{Patientenkollektiv}

Der Liquor der für diese Untersuchung ausgewählten Patienten stammte aus dem bereits vorhandenen Pool des Nationalen Referenzzentrums für die Surveillance Transmissibler Spongiformer Enzephalopathien Göttingen, an das alle bundesweit auftretenden Verdachtsfälle gemeldet werden und Liquor zu diagnostischen Zwecken eingesandt wird. Eine zusätzliche Liquorpunktion der Patienten eigens für diese Untersuchung war daher nicht notwendig. Als Einschlusskriterien für diese Arbeit galten:

1. Neuropathologisch gesicherte sporadische Creutzfeldt-Jakob-Krankheit ( $\mathrm{sCJK}$ )

2. Bekannter Genotyp und PrP ${ }^{\mathrm{sc}}$-Typ (d.h. bekannter Subtyp)

3. Liquor der Patienten aus dem letzten Drittel der gesamten Krankheitsdauer

Der mittels Lumbalpunktion entnommene Liquor cerebrospinalis wurde so gewählt, dass er jeweils aus dem letzten Krankheitsdrittel stammte, um eine Vergleichbarkeit zu erreichen und verfälschende Einflüsse auf Grund der unterschiedlichen mittleren Krankheitsdauer der Subtypen zu vermeiden (Gmitterova et al. 2009, Sanchez-Juan et al. 2007).

Ausgeschlossen von der Studie wurden Patienten mit:

1. Anderen Formen der CJK (genetisch, iatrogen, variant)

2. Fehlender neuropathologischer Sicherung

3. Liquorpunktionen in früheren Krankheitsstadien (1. oder 2. Krankheitsdrittel)

4. Assoziierten Erkrankungen wie entzündlichem Liquor, frischer Ischämie sowie Zeichen anderer neurodegenerativer Erkrankungen

Als falsch-positive Kontrollen wurden acht nicht an CJK erkrankte Patienten, je vier mit ischämischem bzw. entzündlichem Geschehen, in diese Untersuchung eingeschlossen. Im Rahmen der Routinediagnostik des Nationalen Referenzzentrums wurden diese acht Patientenliquores eingangs mit unspezifischen 14-3-3-Antikörpern als positiv für dieses Protein diagnostiziert, obwohl keine 
Creutzfeldt-Jakob-Krankheit vorlag. Auch hier waren keine ausschließlich für diese Untersuchung durchgeführten Liquorpunktionen notwendig.

Die Liquorpoben wurden im Nationalen Referenzzentrum für die Surveillance Transmissibler Spongiformer Enzephalopathien Göttingen im Rahmen von Routinediagnostik und Epidemiologie gesammelt und aliquotiert bei $-80^{\circ} \mathrm{C}$ tiefgekühlt gelagert. Neben der Bestimmung von 14-3-3 im Western Blot wurden von einigen Patienten noch weitere Parameter (Tau-/Phosphotau-Protein, Neuronen-spezifischeEnolase (NSE), S100-Protein und $\beta 1$-42-Amyloid) bestimmt.

Von jedem CJK-Subtyp (MM1, MM2, MV1, MV2, VV1, VV2) sollte der Liquor von sieben Patienten untersucht werden. Nicht von allen CJK-Subtypen gab es jedoch genügend, den Untersuchungskriterien entsprechende Liquorproben, so dass bei den seltenen Subtypen die Patientenzahl kleiner gewählt werden musste (jeweils $n=4$ bei Subtyp V1 und MM2).

\subsection{Material}

Im Folgenden sind die verwendeten Materialien aus Gründen der Übersichtlichkeit tabellarisch, für die verschiedenen Methoden zusammenfassend, dargestellt.

\subsubsection{Chemikalien}

Alle in dieser Studie verwendeten Chemikalien, falls im Text nicht anders beschrieben, stammen von den Firmen Applichem (Darmstadt, Deutschland), Biochrom (Berlin, Deutschland), Bio-Rad (München, Deutschland), Merck (Darmstadt, Deutschland), Roth (Karlsruhe, Deutschland) und Sigma-Aldrich (Steinheim, Deutschland).

\subsubsection{Molekulare Größenmarker}

Precision Plus Protein Standards (dual color) Bio-Rad, München, Deutschland Kaleidoscope Prestained Standard Bio-Rad, München, Deutschland 


\subsubsection{Proteine}

\begin{tabular}{|ccc|}
\hline Beschreibung & Menge & Hersteller \\
\hline GST-14-3-3 $\beta$ (human, rekombinant) & $10 \mathrm{ng}$ & BIOMOL International, USA \\
GST-14-3-3 $\gamma$ (human, rekombinant) & $10 \mathrm{ng}$ & BIOMOL International, USA \\
GST-14-3-3 $\eta$ (human, rekombinant) & $10 \mathrm{ng}$ & BIOMOL International, USA \\
GST-14-3-3 $\varepsilon$ (human, rekombinant) & $10 \mathrm{ng}$ & BIOMOL International, USA \\
GST-14-3-3 $\zeta$ (human, rekombinant) & $10 \mathrm{ng}$ & BIOMOL International, USA \\
GST-14-3-3 $\sigma$ (human, rekombinant) & $10 \mathrm{ng}$ & BIOMOL International, USA \\
GST-14-3-3 $\tau$ (human, rekombinant) & $10 \mathrm{ng}$ & BIOMOL International, USA \\
\hline
\end{tabular}

Tabelle 5: $\quad$ 14-3-3-Proteine; GST = Glutathion-S-Transferase

Die Mengenangaben beziehen sich auf die Menge an 14-3-3-Protein verwendet als Positivkontrolle bei SDS-PAGE und Western Blot.

\subsubsection{Primäre Antikörper}

\begin{tabular}{|c|c|c|c|}
\hline Beschreibung & Spezifizierung & Verdünnung & Hersteller \\
\hline $\begin{array}{c}\text { Anti-Human- } \\
14-3-3-\beta\end{array}$ & $\begin{array}{l}\text { Kaninchen, } \\
\text { polyklonal }\end{array}$ & $1: 25$ & $\begin{array}{l}\text { Immunolaboratories } \\
\text { IBL Japan }\end{array}$ \\
\hline $\begin{array}{c}\text { Anti-Human- } \\
14-3-3-\gamma\end{array}$ & $\begin{array}{l}\text { Kaninchen, } \\
\text { polyklonal }\end{array}$ & $1: 25$ & $\begin{array}{l}\text { Immunolaboratories } \\
\text { IBL Japan }\end{array}$ \\
\hline $\begin{array}{c}\text { Anti-Human- } \\
\text { 14-3-3- }\end{array}$ & $\begin{array}{l}\text { Kaninchen, } \\
\text { polyklonal }\end{array}$ & $1: 80$ & $\begin{array}{l}\text { Immunolaboratories } \\
\text { IBL Japan }\end{array}$ \\
\hline $\begin{array}{l}\text { Anti-Human- } \\
14-3-3-\varepsilon\end{array}$ & $\begin{array}{l}\text { Kaninchen, } \\
\text { polyklonal }\end{array}$ & $1: 200$ & $\begin{array}{l}\text { Immunolaboratories } \\
\text { IBL Japan }\end{array}$ \\
\hline $\begin{array}{c}\text { Anti-Human- } \\
14-3-3-\zeta\end{array}$ & $\begin{array}{l}\text { Kaninchen, } \\
\text { polyklonal }\end{array}$ & $1: 25$ & $\begin{array}{l}\text { Immunolaboratories } \\
\text { IBL Japan }\end{array}$ \\
\hline $\begin{array}{c}\text { Anti-Human- } \\
\text { 14-3-3- } \sigma\end{array}$ & $\begin{array}{l}\text { Kaninchen, } \\
\text { polyklonal }\end{array}$ & $1: 25$ & $\begin{array}{l}\text { Immunolaboratories } \\
\text { IBL Japan }\end{array}$ \\
\hline $\begin{array}{c}\text { Anti-Human- } \\
14-3-3-\tau\end{array}$ & $\begin{array}{c}\text { Maus, } \\
\text { monoklonal }\end{array}$ & $1: 25$ & $\begin{array}{l}\text { Immunolaboratories } \\
\text { IBL Japan }\end{array}$ \\
\hline
\end{tabular}

Tabelle 6: IBL-Anti-14-3-3-Antikörper 


\begin{tabular}{|c|c|c|c|}
\hline Beschreibung & Spezifizierung & Verdünnung & Hersteller \\
\hline $14-3-3-\beta(K-19)$ & $\begin{array}{l}\text { Kaninchen, } \\
\text { polyklonal }\end{array}$ & 1:2000 & $\begin{array}{c}\text { Santa Cruz } \\
\text { Biotechnology, USA }\end{array}$ \\
\hline $14-3-3-\gamma(C-16)$ & $\begin{array}{l}\text { Kaninchen, } \\
\text { polyklonal }\end{array}$ & 1:2000 & $\begin{array}{c}\text { Santa Cruz } \\
\text { Biotechnology, USA }\end{array}$ \\
\hline $14-3-3-\eta(E-12)$ & $\begin{array}{l}\text { Kaninchen, } \\
\text { polyklonal }\end{array}$ & 1:2000 & $\begin{array}{c}\text { Santa Cruz } \\
\text { Biotechnology, USA }\end{array}$ \\
\hline $14-3-3-\varepsilon(T-16)$ & $\begin{array}{l}\text { Kaninchen, } \\
\text { polyklonal }\end{array}$ & 1:2000 & $\begin{array}{c}\text { Santa Cruz } \\
\text { Biotechnology, USA }\end{array}$ \\
\hline $14-3-3-\zeta(C-16)$ & $\begin{array}{l}\text { Kaninchen, } \\
\text { polyklonal }\end{array}$ & 1:2000 & $\begin{array}{c}\text { Santa Cruz } \\
\text { Biotechnology, USA }\end{array}$ \\
\hline $14-3-3-\sigma(\mathrm{N}-14)$ & $\begin{array}{l}\text { Kaninchen, } \\
\text { polyklonal }\end{array}$ & 1:2000 & $\begin{array}{c}\text { Santa Cruz } \\
\text { Biotechnology, USA }\end{array}$ \\
\hline $14-3-3-\tau(C-17)$ & $\begin{array}{l}\text { Kaninchen, } \\
\text { polyklonal }\end{array}$ & $1: 2000$ & $\begin{array}{c}\text { Santa Cruz } \\
\text { Biotechnology, USA }\end{array}$ \\
\hline
\end{tabular}

Tabelle 7: $\quad$ SC-Anti-14-3-3-Antikörper

\subsubsection{Sekundäre Antikörper}

\begin{tabular}{|c|c|c|c|}
\hline Beschreibung & Spezifizierung & Verdünnung & Hersteller \\
\hline $\begin{array}{l}\text { Goat-Anti-Rabbit- } \\
\lg G(\mathrm{H}+\mathrm{L})\end{array}$ & $\begin{array}{c}\text { Ziege, } \\
\text { Peroxidase-konjugiert }\end{array}$ & 1:10000 & $\begin{array}{l}\text { Jackson ImmunoResearch } \\
\text { Laboratories, USA }\end{array}$ \\
\hline $\begin{array}{c}\text { Goat-Anti-Mouse- } \\
\text { IgG }(\mathrm{H}+\mathrm{L})\end{array}$ & $\begin{array}{c}\text { Ziege, } \\
\text { Peroxidase-konjugiert }\end{array}$ & 1:10000 & $\begin{array}{l}\text { Jackson ImmunoResearch } \\
\text { Laboratories, USA }\end{array}$ \\
\hline
\end{tabular}

Tabelle 8: Sekundäre Antikörper

\subsubsection{Kits}

\begin{tabular}{|lll|}
\hline Beschreibung & Model & Hersteller \\
\hline Thrombin-Cleavage-Kit & CleanCleave $^{\text {TM KIT }}$ & Sigma-Aldrich, \\
Deutschland \\
Tau-Protein-ELISA & INNOTEST® hTAU AG & $\begin{array}{l}\text { Innogenetics N.V., } \\
\text { Belgien }\end{array}$ \\
Deglykosylierungs-Kit & N-Glycosidase F Deglycosylation & Roche Diagnostics \\
Deglykosylierungs-Kit & Kit & GmbH, Deutschland \\
\hline
\end{tabular}

Tabelle 9: Kits 


\subsubsection{Instrumente}

\begin{tabular}{|lll|}
\hline Beschreibung & Model & Hersteller \\
\hline Blotter (Semi-Dry Transfer Cell) & Trans Blot SD & Bio-Rad, Deutschland \\
Blot-Prozessor & BioLane HTI & $\begin{array}{l}\text { Hölle \& Hüttner AG, } \\
\text { Deutschland }\end{array}$ \\
Energiequelle (Power Supply) & Power Pac 3000 & $\begin{array}{l}\text { Bio-Rad, Deutschland } \\
\text { Entwicklungsmaschine }\end{array}$ \\
Gelkammern & SRX-101A & Konica, Deutschland \\
Scanner & Mini Protean III TM & Bio-Rad, Deutschland \\
Schüttel-und Mischgeräte & CanoScan 8400F & Canon, USA \\
& HS 501 (horizontal) & IKA Labortechnik, \\
& REAX 3 (taumelig) & Heidschland \\
& REAX 2000 (Vortexer) & Heidolph, Deutschland \\
Thermomixer & Comfort & Eppendorf, Deutschland \\
Zentrifuge & 5415 D & Eppendorf, Deutschland \\
\hline
\end{tabular}

Tabelle 10: Instrumente

\subsubsection{Puffer und Lösungen}

APS 10\%:

$\underline{\text { BLOTTO }=\text { bovine lacto }}$

transfer technic optimizer):

ECL-1:

ECL-2:

Elektrophoresepuffer

(SDS-running buffer):

Okano:

PBS:

PBS-T:

Probenpuffer:

Rotiphorese ${ }^{\circledR}$ Gel 40 (Roth):

Sammelgelpuffer:

TEMED $®$ (Roth):

Transferpuffer:

Trenngelpuffer:
$100 \mathrm{~g}$ Ammoniumperoxidisulfat in $1 \mathrm{I}_{d d} \mathrm{H}_{2} \mathrm{O}$

5\% Milchpulver in PBS-T

2,5 mM Luminol, 0,4 mM p-Coumarsäure, 0,1 M Tris- $\mathrm{HCl}$

$\mathrm{pH}=8,5$

$0,018 \% \mathrm{H}_{2} \mathrm{O}_{2}, 0,1 \mathrm{M}$ Tris- $\mathrm{HCl} \mathrm{pH}=8,5$

$192 \mathrm{mM}$ Glycin, 0,1\% SDS, $25 \mathrm{mM}$ Tris- $\mathrm{HCl} \mathrm{pH}=8,3$

0,1\% BSA, 0,002\% SDS, 0,1 mM EDTA, 0,5\% Triton X 100, 0,2

$\mathrm{M} \mathrm{NaCl}, 0,1 \mathrm{M}$ Tris-HCl pH=8

9,55 g PBS-Pulver in $1 \mathrm{I}_{\mathrm{dd}} \mathrm{H}_{2} \mathrm{O}$

PBS und $0,1 \%$ Tween-20

Roti囚 Load1 4x-Konz. (Roth)

$40 \%$ acrylamid/bisacrylamid $(37.5: 1)$

$0,04 \%$ SDS, $1,5 \mathrm{M}$ Tris- $\mathrm{HCl} \mathrm{pH}=6,8$

$\mathrm{N}, \mathrm{N}, \mathrm{N}, \mathrm{N}^{\prime}-$ Tetramethylethylendiamin, 99\% p.a.

192 mM Glycin, 20\% Methanol, 25 mM Tris- $\mathrm{HCl}$ pH=8,3

$0,4 \%$ SDS, $1,5 \mathrm{M}$ Tris- $\mathrm{HCl} \mathrm{pH}=8,8$ 


\subsection{Methoden}

\subsubsection{Dot Blot}

Um im Liquor des ausgewählten Patientenkollektivs im Rahmen dieser Studie die Isoformen des 14-3-3-Proteins mittels SDS-PAGE und Western Blot zu bestimmen, wurden zunächst gegen die einzelnen Isoformen gerichtete 14-3-3-Antikörper auf ihre Spezifität hin untersucht.

Als Methode wurde der Dot Blot gewählt, der dem Nachweis von spezifischer Antigen-Antikörperbindung dient bzw. unspezifische Kreuzreaktionen nachweist. Verglichen wurden Antikörper der Firma IBL, Japan, und Santa Cruz Biotechnology, USA, in den in Tabelle 6 und 7 angegebenen Verdünnungen. Die optimalen Verdünnungen wurden zuvor mittels Verdünnungsreihe für die einzelnen Antikörper ermittelt. Für den Dot Blot wurden jeweils $10 \mathrm{ng}$ Protein der sieben als Antigen dienenden GST (Glutathion-S-Transferase)-14-3-3-Isoformen (Biomol) auf insgesamt 14 Nitrocellulosestreifen (für Inkubation mit 7x IBL-Primärantikörpern und $7 \times$ Santa Cruz-Primärantikörpern) aufgetragen, d. h. sieben „Dots“ pro Streifen. Die freien Bindungsstellen der Nitrocellulose wurden für 30 Minuten bei Raumtemperatur (RT) mit BLOTTO blockiert. Die Streifen wurden dann über Nacht bei $4^{\circ} \mathrm{C}$ mit den verschiedenen in Tabelle 6 und 7 aufgeführten Anti-14-3-3-Isoform-Antikörpern inkubiert. Nach Inkubation mit den Primärantikörpern und der zu erwartenden Antigen-Antikörperbindung wurden die Streifen entsprechend dem Protokoll für Western Blots gewaschen und mit Sekundärantikörpern inkubiert. Eingesetzt wurde als Sekundärantikörper in dieser Studie der Peroxidase-konjugierte Anti-Rabbit-lgG$(\mathrm{H}+\mathrm{L})$-Antikörper, außer für die Detektion des monoklonalen Anti-Human-14-3-3- $\tau-$ Primärantikörpers der Firma IBL. Da von dieser Firma kein polyklonaler Anti-Human14-3-3- $\tau$-Antikörper angeboten wurde, haben wir den monoklonalen Anti-Human-143-3- $\tau$-Antikörper der Firma IBL gewählt, bei dem entsprechend als Sekundärantikörper der Peroxidase-konjugierte Anti-Mouse-lgG-(H+L)-Antikörper verwendet wurde. Die anschließende Chemilumineszenzreaktion wurde auf Röntgenfilm (ECL-Hyperfilm, Amersham, UK) visualisiert und je nach Spezifität der Antikörper waren die einzelnen „Dots“ für die sieben 14-3-3-Isoformen sichtbar. 


\subsubsection{SDS-PAGE}

Die SDS-PAGE ([engl.] sodium dodecylsulfate polyacrylamide gel electrophoresis) ist eine Methode zur Auftrennung von Proteinen nach ihrem Molekulargewicht in einem elektrischen Feld. In dieser Untersuchung wurde sie genutzt, um den Liquor von Patienten mit sporadischer Creutzfeldt-Jakob-Krankheit auf das Vorhandensein von 14-3-3-Protein-Isoformen mit einer Größe von circa 30 kDa zu untersuchen.

Als Trennmedium dienten $0,75 \mathrm{~mm}$ dicke Gele auf Polyacrylamidbasis (5\%iges Sammelgel und $12 \%$ iges Trenngel), welche aus einer quervernetzten Matrix aus Polyacrylamid und Bisacrylamid $(37,5: 1)$ bestehen. Die Quervernetzung wird durch freie Radikale nach Zusatz von APS und TEMED® katalysiert und führt zur Polymerisation des Gels, welches in einen Elektrophoresepuffer eingelegt wird. Des Weiteren enthält das Trenngel SDS, ein anionisches Detergens, welches die Eigenladung der Proteine überdeckt und so eine Trennung der Proben ausschließlich anhand der Proteingröße möglich macht.

SDS wird ebenfalls in der Probenvorbereitung im Überschuss zugefügt [4 $x$ Roti® Load1 4x-Konz. (Roth)], damit die somit negativ geladenen Proben im elektrischen Feld durch das siebartig wirkende Gel zur positiven Elektrode wandern können.

In dieser Arbeit wurden von allen Patienten jeweils $15 \mu$ Liquor als Probe verwendet und diese mit dem Probenpuffer zusammen auf $95^{\circ} \mathrm{C}$ erhitzt, um mittels Spaltung von Wasserstoff- und Disulfidbrücken die Sekundär- und Tertiärstrukturen der Proteine aufzubrechen. Die somit denaturierten Proteinproben wurden anschließend auf das Gel aufgetragen und bei konstanten $100 \mathrm{~V}$ für 2 Stunden gemäß ihrer Größe aufgetrennt, da kleine Proteine eine höhere elektrophoretische Mobilität haben und das Gel schneller durchwandern, während große Proteine von der Gelmatrix eher zurückgehalten werden.

Zusätzlich wurde auf jedes Gel ein Größenmarker [Precision Plus Protein Standards (dual color) oder Kaleidoscope Prestained Standard, Bio-Rad] aufgetragen, bestehend aus Proteinen bekannter Größe zur Abschätzung der Proteingröße in den eigentlichen Liquorproben. Außerdem wurde stets mindestens eine positive Kontrolle aufgetragen, bei der es sich entweder um eine rekombinante GST-(Glutathion-S- 
Transferase)-14-3-3-Isoform mit einer Größe von $60 \mathrm{kDa}$ handelte oder um rekombinante 14-3-3-Isoformen mit einer Größe von 30 kDa nach Entfernung der GST-Aminosäurenkette (sog. GST-Tag) durch die Methode der Thrombin-Cleavage.

Für die Subtypen MM1, MV1, MV2 und VV2 der sCJK wurde folgende Auftragungsanordnung auf die Gele gewählt:

\begin{tabular}{|cl|}
\hline 1 & Größenmarker $(10 \mu \mathrm{l})$ \\
2 & Positive Kontrolle $60 \mathrm{kDa}$ (rekombinante GST-14-3-3-Isoform) \\
3 & Positive Kontrolle $30 \mathrm{kDa}$ (rekombinante 14-3-3-Isoform) \\
4 & Patientenprobe 1 \\
5 & Patientenprobe 2 \\
6 & Patientenprobe 3 \\
7 & Patientenprobe 4 \\
8 & Patientenprobe 5 \\
9 & Patientenprobe 6 \\
10 & Patientenprobe 7 \\
\hline
\end{tabular}

Bei einigen Gelen wurde die Anordnung der Positivkontrollen (d.h. Position 2 und 3) vertauscht, was bei den Abbildungen der Western Blots im Folgenden beachtet werden sollte.

Bei den beiden seltenen Subtypen VV1 und MM2 wurde auf Grund der wenigen, den Studienkriterien entsprechenden Liquorproben folgende Anordnung gewählt:

\begin{tabular}{|ll|}
\hline 1 & Größenmarker $(10 \mu \mathrm{l})$ \\
2 & Positive Kontrolle 60 kDa (rekombinante GST-14-3-3-Isoform) \\
3 & Patientenprobe 1 (VV1) \\
4 & Patientenprobe 2 (VV1) \\
5 & Patientenprobe 3 (VV1) \\
6 & Patientenprobe 4 (VV1) \\
7 & Patientenprobe 1 (MM2) \\
8 & Patientenprobe 2 (MM2) \\
9 & Patientenprobe 3 (MM2) \\
10 & Patientenprobe 4 (MM2) \\
\hline
\end{tabular}

Wie aus dieser Anordnung hervorgeht, wurde die Positivkontrolle nur einmal für beide Subtypen aufgetragen. Bei der Darstellung der Blots im Ergebnisteil, eingeteilt nach Subtypen, bedeutet dies für den MM2-Subtyp, dass die Positivkontrolle nicht an die Proben angrenzend ist und daher graphisch hinzugefügt wurde. 


\subsubsection{Western Blot}

Der Western Blot (WB) dient der Übertragung der im Polyacrylamidgel elektrophoretisch aufgetrennten Proteine auf eine Membran, um diese dann weiteren Methoden mit dem Ziel der Detektion der Proteine, u. a. Antikörper-vermittelt, zugänglich zu machen. In dieser Arbeit wurde der Western Blot für den Nachweis von 14-3-3-Isoformen im Liquor von Patienten mit sporadischer Creutzfeldt-JakobKrankheit eingesetzt, wobei zunächst zahlreiche Western Blots zur Bestimmung der optimalen Antikörperkonzentrationen durchgeführt werden mussten. Die aus diesen Versuchen ermittelten Konzentrationen sind in den im Materialteil dargestellten Tabellen aufgeführt.

Beim Western Blot wird ein zu dem Gel senkrechtes elektrisches Feld angelegt $(0,6$ A/Gel für 1 Stunde), wodurch die Proteine auf eine PVDF (Polyvinyldifluorid)Membran (Amersham, UK) übertragen werden und auf Grund hydrophober Wechselwirkungen an ihr haften bleiben. Die PVDF-Membran ist charakterisiert durch ihre unspezifischen Bindungseigenschaften, so dass alle Proteine gleich stark gebunden werden und das Muster der elektrophoretischen Auftrennung erhalten bleibt.

Die sich nach dem Blotvorgang auf der Membran befindenden 14-3-3-Proteine, falls zuvor überhaupt im Liquor vorhanden, sollten nun mittels, der durch Dot Blot ermittelten, spezifischen Primärantikörper gegen die 14-3-3-Isoformen detektiert werden. Da sich im Dot Blot zeigte, dass die IBL-Primärantikörper eine höhere Spezifität aufwiesen, wurden für den Western Blot ausschließlich Antikörper der Firma IBL verwendet. Die Membranen wurden zunächst für 1 Stunde bei Raumtemperatur in BLOTTO inkubiert, um die freien Bindungsstellen der PVDFMembran zu blockieren und eine fälschliche Bindung der Primärantikörper an die Membran anstatt an die Zielproteine zu verhindern. Erst anschließend wurde der Primärantikörper in der in Tabelle 6 angegebenen Verdünnung hinzugegeben und über Nacht bei $4^{\circ} \mathrm{C}$ auf einem Schüttler, in luftdichter Folie eingeschweißt, inkubiert.

Nach der nächtlichen Inkubation mit dem Primärantikörper wurden die Membranen für insgesamt 45 Minuten mit BLOTTO und PBS-T gewaschen, um unspezifische 
Bindungen zu eliminieren und somit falsche Signale (sog. Background) bei der späteren Entwicklung gering zu halten.

Im Folgenden wurden die Membranen für 1 Stunde bei Raumtemperatur mit dem entsprechenden Sekundärantikörper inkubiert, der an die Fc-Region des Primärantikörpers bindet. Für die Antikörper gegen die Isoformen 14-3-3- $\beta,-\gamma,-\eta,-\varepsilon,-$ $\zeta$ und $-\sigma(\mathrm{IBL})$ wurde der Goat-Anti-Rabbit-IgG-Antikörper in einer Verdünnung von 1:10000 eingesetzt, während der Maus-monoklonale Anti-Human-14-3-3- $\tau$ Primärantikörper (IBL) von dem Goat-Anti-Mouse-IgG-Antikörper mit ebenfalls 1:10000 Verdünnung detektiert wurde. An beide Sekundärantikörper ist das Enzym Meerrettichperoxidase ([engl.] horseradish-peroxidase (HRP)) konjugiert, welches die Umsetzung von Luminol in seine oxidierte Form katalysiert, dessen Chemilumineszenz auf einem Röntgenfilm detektiert werden kann. Vorteilhaft bei dieser zweistufigen Detektion (Primär- und Sekundärantikörper) ist die Signalverstärkung durch die Möglichkeit der multiplen Bindung des Sekundärantikörpers (s. Abb. 5).

Nach Inkubation mit dem Sekundärantikörper wurden die Membranen wiederum ausgiebig für 45 Minuten in BLOTTO, PBS-T und Okano gewaschen, um schlecht haftende bzw. unspezifisch gebundene Antikörper zu eliminieren und somit ebenfalls den sogenannten „Background“ zu reduzieren.

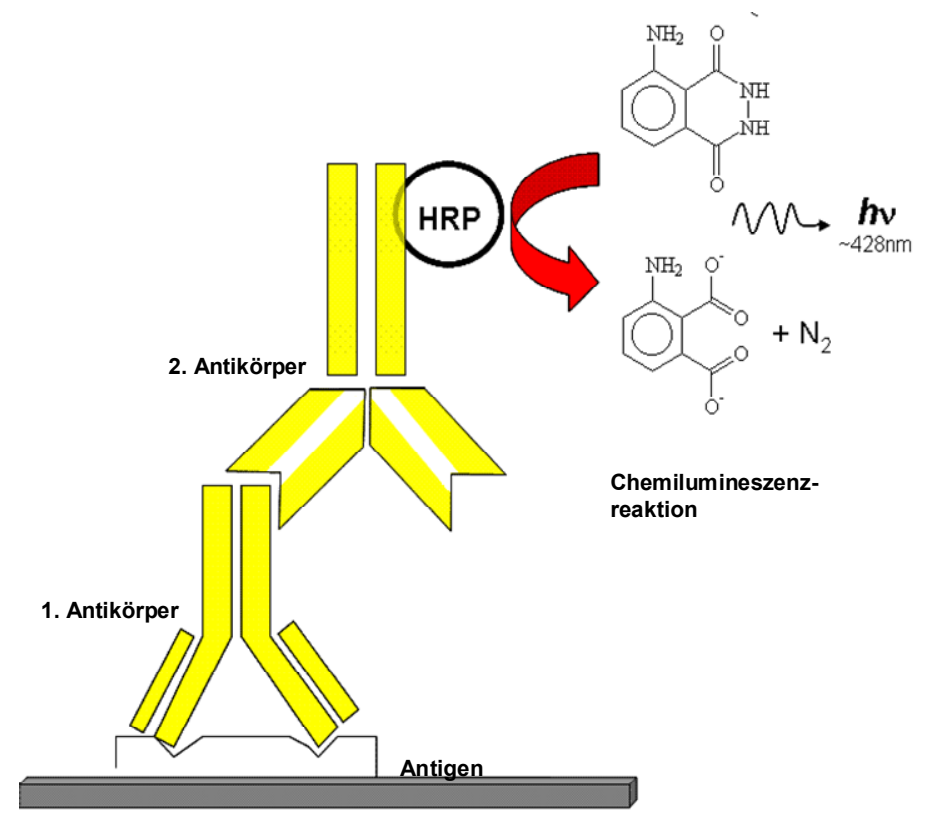

Abbildung 5: Immundetektion und Chemilumineszenz 
Anschließend folgte die Inkubation der Membranen für 1 Minute in Entwicklungslösung $(1: 1=E C L 1: E C L 2)$, wobei die oben beschriebene Chemilumineszenzreaktion aktiviert und ein Röntgenfilm (ECL-Hyperfilm, Amersham, UK) für 2-4 Minuten belichtet und entwickelt wurde.

\subsubsection{Thrombin-Cleavage}

Die Methode der sogenannten Thrombin-Cleavage zur Spaltung von rekombinanten Fusionsproteinen wurde in dieser Arbeit angewendet, um die als Positivkontrollen dienenden GST-14-3-3-Isoformproteine mit einer Größe von 60 kDa durch Entfernung des GST-(Glutathion-S-Transferase)-Tags auf ihre Originalgröße von 30 kDa zu reduzieren. Die dadurch entstandenen 14-3-3-Proteine wurden ebenfalls als Positivkontrollen im Western Blot eingesetzt mit dem Vorteil, dass sich die Bandenhöhen von Positivkontrolle und 14-3-3-Proteinisoformen der Liquorproben entsprechen und somit die Identifikation der spezifischen Banden erleichtert wurde. Die Glutathion-S-Transferase wird häufig bei der Entwicklung von rekombinanten Proteinen als sogenanntes GST-Genfusionssystem verwendet. Bei dem "Tag“ handelt es sich um eine Kette von 220 Aminosäuren, die an den N-Terminus des im Interesse stehenden rekombinanten Proteins, in diesem Falle 14-3-3- $\beta,-\gamma,-\eta,-\varepsilon,-\zeta,-$ $\sigma,-\tau$ gehängt bzw. durch das Bakterium Escherichia coli produziert wird. Der Vorteil des GST-Tags liegt in seiner hohen Affinität zu Glutathion. Diese Eigenschaft erlaubt eine hochgradige Aufreinigung des Fusionsproteins aus Zelllysaten mit Hilfe von z. B. Glutathion-Sepharose-4B-Beads (Biomol). Zusätzlich enthalten die GST-14-3-3Isoformen eine bestimmte Spaltungsdomäne (Leu-Val-Pro-Arg-Gly-Ser) für Thrombin in der GST-Fusionsregion. An dieser Domäne kann das Thrombin, eine Serinprotease mit hoher proteolytischer Spezifität, schneiden und somit das GSTTag von dem rekombinanten Protein trennen. Diese Eigenschaft des Thrombins wurde bei der hier angewandten Methode der Thrombin-Cleavage genutzt und mit Hilfe des THROMBIN CleanCleave ${ }^{\text {TM }}$ KITs (Sigma-Aldrich) das GST-Tag von den rekombinant hergestellten 14-3-3-Isoformen entfernt.

In dieser Arbeit wurden pro Isoform $50 \mu \mathrm{g}$ Fusionsprotein, d.h. GST-14-3-3-Protein, in $250 \mu \mathrm{l}$ Endvolumen aufgereinigt. Zunächst wurden die Thrombin-AgaroseGranulate in eine homogene Lösung überführt, $25 \mu \mathrm{l}$ der $50 \%(\mathrm{v} / \mathrm{v})$ Suspension für 5 
Minuten bei $500 \times g$ zentrifugiert und der Überstand verworfen. $125 \mu \mathrm{l}$ des mitgelieferten einfach konzentrierten Cleavagepuffers wurden hinzugefügt, wiederum für 5 Minuten bei $500 \times g$ zentrifugiert und der Überstand verworfen. Dieser Vorgang wurde noch einmal wiederholt, um die Thrombin-Agarose-Granulate optimal aufzureinigen. Um die eigentliche Spaltungsreaktion in Gang zu setzen, wurden die Granulate in $25 \mu \mathrm{l}$ zehnfach-konzentriertem Cleavagepuffer resuspendiert, $50 \mu \mathrm{g}$ Fusionsprotein hinzugegeben und das Volumen anschließend mit ${ }_{d d} \mathrm{H}_{2} \mathrm{O}$ auf $250 \mu \mathrm{l}$ aufgefüllt. Anschließend erfolgte die Inkubation der Spaltungsreaktion bei $25^{\circ} \mathrm{C}$ für 6 Stunden unter ständiger Bewegung der verwendeten Eppendorfcups (Thermomixer). Darauffolgend wurden die Proben zwei Minuten bei geringer Umdrehungszahl zentrifugiert, der Überstand aliquotiert und mittels SDS-PAGE und Western Blot auf die erwarteten Spaltprodukte hin untersucht, d.h. 14-3-3-Isoformen ohne GST-Tag mit einer Größe von 30 kDa.

\subsubsection{Tau-Proteinbestimmung im Liquor}

Das Tau-Protein im Liquor der sCJK-Patienten wurde mit dem FestphasenEnzymimmunoassay INNOTEST® hTAU AG (Innogenetics N.V., Belgien) quantitativ bestimmt. Bei diesem Sandwich-ELISA wird durch den ersten monoklonalen Antikörper (AT120) das Tau-Protein im Liquor (25 $\mu$ l) in der Festphase gebunden und anschließend mit zwei weiteren biotinylierten monoklonalen Antikörpern (HT7 und BT2) gegen verschiedene Tau-Proteinepitope inkubiert. Der Nachweis dieser gebundenen Antikörper erfolgt über Peroxidase-markiertes Streptavidin, welches nach Zugabe von Substrat-Gebrauchslösung zu einer Blauverfärbung der positiven Proben führt. Diese Reaktion wird durch den Zusatz von Schwefelsäure unterbrochen, gefolgt von einer Gelbfärbung der Proben. Die Extinktionen werden bei $450 \mathrm{~nm}$ gemessen und anhand einer für diesen ELISA etablierten Standardkurve die entsprechenden quantitativen Werte des Tau-Proteins in den Liquorproben bestimmt. Die Anwendung des INNOTEST® hTAU AG erfolgte gemäß Protokoll des Herstellers. 


\subsection{Ergebnisauswertung}

Die Western Blots wurden semiquantitativ von zwei Betrachtern (S.J. und U.H.) ausgewertet, wobei U.H. für Subtyp und 14-3-3-Isoform geblindet war. Beurteilt wurde zum einen qualitativ das reine Vorhandensein von Banden auf Höhe von 30 $\mathrm{kDa}$, entsprechend der Molekulargröße der 14-3-3-Isoformen. Zum anderen erfolgte eine semiquantitative Auswertung orientierend an der Bandenstärke der Positivkontrolle bei entweder $60 \mathrm{kDa}$ oder $30 \mathrm{kDa}$ gemäß folgendem Algorithmus:

- $(0$ Punkte $)=$ negativ, keine Banden detektierbar

(+) $(1$ Punkt $)$ = schwach positiv, schwache Banden erkennbar

$+(2$ Punkte $)=$ positiv, Banden sichtbar

++ $(3$ Punkte $)=$ stark positiv, Bandenstärke deutlich sichtbar

+++ (4 Punkte) $=$ sehr stark positiv, Banden sehr deutlich und breit

Jede Liquorprobe wurde semiquantitativ mit einer Punktzahl von 0 (negativ) bis 4 (sehr stark positiv) bewertet. Bei jeweils sieben Proben von MM1, MV1, MV2 und VV2, konnte eine maximale Punktzahl von 28 für Subtyp und korrespondierender Isoform erzielt werden, bei MM2 und VV1 mit jeweils vier Proben entsprechend 16 Punkte maximal. Um Häufigkeit und Intensität der Banden für jeden molekularen Subtyp zu vergleichen, wurde der Prozentsatz der maximal erreichbaren Punkte berechnet. Zusätzlich wurde die semiquantitative Auswertung mittels Punktzahl verwendet, um jede 14-3-3-Isoform, jeden Subtyp, jeden Genotyp und beide PrP ${ }^{\mathrm{Sc}}$ Typen jeweils zusammenzufassen. Alle Western Blots mit den Patienten der verschiedenen Subtypen und auch die Kontrollen wurden gemäß dem oben genannten Algorithmus ausgewertet und nach 14-3-3-Isoformen unterteilt tabellarisch aufgeführt.

Des Weiteren wurden alle Patienten eines Subtyps gemeinsam betrachtet und rein qualitativ für eine 14-3-3-Isoform als positiv [+] gewertet, wenn bei mindestens $70 \%$, d.h. 5 der 7 Patientenliquores (bzw. 3 von 4 Patienten bei VV1 und MM2) diese Isoform im Western Blot nachgewiesen werden konnte. Negativ [-] für eine 14-3-3Isoform wurde der Subtyp gewertet, wenn wiederum bei mindestens $70 \%$ keine Banden für die entsprechende Isoform nachgewiesen werden konnten. Subtypen, die diesen Kriterien nicht entsprachen, wurden mit [+/-] gewertet und erlauben keine 
eindeutige Aussage hinsichtlich der An- bzw. Abwesenheit der jeweiligen untersuchten 14-3-3-Isoform bezogen auf den gesamten Subtyp.

Außerdem erfolgte eine Analyse hinsichtlich Abhängigkeit der Bandenintensität von der 14-3-3-Isoform zum einen unabhängig vom sCJK-Subtyp, zum anderen abhängig vom sCJK-Subtyp. Als letzter Punkt erfolgte die Korrelation des Tau-Proteins, als weiterem neurodegenerativen Marker, einerseits mit den Subtypen und andererseits mit der Bandenintensität der Western Blots bei den jeweiligen 14-3-3-Isoformen.

Die Auswertung und graphische Darstellung der ermittelten Ergebnisse erfolgte mit Hilfe des Statistik- und Graphikprogramms GraphPadPrism 4.0. Als statistische Methoden wurden verwendet Mittelwerte mit 95\%-Konfidenzintervall und nichtlineare Regression. Weitere statistische Analysen wurden auf Grund der geringen Patientenzahlen und der damit verbundenen verminderten Aussagekraft nicht angewandt. 


\section{Ergebnisse}

\subsection{Das Patientenkollektiv}

Im Rahmen dieser Studie wurden Liquorproben von insgesamt 36 Patienten mit gesicherter sporadischer Creutzfeldt-Jakob-Krankheit und 8 Kontrollpatienten mit anderer neurologischer Diagnose auf das Vorhandensein von 14-3-3-Isoformen getestet. Die 36 CJK-Patienten wurden gemäß ihrem Polymorphismus an Codon-129 und der Größe des Proteinase-K-resistenten Prionproteinfragments in die bekannten 6 Subtypen der Creutzfeldt-Jakob-Krankheit unterteilt. Dementsprechend gab es folgende Patientengruppen:

- MM1-Subtyp $\mathrm{n}=7$

- MM2-Subtyp $\quad \mathrm{n}=4$

- MV1-Subtyp $\mathrm{n}=7$

- MV2-Subtyp $\mathrm{n}=7$

- VV1-Subtyp $\mathrm{n}=4$

- VV2-Subtyp $n=7$

Von den Subtypen MM2 und VV1 konnten jeweils nur 4 Proben untersucht werden, da diese Subtypen weltweit selten vorkommen und nur wenige Patienten die bereits genannten Untersuchungskriterien, insbesondere die Liquorpunktion im letzten Krankheitsdrittel, erfüllten. Die demographischen Charakteristika der CJKPatientenkollektive sind in Tabelle 11, die der Kontrollpatienten in Tabelle 12 wiedergegeben:

\begin{tabular}{|c|c|c|c|c|c|c|c|}
\hline & $\begin{array}{c}\text { sCJK } \\
\text { ges } \\
(n=36)\end{array}$ & $\begin{array}{l}\text { MM1 } \\
(n=7)\end{array}$ & $\begin{array}{l}\text { MM2 } \\
(n=4)\end{array}$ & $\begin{array}{l}\text { MV1 } \\
(n=7)\end{array}$ & $\begin{array}{l}\text { MV2 } \\
(\mathrm{n}=7)\end{array}$ & $\begin{array}{l}\text { VV1 } \\
(n=4)\end{array}$ & $\begin{array}{l}\text { VV2 } \\
(\mathrm{n}=7)\end{array}$ \\
\hline $\begin{array}{l}\text { Geschlecht im } \\
\text { Verhältnis } \hat{\delta}: \uparrow\end{array}$ & $5: 7$ & $3: 4$ & $1: 1$ & $3: 4$ & $2: 5$ & $4: 0$ & $1: 3$ \\
\hline $\begin{array}{l}\text { Mittleres Alter in } \\
\text { Jahren bei } \\
\text { Symptombeginn } \\
\text { (Spannweite) }\end{array}$ & $\begin{array}{l}60,94 \\
(40-81)\end{array}$ & $\begin{array}{l}68,86 \\
(58-78)\end{array}$ & $\begin{array}{c}63 \\
(47-76)\end{array}$ & $\begin{array}{l}60,29 \\
(46-79)\end{array}$ & $\begin{array}{c}63 \\
(53-76)\end{array}$ & $\begin{array}{c}53 \\
(41-69)\end{array}$ & $\begin{array}{c}57,5 \\
(40-81)\end{array}$ \\
\hline $\begin{array}{c}\text { Mittlere } \\
\text { Krankheitsdauer in } \\
\text { Monaten } \\
\text { (Spannweite) }\end{array}$ & $\begin{array}{l}8,93 \\
(2-23)\end{array}$ & $\begin{array}{l}4,29 \\
(2-9)\end{array}$ & $\begin{array}{l}10,25 \\
(3-17)\end{array}$ & $\begin{array}{l}5,14 \\
(2-10)\end{array}$ & $\begin{array}{l}14,14 \\
(4-23)\end{array}$ & $\begin{array}{c}11,75 \\
(5-17)\end{array}$ & $\begin{array}{c}8 \\
(3-16)\end{array}$ \\
\hline
\end{tabular}

Tabelle 11: Demographische Tabelle des CJK-Patientenkollektivs 


\begin{tabular}{|c|cccc|}
\hline $\begin{array}{c}\text { Kontrollpatienten } \\
\text { (Nicht-CJK) }\end{array}$ & Anzahl & $\begin{array}{c}\text { Geschlecht } \\
\text { : }:\end{array}$ & $\begin{array}{c}\text { Mittleres Alter in } \\
\text { Jahren bei } \\
\text { Krankheitsbeginn }\end{array}$ & $\begin{array}{c}\text { 14-3-3 bei } \\
\text { Routinediagnostik }\end{array}$ \\
\hline Ischämisch & 4 & $1: 3$ & 76,5 & Positiv \\
\hline Entzündlich & 4 & $3: 1$ & 72 & Positiv \\
\hline
\end{tabular}

Tabelle 12: Demographische Tabelle der Kontrollpatienten

\subsection{Nachweis der Antikörperspezifität}

Der Dot Blot als Methode zur Untersuchung der Antikörperspezifität wurde, wie bereits beschrieben, in dieser Arbeit angewandt, um die Spezifität der verwendeten Antikörper der Firmen IBL, Japan, und Santa Cruz Biotechnology, USA, für die 14-33-Isoformen zu ermitteln und zu vergleichen, um diese dann als Primärantikörper in den Western Blots zu verwenden. Als Antigene wurden rekombinant hergestellte 143-3-Proteinisoformen verwendet. Abbildung 6 zeigt das Ergebnis des Dot Blots:

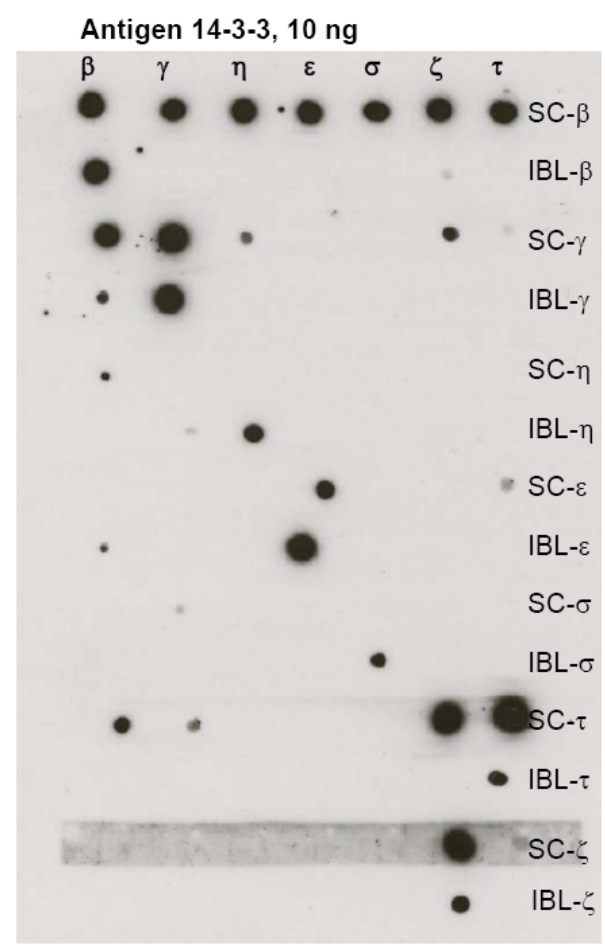

Abbildung 6:

Dot Blot zum Nachweis der Antikörperspezifität

SC = Anti-14-3-3-Isoform-Antikörper der Firma Santa Cruz Biotechnology

$\mathrm{IBL}=$ Anti-14-3-3-Isoform-Antikörper der Firma IBL Japan 
Der Dot Blot zeigt spezifische Antigen-Antikörperreaktionen für die Antikörper IBL$\beta$, IBL- $\eta$, SC- $\varepsilon$, IBL- $\sigma$, IBL- $\tau$, SC- $\zeta$ und IBL- $\zeta$. Bei den Antikörpern IBL- $\gamma$ und IBL- $\varepsilon$ sind zusätzlich kleine „Dots“ (Punkte), im Sinne einer geringfügigen Kreuzreaktion mit der Isoform 14-3-3- $\beta$ zu sehen, die jedoch im Vergleich zu den Punkten der spezifischen Antigen-Antikörperreaktion der jeweiligen 14-3-3-Isoform deutlich kleiner sind, wie aus der Abbildung hervorgeht. Die Antikörper der Firma Santa Cruz Biotechnology, die gegen die Isoformen 14-3-3- $\beta,-\gamma$ und - $\tau$ gerichtet sind, weisen hingegen, neben ihrer spezifischen Isoformreaktion, mehrere, vergleichsweise starke Kreuzreaktionen mit anderen 14-3-3-Isoformen auf. Für die Antikörper SC- $\sigma$ und $-\eta$ zeigte der Dot Blot mit den verwendeten Konzentrationen für Antigen und Antikörper keine „Dots“, bei SC- $\eta$ jedoch eine geringe Kreuzreaktion mit der Isoform $\beta$.

Die oben beschriebenen Ergebnisse zeigen eine höhere Spezifität der IBL-Antikörper gegenüber den einzelnen 14-3-3-Isoformen als die Antikörper der Firma Santa Cruz, so dass für die folgenden Untersuchungen der Patientenliquores mittels Western Blot die Antikörper der Firma IBL als Primärantikörper gewählt wurden.

\subsection{Auswertung der Western Blots}

Das gesamte Patientenkollektiv, d.h. alle sCJK-Subtypen und Kontrollen, wurde auf das Vorhandensein der sieben 14-3-3-Isoformen $(\beta, \gamma, \eta, \varepsilon, \zeta, \sigma, \tau)$ hin untersucht. Um Übersichtlichkeit zu gewähren, wurden die Western Blots eines Subtyps in einer Abbildung zusammengefasst und die Blots auf Höhe der $30 \mathrm{kDa}$-Banden ausgeschnitten. Bei einigen Western Blots ist die Positivkontrolle bei $30 \mathrm{kDa}$ kaum zu sehen, in der Höhe leicht von den Banden der Patientenliquores abweichend oder wie bei den MM2- und VV1-Subtypen nur als Positivkontrolle bei $60 \mathrm{kDa}$ aufgetragen. Da auf jedem Western Blot jedoch ein molekularer Größenmarker aufgetragen wurde, der zwar mittels Chemilumineszenzreaktion nicht detektiert wurde, auf der Membran des jeweiligen Blots jedoch farbig zu erkennen war, konnte stets ein Vergleich der Bandenhöhen mit dem Molekulargewichtmarker stattfinden. Somit wurde sichergestellt, dass es sich bei den beschriebenen Banden tatsächlich um die 14-3-3-Isoformen handelt.

Um eine semiquantitative Aussage über den Nachweis der 14-3-3-Isoformen zu ermöglichen, wurden zunächst die Antikörperkonzentrationen über genormte Proben 
mit einer definierten Menge von Antigen (10 ng) mittels Western Blot ermittelt. Es wurden diejenigen Antikörperkonzentrationen bestimmt, die bei identischer Antigenkonzentration optisch gleiche Bandenintensitäten aufzeigten.

Mit diesen ermittelten Antikörperkonzentrationen wurde jeweils dieselbe Liquormenge (15 $\mu$ l) aus den einzelnen Patientenproben auf das Vorhandensein von 14-3-3-Isoformen untersucht. In früheren Arbeiten wurde eine Korrelation der Bandenintensitäten mit der 14-3-3-Konzentration nachgewiesen (Wakabayashi et al. 2001). Dadurch lässt sich eine qualitative und sogar eine semiquantitative Aussage hinsichtlich der Bandenstärken im Western Blot der 14-3-3-Isoformen machen. Es ist jedoch nicht auszuschließen, dass eine 14-3-3-Isoform, die im Western Blot nicht detektiert wurde, in geringer Konzentration im Liquor vorhanden sein könnte. Die Konzentration dieser Isoform läge dann jedoch unter der Nachweisgrenze der in dieser Arbeit gewählten Antikörperkonzentration und Methode und hat für das Ziel dieser Arbeit, nämlich Differenzierung der molekularen Subtypen von CreutzfeldtJakob-Krankheit mittels Western Blot, keine diagnostische Relevanz. Die semiquantitative Auswertung erfolgte wie im Methodenteil 2.4 beschrieben und ist tabellarisch für jeden Subtyp aufgeführt.

\subsubsection{MM1-Subtyp}

Abbildung 7 zeigt die Western Blots der sieben Isoformen für den MM1-Subtyp bei $30 \mathrm{kDa}$. Die Positivkontrollen, bestehend aus den rekombinanten 14-3-3-Isoformen mit GST-Tag und somit einer Größe von $60 \mathrm{kDa}$, sind bei dieser Darstellung der WB nicht sichtbar. Die nach Thrombin-Cleavage als Positivkontrollen dienenden rekombinanten 14-3-3-Isoformen von $30 \mathrm{kDa}$ sind bei den Blots an dritter Position aufgetragen, ausgenommen der Isoformen $\varepsilon$ und $\zeta$, wo sie sich an zweiter Stelle befinden. Daher erfolgte die Beschriftung der Positivkontrollen mit Antigen $60 \mathrm{kDa}$ oder Antigen 30 kDa (Ag60/Ag30) bzw. umgekehrt (Ag30/Ag60), abhängig von der Auftragung auf die Gele. 


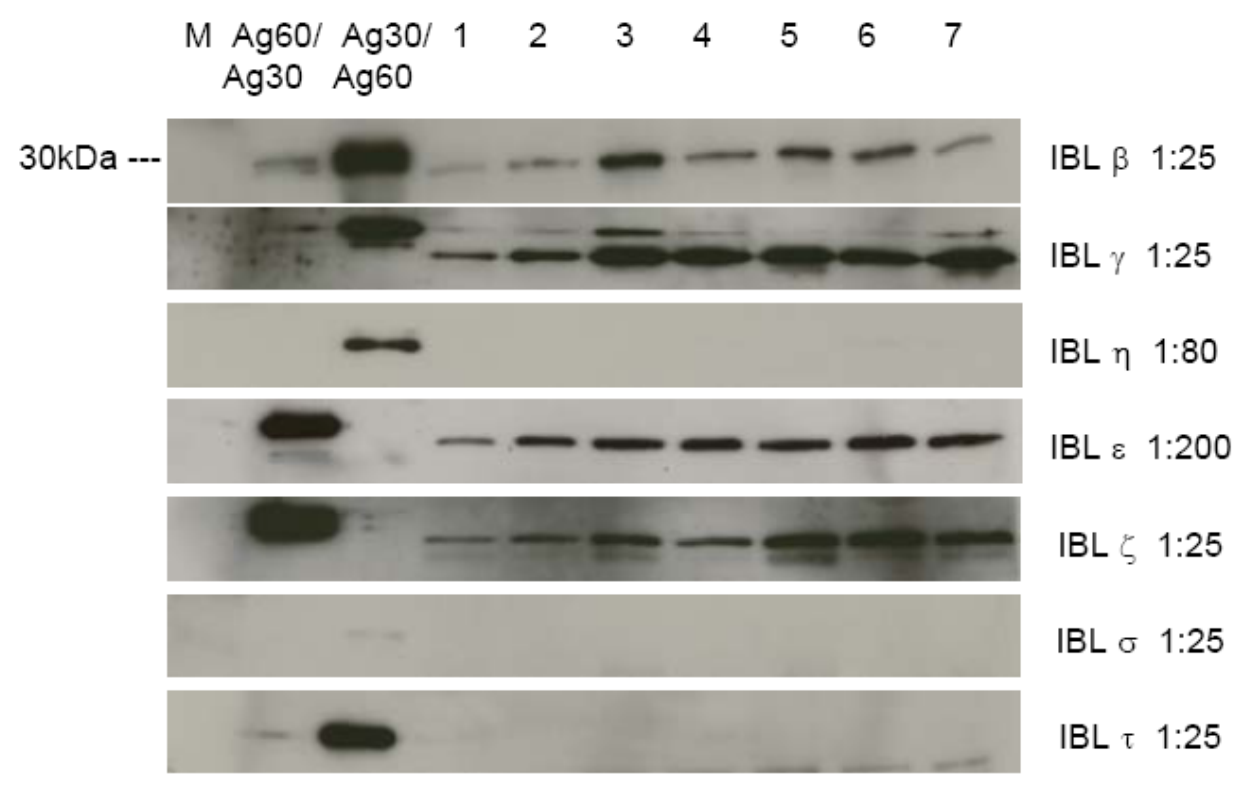

Abbildung 7: MM1-Subtyp

$\mathrm{M}=$ Marker; 1-7 = Patienten

Ag60 = rekombinantes Antigen der jeweiligen Isoform, $60 \mathrm{kDa}$

$\mathrm{Ag} 30=$ rekombinantes Antigen der jeweiligen Isoform, 30kDa nach Thrombin-Cleavage

Bei allen sieben Patienten des MM1-Subtyps konnten die vier Isoformen 14-3-3- $\beta$, $\gamma,-\varepsilon$ und $-\zeta$ mit deutlichen Banden im WB nachgewiesen werden. Bei den WBs der Isoformen $\gamma$ und $\zeta$ sind die Banden besonders stark ausgeprägt und weisen bei der Mehrzahl der Patienten sogenannte Doppelbanden auf, die sich allerdings in ihrem Muster unterscheiden. Bei dem 14-3-3- $\gamma$-WB ist bei den Patientenliquores die untere Bande stärker als die obere. Die Positivkontrolle von 14-3-3- $\gamma$, die ebenfalls eine leichte Doppelbande zeigt, liegt jedoch in Höhe der oberen, feineren Bande der Patienten. Bei dem 14-3-3- $\zeta-$ WB sind bei den Patientenliquores die oberen Banden betont.

Zusätzlich zeigen sich für die Isoformen $\beta$ und $\zeta$ variable Bandenstärken bei den verschiedenen Patienten. So sind in Abbildung 7 die Banden für die Isoform 14-3-3- $\beta$ bei den Patienten 3, 4, 5 und 6 stärker als die der restlichen Patienten. Dieses Muster ist nahezu analog für die Isoform $\zeta$, wobei dort auch Patient 7 eine starke Bande aufweist. Bei den Western Blots für die Isoformen 14-3-3- $\eta,-\sigma$ und $-\tau$ sind bei keinem Patienten Banden sichtbar, wobei die Positivkontrolle bei der Isoform14-3-3$\sigma$ nur schwach zu erkennen ist. 
Tabelle 13 zeigt die semiquantitative Auswertung der Bandenstärken für den MM1Subtyp gemäß dem im Methodenteil beschriebenen Algorithmus für die einzelnen 14-3-3-Isoformen.

\begin{tabular}{|c|c|c|c|c|c|c|c|}
\hline MM1 & $\begin{array}{c}14-3-3 \\
\beta\end{array}$ & $\begin{array}{c}14-3-3 \\
\gamma\end{array}$ & $\begin{array}{c}14-3-3 \\
\eta\end{array}$ & $\begin{array}{c}14-3-3 \\
\varepsilon\end{array}$ & $\begin{array}{c}14-3-3 \\
\zeta\end{array}$ & $\begin{array}{c}14-3-3 \\
\sigma\end{array}$ & $\begin{array}{c}14-3-3 \\
\tau\end{array}$ \\
\hline Pat. 1 & $(+)$ & + & - & + & + & - & - \\
\hline Pat. 2 & $(+)$ & ++ & - & ++ & + & - & - \\
\hline Pat. 3 & + & +++ & - & ++ & ++ & - & - \\
\hline Pat. 4 & + & +++ & - & ++ & + & - & - \\
\hline Pat. 5 & + & +++ & - & ++ & ++ & - & - \\
\hline Pat. 6 & + & +++ & - & ++ & ++ & - & - \\
\hline Pat. 7 & $(+)$ & +++ & - & ++ & + & - & - \\
\hline Alle & $\begin{array}{c}11 / 28 \\
39 \%\end{array}$ & $\begin{array}{c}25 / 28 \\
89 \%\end{array}$ & 0 & $\begin{array}{c}20 / 28 \\
71 \%\end{array}$ & $\begin{array}{c}17 / 28 \\
61 \%\end{array}$ & 0 & 0 \\
\hline
\end{tabular}

Tabelle 13: MM1-Subtyp, Semiquantitative Auswertung der 14-3-3-Isoform-Western-Blots; Pat. = Patient

\subsubsection{MV1-Subtyp}

Die Western Blots des MV1-Subtyps sind in Abbildung 8 dargestellt. Ebenso wie beim MM1-Subtyp sind die Isoformen 14-3-3- $\beta,-\gamma,-\varepsilon$ und $-\zeta$ bei der Mehrheit der MV1Patienten nachweisbar, die Isoformen $\eta, \sigma$ und $\tau$ hingegen nicht.

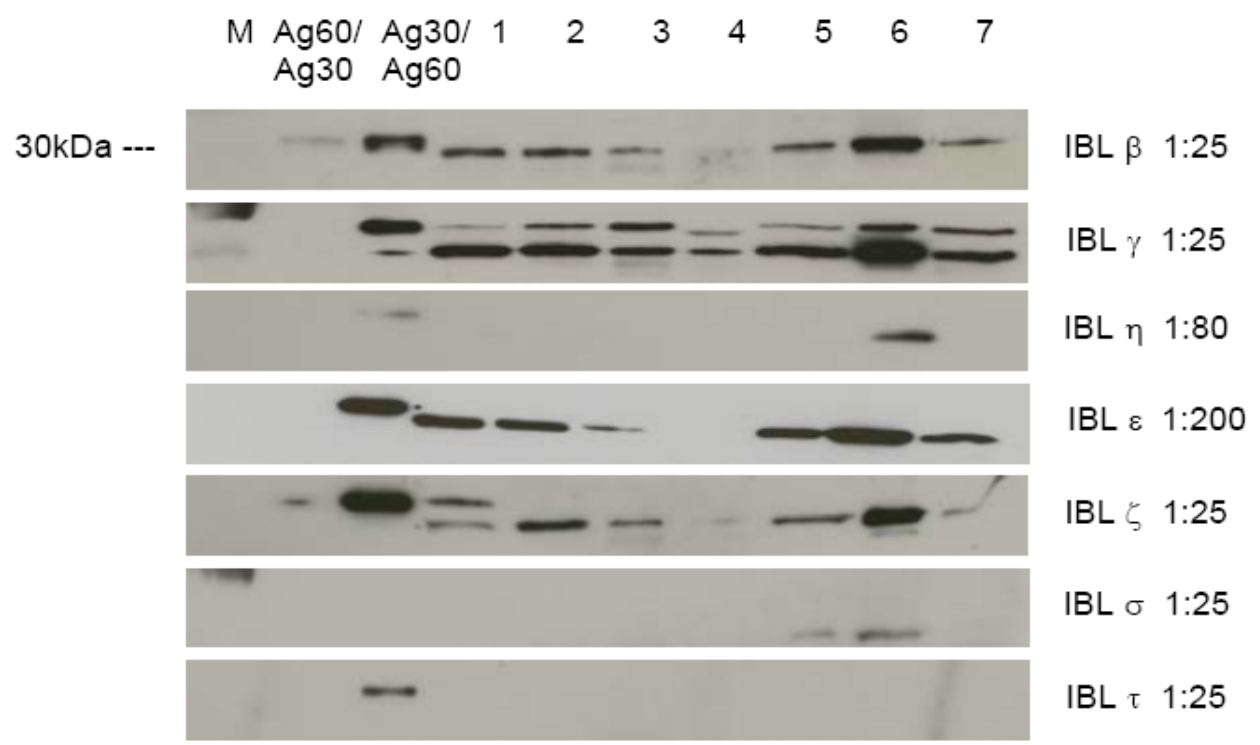




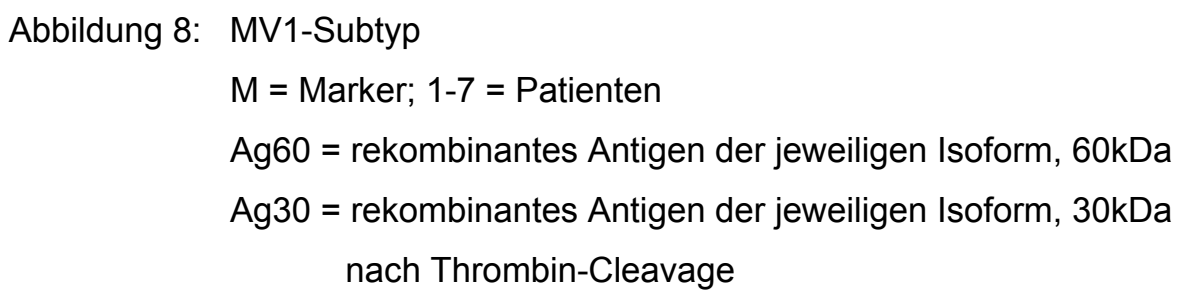

Ebenso wie beim MM1-Subtyp sind deutliche Doppelbanden bei der $\gamma$-Isoform aller sieben Patienten zu erkennen, mit dem gleichen Muster der intensiveren unteren Bande. Die Isoform 14-3-3- $\zeta$ zeigt im Gegensatz beim MV1-Subtyp nur bei Patient 1 eine deutliche, bei Patient 6 nur eine diskrete Doppelbande.

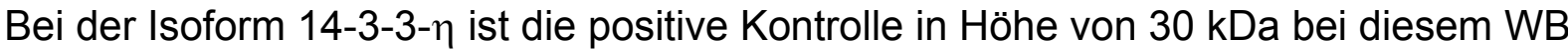
sehr schwach. Dennoch kann man sagen, dass außer bei dem Patienten 6, wo sich eine schwache Bande bei $30 \mathrm{kDa}$ andeutet, kein Nachweis von 14-3-3- $\eta$ bei den anderen sechs MV1-Patienten zu erkennen ist. Ebenso sind die Isoformen $\tau$ und $\sigma$ nicht als Bande im Liquor des Patientenkollektives nachweisbar, wobei bei letzterer Isoform die positive Kontrolle ebenfalls nicht in Höhe von $30 \mathrm{kDa}$ zu sehen ist und der Patient 6 als einziger eine mögliche schwach positive Bande zeigt.

Auffällig bei den Patienten unabhängig von der nachzuweisenden Isoform ist die unterschiedliche Bandenintensität. Die Banden des Patienten 4 sind, wenn überhaupt vorhanden, bei den verschiedenen Isoformen sehr schwach, bei der Isoform $\gamma$ im Vergleich gesehen noch am stärksten. Diese Isoform ist insgesamt bei allen Patienten mit der stärksten Intensität abgebildet. Vergleicht man die Bandenstärken der Patienten untereinander, so ist die Bandenintensität bei Patient 4 stets am schwächsten, bei Patient 6 am stärksten. Die Banden des Patienten 6 zeigen bei allen, mehrheitlich für den MV1-Subtyp nachgewiesenen, Isoformen ( $\beta$, $\gamma, \varepsilon, \zeta)$ die höchste Intensität. Zusätzlich kann ausschließlich bei dem Patienten 6 eine Bande für die Isoform 14-3-3-ๆ nachgewiesen werden.

Tabelle 14 zeigt zusammenfassend die semiquantitative Auswertung der Bandenstärken für den MV1-Subtyp. 


\begin{tabular}{|c|c|c|c|c|c|c|c|}
\hline MV1 & $\begin{array}{c}14-3-3 \\
\beta\end{array}$ & $\begin{array}{c}14-3-3 \\
\gamma\end{array}$ & $\begin{array}{c}14-3-3 \\
\eta\end{array}$ & $\begin{array}{c}14-3-3 \\
\varepsilon\end{array}$ & $\begin{array}{c}14-3-3 \\
\zeta\end{array}$ & $\begin{array}{c}14-3-3 \\
\sigma\end{array}$ & $\begin{array}{c}14-3-3 \\
\tau\end{array}$ \\
\hline Pat. 1 & + & ++ & - & + & + & - & - \\
\hline Pat. 2 & + & ++ & - & + & + & - & - \\
\hline Pat. 3 & $(+)$ & + & - & $(+)$ & + & - & - \\
\hline Pat. 4 & - & $(+)$ & - & - & $(+)$ & - & - \\
\hline Pat. 5 & + & ++ & - & + & + & - & - \\
\hline Pat. 6 & ++ & +++ & + & ++ & ++ & $(+)$ & - \\
\hline Pat. 7 & $(+)$ & ++ & - & + & $(+)$ & - & - \\
\hline Alle & $\begin{array}{c}11 / 28 \\
39 \%\end{array}$ & $\begin{array}{c}19 / 28 \\
\mathbf{6 8} \%\end{array}$ & $\begin{array}{c}2 / 28 \\
7 \%\end{array}$ & $\begin{array}{c}12 / 28 \\
43 \%\end{array}$ & $\begin{array}{l}13 / 28 \\
\mathbf{4 6} \%\end{array}$ & $\begin{array}{c}1 / 28 \\
4 \%\end{array}$ & 0 \\
\hline
\end{tabular}

Tabelle 14: MV1-Subtyp, Semiquantitative Auswertung der 14-3-3-Isoform-Western-Blots; Pat. = Patient

\subsubsection{VV2-Subtyp}

Bei allen sieben Patienten mit VV2-Subtyp konnten Banden, geringfügig unterschiedlicher Intensität, bei den folgenden vier 14-3-3-Isoformen gezeigt werden: $\beta, \gamma, \varepsilon$ und $\zeta$. Die beiden Isoformen $\eta$ und $\sigma$ weisen bei keinem der sieben VV2Patienten Banden auf, die Isoform 14-3-3- $\tau$ hingegen lässt bei sechs der sieben Patienten Banden erkennen. Die positive Kontrolle zeigt bei diesem WB keine sichtbare Bande bei $30 \mathrm{kDa}$, jedoch eine schwache Bande bei $60 \mathrm{kDa}$, ebenso wie die positive Kontrolle für die Isoform $\sigma$.

Wie auch bei den vorher beschriebenen Subtypen ist die Isoform $\gamma$ mit Doppelbanden assoziiert, wobei die oberen Banden sehr schwach und damit kaum sichtbar sind. Ebenso finden sich auch bei 14-3-3- $\zeta$ diskrete Doppelbanden, die mit dem bereits bei dem MM1-Subtyp beschriebenen Muster für 14-3-3- $\zeta$, mit einer stärkeren oberen Bande, einhergehen. Abbildung 9 zeigt die Blots für den Subtyp VV2: 


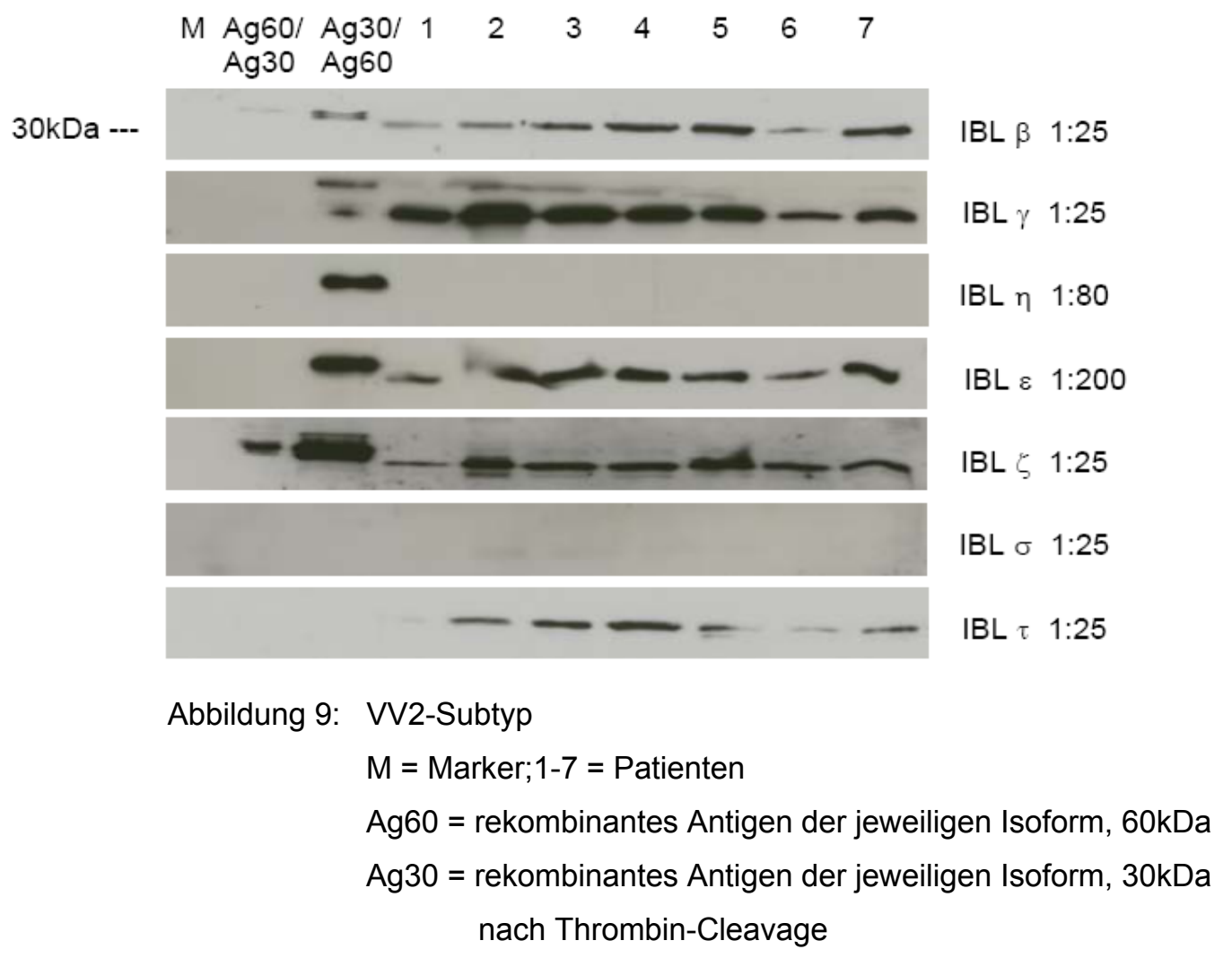

Die nachfolgende Tabelle 15 zeigt für den VV2-Subtyp die semiquantitative Auswertung der in den Western Blots dargestellten Banden nach dem beschriebenen Algorithmus:

\begin{tabular}{|c|c|c|c|c|c|c|c|}
\hline VV2 & $\begin{array}{c}14-3-3 \\
\beta\end{array}$ & $\begin{array}{c}14-3-3 \\
\gamma\end{array}$ & $\begin{array}{c}14-3-3 \\
\eta\end{array}$ & $\begin{array}{c}14-3-3 \\
\varepsilon\end{array}$ & $\begin{array}{c}14-3-3 \\
\zeta\end{array}$ & $\begin{array}{c}14-3-3 \\
\sigma\end{array}$ & $\begin{array}{c}14-3-3 \\
\tau\end{array}$ \\
\hline Pat. 1 & $(+)$ & ++ & - & + & + & - & - \\
\hline Pat. 2 & + & +++ & - & ++ & ++ & - & + \\
\hline Pat. 3 & + & +++ & - & ++ & ++ & - & + \\
\hline Pat. 4 & ++ & +++ & - & ++ & ++ & - & + \\
\hline Pat. 5 & ++ & +++ & - & ++ & ++ & - & $(+)$ \\
\hline Pat. 6 & $(+)$ & + & - & + & ++ & - & $(+)$ \\
\hline Pat. 7 & ++ & ++ & - & ++ & ++ & - & + \\
\hline Alle & $\begin{array}{c}15 / 28 \\
54 \%\end{array}$ & $\begin{array}{c}24 / 28 \\
86 \%\end{array}$ & 0 & $\begin{array}{c}19 / 28 \\
68 \%\end{array}$ & $\begin{array}{c}20 / 28 \\
71 \%\end{array}$ & 0 & $\begin{array}{c}10 / 28 \\
36 \%\end{array}$ \\
\hline
\end{tabular}

Tabelle 15: VV2-Subtyp, Semiquantitative Auswertung der 14-3-3-Isoform-Western-Blots; Pat. = Patient 


\subsubsection{MV2-Subtyp}

Im nachfolgenden sind die Western Blots der verschiedenen Isoformen für den MV2Subtyp dargestellt. Sie zeigen ein eher heterogenes Bild, so dass die im Anschluss folgende tabellarische Auswertung der Bandenintensität näher betrachtet werden sollte. Zunächst einmal kann man jedoch sagen, dass, wie bei den vorangehend beschriebenen Subtypen auch, bei dem MV2-Subtyp die 14-3-3-Isoformen $\beta, \gamma, \varepsilon$ und $\zeta$ bei der Mehrzahl der Patienten nachgewiesen werden konnten, wenn auch in sehr stark variierender Intensität der Banden (s. Abb. 10).

Bei dem hier beschriebenen MV2-Subtyp sind bei keinem der sieben Patienten Banden bei den Isoformen 14-3-3- $\eta,-\sigma$ und $-\tau$ zu erkennen. Die Isoform $\gamma$ zeigt erneut deutliche Doppelbanden des bereits für diese Isoform beschriebenen Musters, wobei die Patienten 4, 5, 6 und 7 zusätzlich noch eine dritte Bande zeigen, die dem Muster der Doppelbanden der Isoform $\zeta$ ähneln.

Auch in dieser Abbildung des Subtyps MV2 wird deutlich, dass diejenigen Patienten, die in einer Isoform starke Bandenintensitäten aufweisen, dies auch bei den anderen Isoformen tun, z.B. Patienten 1, 3 und 5. Diejenigen Patienten hingegen, deren Bandenintensität bei einer Isoform schwach ist, z.B. Patienten 2 und 4, haben auch bei den anderen Isoformen schwache oder sogar keine Banden.

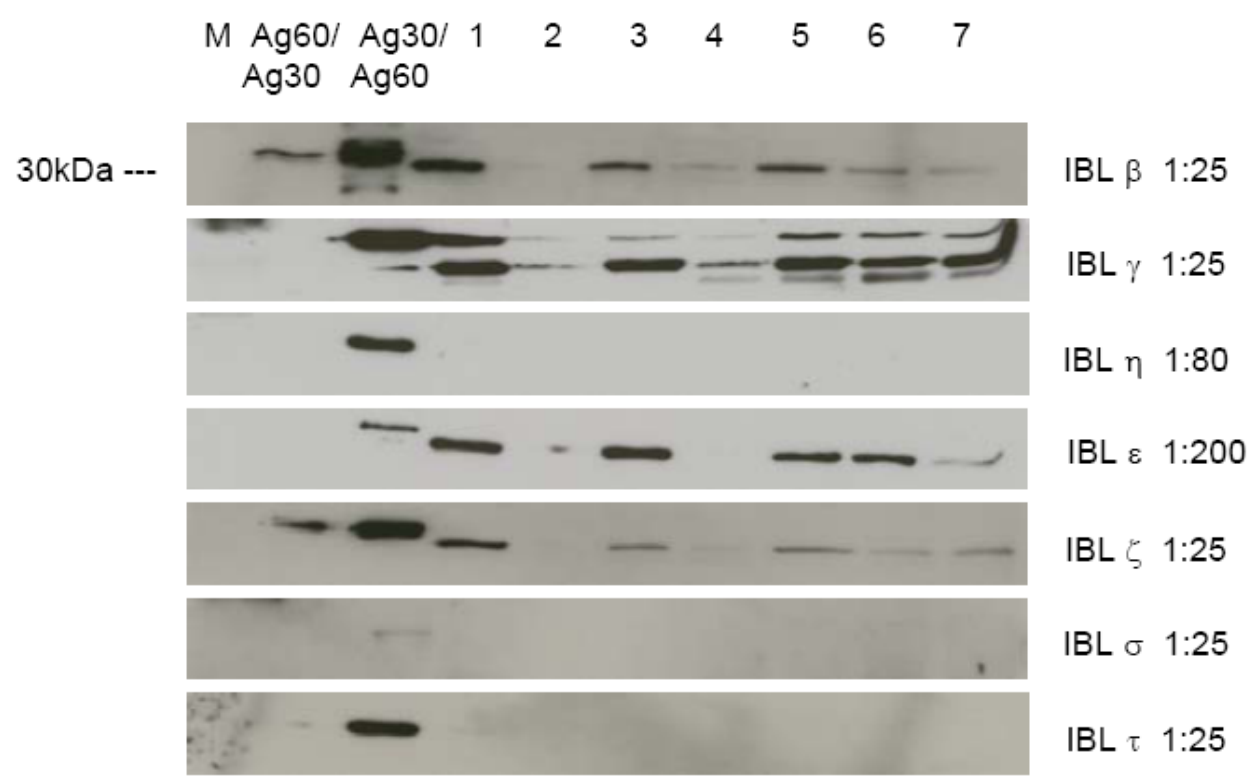




$$
\begin{aligned}
\text { Abbildung 10: } & \text { MV2-Subtyp } \\
& \begin{aligned}
& \mathrm{M}=\text { Marker; } 1-7=\text { Patienten } \\
& \mathrm{Ag} 60= \text { rekombinantes Antigen der jeweiligen Isoform, } 60 \mathrm{kDa} \\
& \mathrm{Ag} 30= \text { rekombinantes Antigen der jeweiligen Isoform, 30kDa } \\
& \text { nach Thrombin-Cleavage }
\end{aligned}
\end{aligned}
$$

\begin{tabular}{|c|c|c|c|c|c|c|c|}
\hline MV2 & $\begin{array}{c}14-3-3 \\
\beta\end{array}$ & $\begin{array}{c}14-3-3 \\
\gamma\end{array}$ & $\begin{array}{c}14-3-3 \\
\eta\end{array}$ & $\begin{array}{c}14-3-3 \\
\varepsilon\end{array}$ & $\begin{array}{c}14-3-3 \\
\zeta\end{array}$ & $\begin{array}{c}14-3-3 \\
\sigma\end{array}$ & $\begin{array}{c}14-3-3 \\
\tau\end{array}$ \\
\hline Pat. 1 & ++ & +++ & - & ++ & + & - & - \\
\hline Pat. 2 & - & $(+)$ & - & - & - & - & - \\
\hline Pat. 3 & + & ++ & - & ++ & $(+)$ & - & - \\
\hline Pat. 4 & $(+)$ & + & - & - & - & - & - \\
\hline Pat. 5 & + & ++ & - & + & $(+)$ & - & - \\
\hline Pat. 6 & $(+)$ & ++ & - & + & $(+)$ & - & - \\
\hline Pat. 7 & ++ & ++ & - & ++ & ++ & - & + \\
\hline Alle & $\begin{array}{c}12 / 28 \\
\mathbf{4 3} \%\end{array}$ & $\begin{array}{l}19 / 28 \\
68 \%\end{array}$ & 0 & $\begin{array}{l}13 / 28 \\
\mathbf{4 6} \%\end{array}$ & $\begin{array}{l}8 / 28 \\
29 \%\end{array}$ & 0 & $\begin{array}{c}2 / 28 \\
7 \%\end{array}$ \\
\hline
\end{tabular}

Die unterschiedlichen Bandenintensitäten sind in der Tabelle 16 für den Subtyp MV2 semiquantitativ ausgewertet.

Tabelle 16: MV2-Subtyp, Semiquantitative Auswertung der 14-3-3-Isoform-Western-Blots; Pat. = Patient

\subsubsection{VV1- und MM2-Subtyp}

Da es sich bei den beiden Subtypen VV1 und MM2 um sehr seltene Formen der Creutzfeldt-Jakob-Krankheit handelt und, wie bereits im Methodenteil erwähnt, nur sehr wenige Patienten (jeweils 4) den Untersuchungskriterien entsprachen, wurden beide Subtypen gemeinsam auf das Vorhandensein der 14-3-3-Isoformen untersucht. Die Abbildung 11 zeigt dementsprechend die ersten vier Patientenliquores (VV1, 1-4) des Subtyps VV1, bei den nächsten 4 Patienten (MM2, 1-4) handelt es sich um den MM2-Subtyp. 


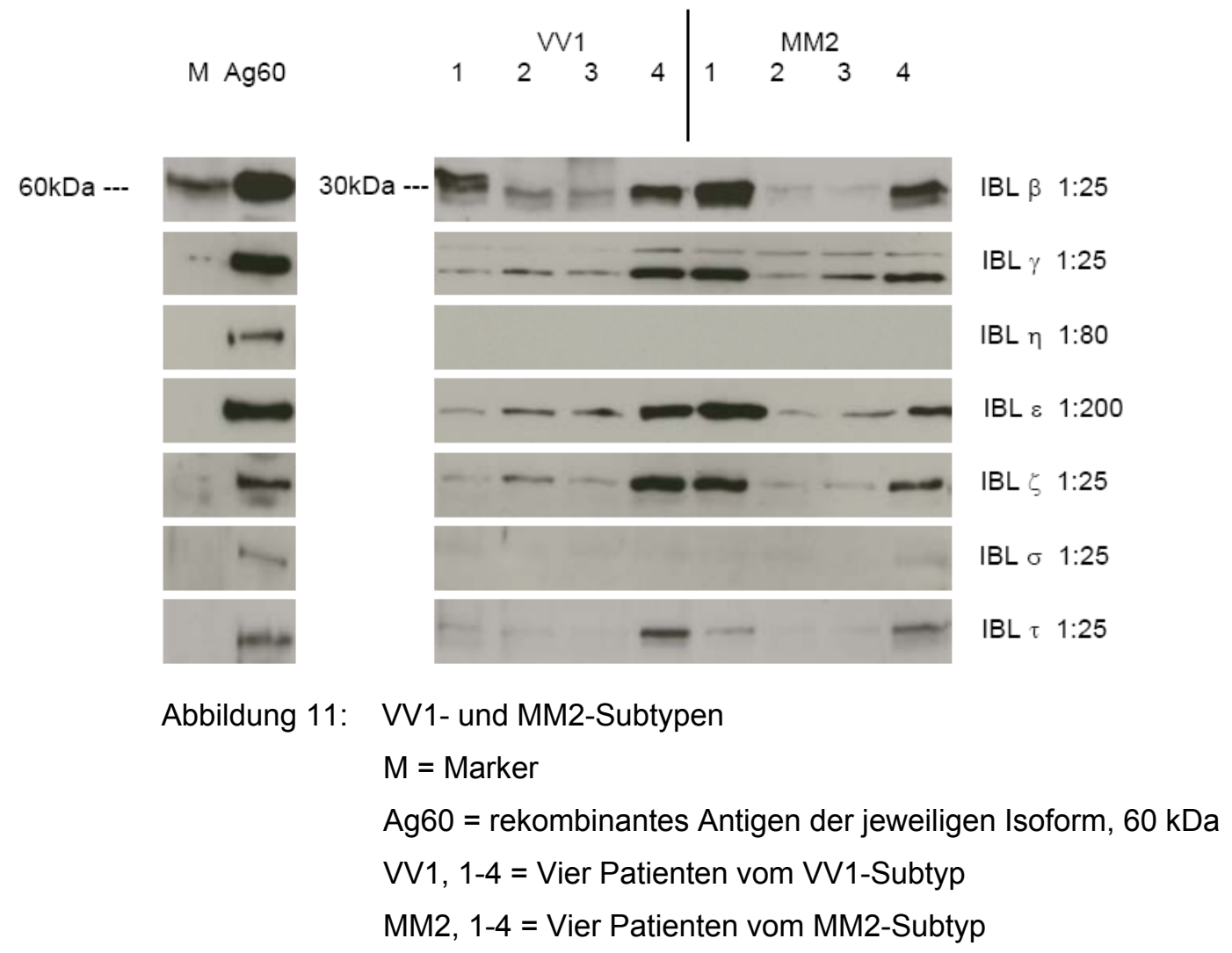

Bei den positiven Kontrollen handelt es sich hierbei um die direkt kommerziell erworbenen, rekombinanten Antigene mit einem Molekulargewicht von $60 \mathrm{kDa}$. Aus technischen Gründen (limitierte Anzahl der Geltaschen pro Gel) war eine Auftragung einer weiteren positiven Kontrolle nach Thrombin-Cleavage und somit einer Größe von $30 \mathrm{kDa}$ auf das gleiche Gel nicht möglich. Auf Grund der wechselhaften Verlässlichkeit der Thrombin-Cleavage und einer begrenzten Anzahl möglicher Wiederholungen der Western Blots durch den limitierenden Faktor der Liquormenge dieser seltenen Patienten wurde die Auftragung der $60 \mathrm{kDa}$-großen, rekombinanten 14-3-3-Isoformen als Positivkontrolle gewählt. In Abbildung 11 sind diese positiven Kontrollen daher abgesetzt dargestellt und entsprechend mit 60 kDa markiert, wohingegen die 14-3-3-Isoformen bei den Patientenliquores sich wie üblich bei 30 kDa finden und mittels Vergleich mit dem molekularen Größenmarker auf der Membran als solche verifiziert wurden.

\section{VV1-Subtyp}

Abbildung 11 zeigt den Nachweis der Isoformen 14-3-3- $\beta,-\gamma,-\varepsilon$ und $-\zeta$, entsprechend allen vorher beschriebenen Subtypen, und zusätzlich der Isoform $\tau$, welche 
außerdem nur beim VV2-Subtyp noch Banden zeigte. Die Isoformen 14-3-3- $\eta$ und - $\sigma$ sind bei diesem sCJK-Subtyp bei allen vier Patienten nicht nachweisbar. Wiederholt deuten sich leichte Doppelbanden bei der $\gamma$-Isoform an und es sind deutliche Unterschiede in der Bandenintensität der vier Patienten zu erkennen, insbesondere des Patienten 4, der bei allen nachgewiesenen Isoformen die größte Bandenstärke zeigt. Tabelle 17 zeigt die semiquantitative Auswertung der Banden für die vier Patienten des VV1-Subtyps.

\begin{tabular}{|c|c|c|c|c|c|c|c|}
\hline VV1 & $\begin{array}{c}14-3-3 \\
\beta\end{array}$ & $\begin{array}{c}14-3-3 \\
\gamma\end{array}$ & $\begin{array}{c}14-3-3 \\
\eta\end{array}$ & $\begin{array}{c}14-3-3 \\
\varepsilon\end{array}$ & $\begin{array}{c}14-3-3 \\
\zeta\end{array}$ & $\begin{array}{c}14-3-3 \\
\sigma\end{array}$ & $\begin{array}{c}\text { 14-3-3 } \\
\tau\end{array}$ \\
\hline Pat. 1 & ++ & + & - & $(+)$ & $(+)$ & - & $(+)$ \\
\hline Pat. 2 & + & + & - & + & + & - & $(+)$ \\
\hline Pat. 3 & + & + & - & + & $(+)$ & - & - \\
\hline Pat. 4 & ++ & ++ & - & ++ & ++ & - & + \\
\hline Alle & $\begin{array}{c}10 / 16 \\
62,5 \%\end{array}$ & $\begin{array}{l}9 / 16 \\
56 \%\end{array}$ & 0 & $\begin{array}{l}8 / 16 \\
50 \%\end{array}$ & $\begin{array}{l}7 / 16 \\
44 \%\end{array}$ & 0 & $\begin{array}{l}4 / 16 \\
25 \%\end{array}$ \\
\hline
\end{tabular}

Tabelle 17: VV1-Subtyp, Semiquantitative Auswertung der 14-3-3-Isoform-Western-Blots; Pat. = Patient

\section{MM2-Subtyp}

Bei allen vier MM2-Patienten zeigt die Abbildung 11 Banden unterschiedlicher Intensität für die 14-3-3-Isoformen $\beta, \gamma, \varepsilon$ und $\zeta$. Bei der Isoform $\tau$ sind bei zwei der vier Patienten (Patienten 1 und 4) Banden bei 30 kDa zu erkennen. Die anderen beiden Isoformen $\eta$ und $\sigma$ sind auch bei diesem Subtyp nicht nachweisbar. Wiederum sind bei allen vier MM2-Patienten Doppelbanden bei der $\gamma$-Isoform vorhanden und auch das Muster der unterschiedlichen Bandenintensität, mit stärkeren Banden der Patienten 1 und 4, bei allen vorhandenen Isoformen ist bei diesen Western Blots erkennbar. Tabelle 18 zeigt auch für den MM2-Subtyp die Auswertung der Bandenintensität für die vier Patienten. 


\begin{tabular}{|c|c|c|c|c|c|c|c|}
\hline MM2 & $\begin{array}{c}14-3-3 \\
\beta\end{array}$ & $\begin{array}{c}14-3-3 \\
\gamma\end{array}$ & $\begin{array}{c}\text { 14-3-3 } \\
\eta\end{array}$ & $\begin{array}{c}14-3-3 \\
\varepsilon\end{array}$ & $\begin{array}{c}14-3-3 \\
\zeta\end{array}$ & $\begin{array}{c}14-3-3 \\
\sigma\end{array}$ & $\begin{array}{c}14-3-3 \\
\tau\end{array}$ \\
\hline Pat. 1 & +++ & ++ & - & ++ & ++ & - & $(+)$ \\
\hline Pat. 2 & $(+)$ & + & - & $(+)$ & $(+)$ & - & - \\
\hline Pat. 3 & $(+)$ & + & - & + & $(+)$ & - & - \\
\hline Pat. 4 & ++ & ++ & - & + & + & - & + \\
\hline Alle & $\begin{array}{l}9 / 16 \\
56 \%\end{array}$ & $\begin{array}{r}10 / 16 \\
62,5 \%\end{array}$ & 0 & $\begin{array}{l}8 / 16 \\
50 \%\end{array}$ & $\begin{array}{l}7 / 16 \\
44 \%\end{array}$ & 0 & $\begin{array}{l}3 / 16 \\
19 \%\end{array}$ \\
\hline
\end{tabular}

Tabelle 18: MM2-Subtyp, Semiquantitative Auswertung der 14-3-3-Isoform-Western-Blots; Pat. = Patient

\subsubsection{Kontrollpatienten}

Die Western Blots der acht Patienten mit ischämischem bzw. entzündlichem Geschehen zeigen innerhalb dieser beiden Gruppen keine Unterschiede hinsichtlich des Isoformmusters. Die Abbildung 12 zeigt überraschenderweise kaum Banden für die Isoformen $\beta$ und $\varepsilon$, im Gegensatz zu den CJK-Patienten, jedoch vergleichbar deutliche Banden für die Isoformen 14-3-3- $\gamma$ und $-\zeta$. Weiterhin zeigten die Western Blots der Kontrollpatienten für die Isoformen $\eta, \sigma$ und $\tau$ keine Banden.

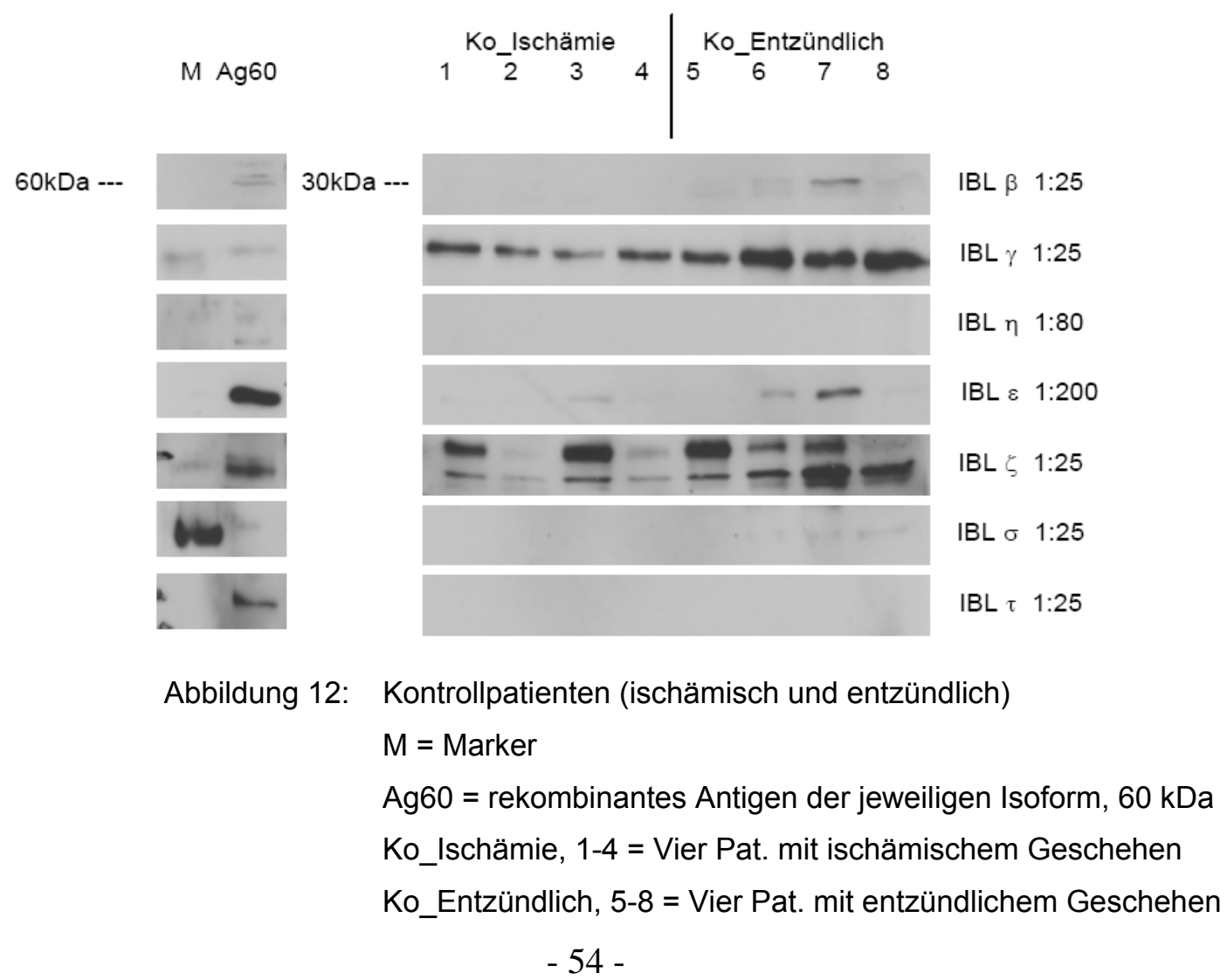


Tabelle 19 veranschaulicht die semiquantitative Auswertung der oben abgebildeten Western Blots für die Liquores von Kontrollpatienten mit von der Creutzfeldt-JakobKrankheit differierenden Diagnosen.

\begin{tabular}{|c|c|c|c|c|c|c|c|}
\hline $\begin{array}{c}\text { Kontroll- } \\
\text { Pat. }\end{array}$ & $\begin{array}{c}14-3-3 \\
\beta\end{array}$ & $\begin{array}{c}14-3-3 \\
\gamma\end{array}$ & $\begin{array}{c}14-3-3 \\
\eta\end{array}$ & $\begin{array}{c}14-3-3 \\
\varepsilon\end{array}$ & $\begin{array}{c}14-3-3 \\
\zeta\end{array}$ & $\begin{array}{c}14-3-3 \\
\sigma\end{array}$ & $\begin{array}{c}14-3-3 \\
\tau\end{array}$ \\
\hline Pat. 1 & - & ++ & - & - & ++ & - & - \\
\hline Pat. 2 & - & ++ & - & - & + & - & - \\
\hline Pat. 3 & - & ++ & - & $(+)$ & +++ & - & - \\
\hline Pat. 4 & - & ++ & - & - & + & - & - \\
\hline Pat. 5 & - & ++ & - & - & +++ & - & - \\
\hline Pat. 6 & $(+)$ & +++ & - & $(+)$ & ++ & - & - \\
\hline Pat. 7 & + & +++ & - & + & +++ & - & - \\
\hline Pat. 8 & - & +++ & - & - & ++ & - & - \\
\hline Alle & $\begin{array}{c}3 / 32 \\
9 \%\end{array}$ & $\begin{array}{c}27 / 32 \\
84 \%\end{array}$ & 0 & $\begin{array}{c}4 / 32 \\
12,5 \%\end{array}$ & $\begin{array}{c}25 / 32 \\
78 \%\end{array}$ & 0 & 0 \\
\hline
\end{tabular}

Tabelle 19: Kontrollpatienten, Semiquantitative Auswertung der 14-3-3-Isoform-Western-Blots; Pat. = Patient

\subsubsection{Zusammenfassung des qualitativen Nachweises der 14-3-3-Isoformen für die einzelnen SCJK-Subtypen}

Im folgenden Ergebnisteil werden die Resultate der bisher vorgestellten Auswertung der Western Blots zusammenfassend dargestellt, mit dem Ziel, eine Aussage über den qualitativen Nachweis der einzelnen 14-3-3-Isoformen für den jeweiligen Subtyp, unabhängig von einzelnen Patienten und deren Bandenstärken, zu treffen. Um dies zu ermöglichen wurde folgendes Vorgehen gewählt:

Alle Patienten eines Subtyps (d.h. 7 bzw. 4 Patienten) wurden rein qualitativ auf das Vorhandensein von Banden geprüft und als positiv oder negativ für die Isoformen befunden. Als positiv wurden alle Bandenintensitäten von schwach positiv bis sehr stark positiv gezählt, als negativ diejenigen Patienten, bei denen keine Bande im Western Blot sichtbar war. Im Anschluss wurde der gesamte Subtyp für eine 14-3-3- 
Isoform als positiv [+] bewertet, wenn mindestens $70 \%$, d.h. 5 der 7 Patienten, bzw. 3/4 bei VV1 und MM2, Banden im Western Blot für diese Isoform gezeigt haben. Als negativ [-] für eine Isoform wurde der Subtyp demzufolge bewertet, wenn mindestens $70 \%$ der Patienten, d.h. 5/7, bzw. 3/4 bei V1 und MM2, keine Banden im WB für diese Isoform zeigten. Ein Subtyp wurde als gemischt positiv/negativ [+/-] gewertet, wenn keines der oben genannten Kriterien zutraf und keine eindeutige Aussage für den gesamten Subtyp getroffen werden konnte. Die Kontrollpatienten wurden analog bewertet.

Diesem Vorgehen gemäß ergab sich folgende Tabelle 20 für den qualitativen Nachweis der 14-3-3-Isoformen bei den verschiedenen sCJK-Subtypen:

\begin{tabular}{|c|c|c|c|c|c|c|c|}
\hline & MM1 & MM2 & MV1 & MV2 & VV1 & VV2 & Kontr. \\
\hline $14-3-3 \beta$ & + & + & + & + & + & + & - \\
$14-3-3 \gamma$ & + & + & + & + & + & + & + \\
$14-3-3 \eta$ & - & - & - & - & - & - & - \\
$14-3-3 \varepsilon$ & + & + & + & + & + & + & $+/-$ \\
$14-3-3 \zeta$ & + & + & + & + & + & + & + \\
$14-3-3 \sigma$ & - & - & - & - & - & - & - \\
$14-3-3 \tau$ & - & $+/-$ & - & - & + & + & - \\
\hline
\end{tabular}

Tabelle 20: Qualitativer Nachweis der 14-3-3-Isoformen bei den verschiedenen SCJK-Subtypen und Kontrollen

Der Tabelle 20 ist zu entnehmen, dass nach Anwendung der beschriebenen Auswertung alle sCJK-Subtypen positiv für vier 14-3-3-Isoformen sind. Dazu gehören die Isoformen $\beta, \gamma, \varepsilon$ und $\zeta$.Zwei 14-3-3-Isoformen konnten bei keinem der sechs sCJK-Subtypen nachgewiesen werden. Dabei handelt es sich um die Isoformen $\eta$ und $\sigma$. Die letzte der sieben Isoformen $(\tau)$ verhält sich heterogen bezüglich der Subtypen und ist positiv für die VV1- und VV2-Subtypen, negativ für die MM1-, MV1und MV2-Subtypen und gemischt positiv/negativ für den MM2-Subtyp. Bei dem Isoformmuster der Kontrollpatienten ist hervorzuheben, dass sie für die Isoform $\beta$ negativ sind, im Gegensatz zu allen sCJK-Subtypen. 


\subsection{Korrelation der 14-3-3-Isoformen mit den Bandenstärken im Western Blot}

Im Folgenden wird die Korrelation der 14-3-3-Isoformen mit der Bandenintensität im Western Blot gezeigt. Hierbei wurden die Bandenintensitäten zum einen unabhängig vom Subtyp untersucht, zum anderen abhängig vom sCJK-Subtyp. Die Bandenintensitäten gehen aus den vorher dargestellten Abbildungen und Tabellen hervor. Abbildung 13 zeigt zunächst den Zusammenhang zwischen den einzelnen 14-3-3-Isoformen und den unterschiedlichen Bandenintensitäten unabhängig vom sCJK-Subtyp.

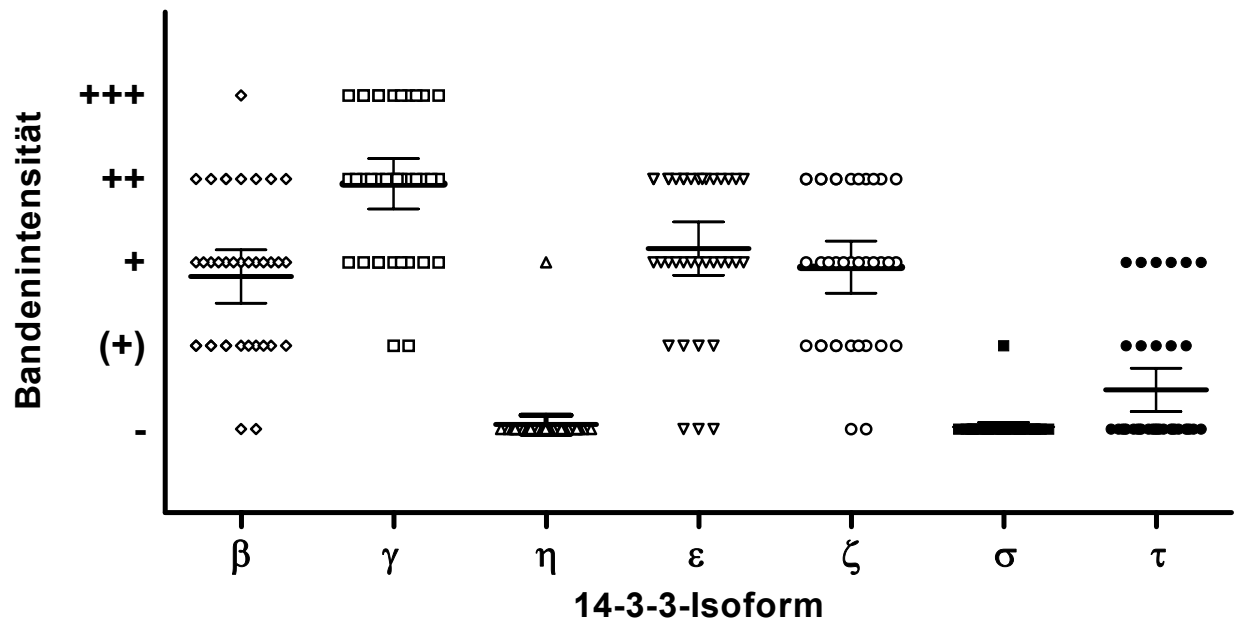

Abbildung 13: Korrelation der Bandenstärken im WB mit den 14-3-3-Isoformen für alle sCJK-Patienten

- $=$ Mittelwert

$=95 \%$-Konfidenzintervall

Aus der Abbildung 13 geht zunächst einmal hervor, dass bei allen 14-3-3-Isoformen ein schmales $95 \%$-Konfidenzintervall zu finden ist, was zum einen für eine genügend große Stichprobe spricht und zum anderen bedeutet, dass mit einer Wahrscheinlichkeit von 95\% der Mittelwert der Bandenintensitäten für eine 14-3-3Isoform in dem ermittelten Konfidenzintervall liegt.

Die mittlere Bandenintensität ist für die Isoformen $\beta, \varepsilon$ und $\zeta$ ähnlich und liegt bei der aufgestellten Intensitätsskala bei ca. einfach positiv [+]. Die 14-3-3- $\gamma$-Isoform hingegen zeigt eine mittlere Bandenstärke von stark positiv [++], die Isoformen $\eta$ und 
$\sigma$ finden sich alle, mit jeweils einer Ausnahme, auf Höhe der negativen Bandenstärke, gleichbedeutend mit fehlenden Banden im WB für diese Isoformen unabhängig vom Subtyp. Für die $\tau$-Isoform liegt die gemittelte Bandenstärke zwischen negativ [-] und schwach positiv [(+)], was auf die hohe Zahl von Patienten mit fehlendem Nachweis von 14-3-3- $\tau$ zurückzuführen ist. Betrachtet man nur die Fälle von nachgewiesenen Banden für $\tau$, so findet sich die mittlere Bandenintensität zwischen schwach positiv [(+)] und positiv [+]. Zusammenfassend kann man sagen, dass bei der Gesamtheit der sCJK-Patienten die 14-3-3-Isoform $\gamma$ gemittelt die größten Bandenstärken zeigt, gefolgt von den Isoformen $\beta, \varepsilon$ und $\zeta$ mit ähnlichen Bandenintensitäten und schließlich der $\tau$-Isoform. 14-3-3- $\eta$ und $-\sigma$ konnten jeweils, wie bereits beschrieben, bei über $97 \%$ der Patienten nicht nachgewiesen werden.

Im Folgenden sind die Korrelationen der Bandenintensitäten mit den einzelnen Isoformen in Abhängigkeit von den sCJK-Subtypen dargestellt. Ziel ist es, die Unterschiede in der Stärke der Banden abhängig von den einzelnen Subtypen für die jeweiligen 14-3-3-Isoformen zu ermitteln.

Abbildung 14 zeigt die Scatter-Plot-Graphen mit Mittelwert und 95\%Konfidenzintervall für jede einzelne 14-3-3-Isoform. Die Abszisse zeigt die sechs sCJK-Subtypen, auf der Ordinate sind wiederum die Bandenstärken nach bekanntem Algorithmus aufgetragen. 

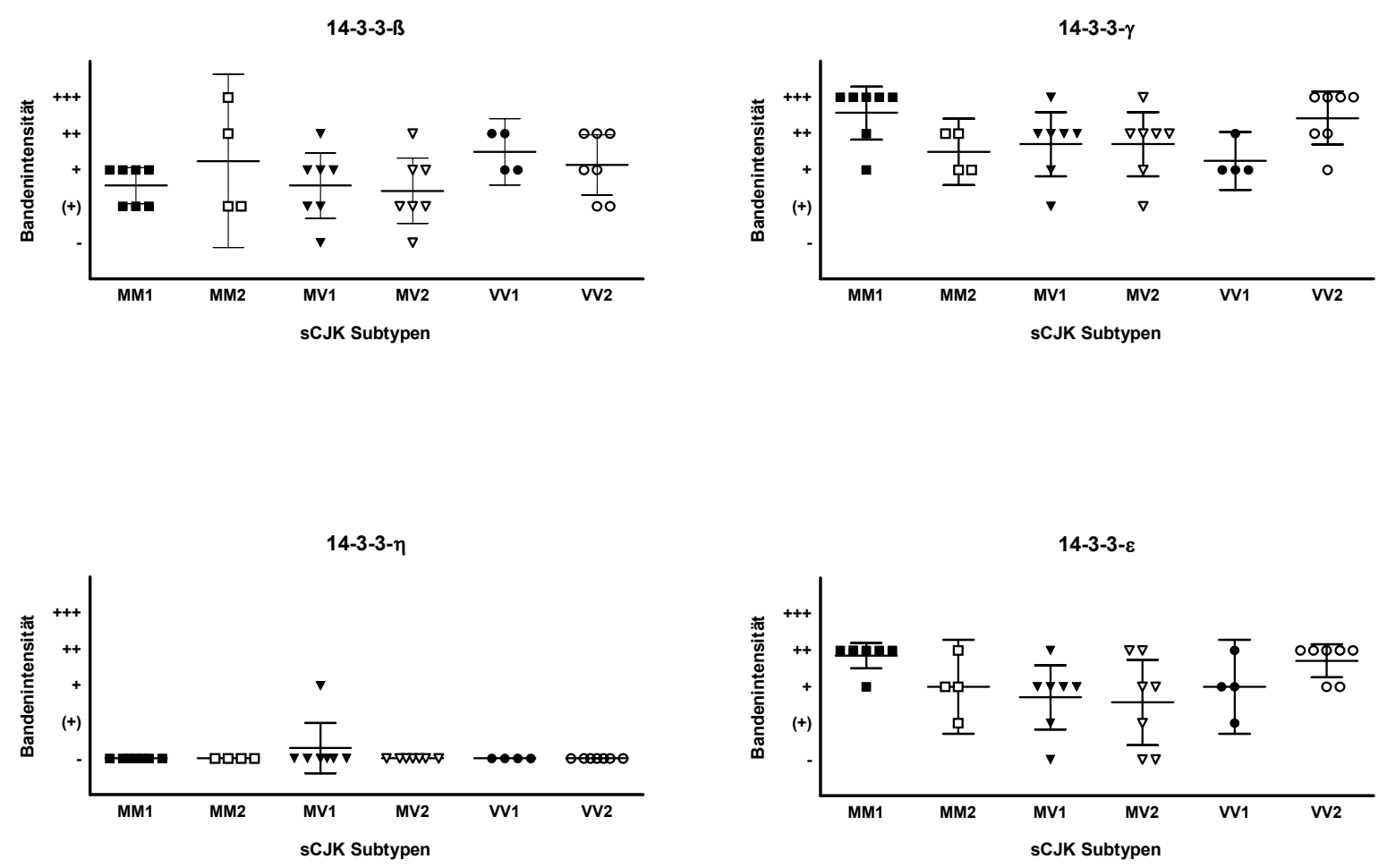

14-3-3- $\zeta$
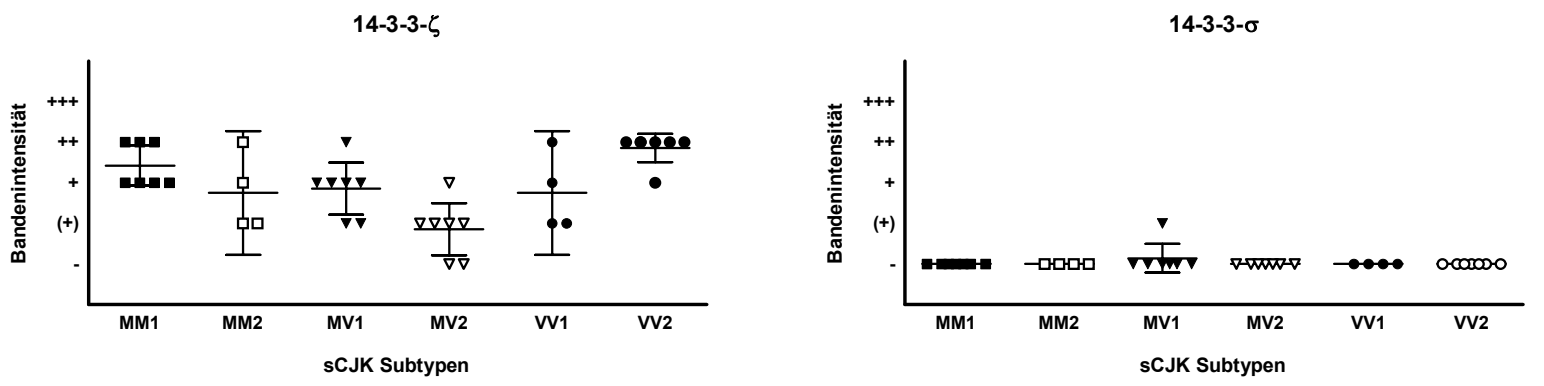

14-3-3- $\tau$

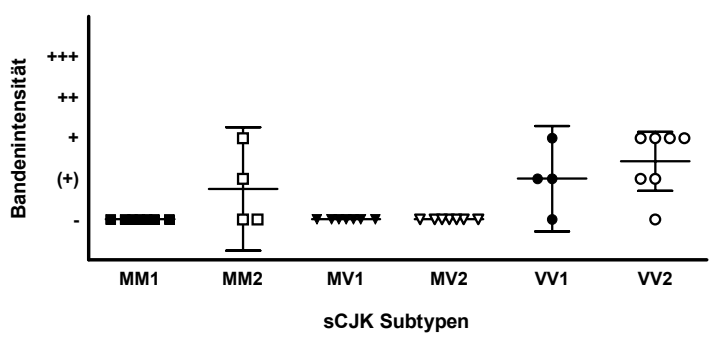

Abbildung 14: Korrelation der Bandenintensität mit den Subtypen bei den einzelnen 14-3-3-Isoformen $-=$ Mittelwert,$I=95 \%$-Konfidenzintervall 
14-3-3- $\beta$ :

Aus der Abbildung und nachfolgender Tabelle 21 ist zu ersehen, dass im Mittel v. a. der VV1-Subtyp, aber auch die VV2- und MM2-Subtypen stärkere Bandenintensitäten aufzeigen, als die anderen drei Subtypen (MM1, MV1 und MV2). Bei dem VV1-Subtypen weist diese Isoform sogar die stärkste Bandenintensität $(62,5 \%)$ verglichen mit den anderen Isoformen auf. Bei dem MM2-Subtyp weist die $\beta$ Isoform die zweitstärksten Banden (56\%), nach der $\gamma$-Isoform $(62,5 \%)$, für diesen Subtyp auf. Jedoch ist anzumerken, dass auf Grund der großen Streuung der wenigen Patientenproben auch das 95\%-Konfidenzintervall sehr groß ist und eine sichere Aussage bezüglich des Mittelwertes für den MM2-Subtyp bei dieser Isoform erschwert ist.

\section{4-3-3- $\gamma:$}

Wie aus der vorherigen Abbildung 13 hervorgeht sind die Bandenstärken bei dieser 14-3-3-Isoform mit 74\% allgemein höher als bei den anderen Isoformen, was auf nahezu alle Subtypen, außer dem VV1-Subtyp zutrifft. Die MM1- und VV2-Subtypen weisen besonders hohe mittlere Bandenstärken auf (89\% bzw. 86\%).

\section{4-3-3- $\eta$}

Da die Isoform $\eta$ bei nur einem Patientenliquor von allen sCJK-Patienten eine positive Bande im WB gezeigt hat, liegen bei dieser Darstellung der Bandenintensitäten nach Subtypen aufgeteilt nahezu alle Werte bei negativer [-] Bandenstärke.

14-3-3- $\varepsilon$ :

Diese Isoform ist, über alle Subtypen gesehen, diejenige mit der zweitstärksten Bandenintensität (55,5\%). Insbesondere wiederum die Subtypen MM1 (71\%) und VV2 (68\%) weisen hohe Mittelwerte der Bandenstärken für die $\varepsilon$-Isoform auf. In vier der sechs Subtypen (MM1, MM2, MV2, VV1) weist die $\varepsilon$-Isoform stärkere Banden im Western Blot auf als 14-3-3- $\zeta$.

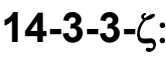

Nach der Isoform $\varepsilon$ ist die 14-3-3- $\zeta$ die Isoform mit den drittstärksten Banden gemittelt über alle Subtypen (50\%). Sie hat besonders hohe Bandenintensitäten bei den Subtypen MM1 und VV2 (61 bzw. 71\%), wobei sie relativ gemessen an den 
anderen 14-3-3-Isoformen auch bei dem MV1-Subtyp starke Banden zeigt (46\%). Bei den MV1- und VV2-Subtypen steht diese Isoform hinsichtlich der Bandenstärke nach der Isoform- $\gamma$ an zweiter Stelle.

\section{4-3-3-б:}

Ebenso wie bei 14-3-3- $\eta$ gilt für die $\sigma$-Isoform, dass nur ein Patientenliquor insgesamt eine schwach positive Bande für diese Isoform zeigte, was wiederum für alle Subtypen zum dargestellten Graphen führte.

\section{4-3-3- $\tau$ :}

Diese Isoform wurde nur bei den drei Subtypen MM2, VV1 und VV2 überhaupt nachgewiesen. Von diesen dreien hat der MM2-Subtyp gemittelt die schwächsten Banden (19\%), der VV2-Subtyp die stärksten (36\%), wobei für alle gilt, dass die Intensitäten der Banden am schwächsten sind verglichen mit allen anderen Isoformen.

Nachfolgende Tabelle 21 soll mit Hilfe des in 2.4 beschriebenen Punktescores (Punktzahl von 0 bis 4) die zuvor graphisch dargestellten Bandenintensitäten für jeden Subtyp und jede Isoform in prozentualer Art wiedergeben und auch die Kontrollpatienten berücksichtigen. Bei jeweils sieben Proben von MM1, MV1, MV2 und VV2, konnte eine maximale Punktzahl von 28 für Subtyp und korrespondierende Isoform erzielt werden, bei MM2 und VV1 mit jeweils vier Proben entsprechend 16 Punkte maximal. Um Häufigkeit und Intensität der Banden für jeden molekularen Subtyp zu vergleichen, wurde der Prozentsatz der maximal erreichbaren Punkte berechnet. Zusätzlich wurde die semiquantitative Auswertung mittels Punktzahl verwendet, um jede 14-3-3-Isoform, jeden Subtyp, jeden Genotyp und beide PrPSc Typen jeweils zusammenzufassen. 


\begin{tabular}{|c|c|c|c|c|c|c|c|c|}
\hline & MM1 & MM2 & MV1 & MV2 & VV1 & VV2 & Kontr. & $\begin{array}{c}\text { sCJK } \\
\text { gesamt }\end{array}$ \\
\hline$\beta$-beta & $\begin{array}{c}11 / 28 \\
39 \%\end{array}$ & $\begin{array}{l}9 / 16 \\
56 \%\end{array}$ & $\begin{array}{c}11 / 28 \\
39 \%\end{array}$ & $\begin{array}{c}12 / 28 \\
43 \%\end{array}$ & $\begin{array}{l}10 / 16 \\
62.5 \%\end{array}$ & $\begin{array}{c}15 / 28 \\
54 \%\end{array}$ & $\begin{array}{c}3 / 32 \\
9 \%\end{array}$ & $\begin{array}{c}68 / 144 \\
47 \%\end{array}$ \\
\hline$\gamma$-gamma & $\begin{array}{c}25 / 28 \\
89 \%\end{array}$ & $\begin{array}{l}10 / 16 \\
62.5 \%\end{array}$ & $\begin{array}{c}19 / 28 \\
68 \%\end{array}$ & $\begin{array}{c}19 / 28 \\
68 \%\end{array}$ & $\begin{array}{l}9 / 16 \\
56 \%\end{array}$ & $\begin{array}{c}24 / 28 \\
86 \%\end{array}$ & $\begin{array}{l}27 / 32 \\
84 \%\end{array}$ & $\begin{array}{c}106 / 144 \\
74 \%\end{array}$ \\
\hline$\eta$-eta & 0 & 0 & $\begin{array}{c}2 / 28 \\
7 \%\end{array}$ & 0 & 0 & 0 & 0 & $\begin{array}{c}2 / 144 \\
1 \%\end{array}$ \\
\hline$\varepsilon$-epsilon & $\begin{array}{c}20 / 28 \\
71 \%\end{array}$ & $\begin{array}{l}8 / 16 \\
50 \%\end{array}$ & $\begin{array}{c}12 / 28 \\
43 \%\end{array}$ & $\begin{array}{c}13 / 28 \\
46 \%\end{array}$ & $\begin{array}{l}8 / 16 \\
50 \%\end{array}$ & $\begin{array}{c}19 / 28 \\
68 \%\end{array}$ & $\begin{array}{c}4 / 32 \\
12.5 \%\end{array}$ & $\begin{array}{l}80 / 144 \\
55.5 \%\end{array}$ \\
\hline$\zeta$-zeta & $\begin{array}{c}17 / 28 \\
61 \%\end{array}$ & $\begin{array}{l}7 / 16 \\
44 \%\end{array}$ & $\begin{array}{c}13 / 28 \\
46 \%\end{array}$ & $\begin{array}{l}8 / 28 \\
29 \%\end{array}$ & $\begin{array}{l}7 / 16 \\
44 \%\end{array}$ & $\begin{array}{l}20 / 28 \\
71 \%\end{array}$ & $\begin{array}{c}25 / 32 \\
78 \%\end{array}$ & $\begin{array}{c}72 / 144 \\
50 \%\end{array}$ \\
\hline$\sigma$-sigma & 0 & 0 & $\begin{array}{l}1 / 28 \\
4 \%\end{array}$ & 0 & 0 & 0 & 0 & $\begin{array}{c}1 / 144 \\
1 \%\end{array}$ \\
\hline$\tau$-tau & 0 & $\begin{array}{l}3 / 16 \\
19 \%\end{array}$ & 0 & $\begin{array}{l}2 / 28 \\
7 \%\end{array}$ & $\begin{array}{l}4 / 16 \\
25 \%\end{array}$ & $\begin{array}{c}10 / 28 \\
36 \%\end{array}$ & 0 & $\begin{array}{c}19 / 144 \\
13 \%\end{array}$ \\
\hline Alle & $\begin{array}{c}73 / 196 \\
37 \%\end{array}$ & $\begin{array}{c}37 / 112 \\
33 \%\end{array}$ & $\begin{array}{c}58 / 196 \\
30 \%\end{array}$ & $\begin{array}{c}54 / 196 \\
28 \%\end{array}$ & $\begin{array}{c}38 / 112 \\
34 \%\end{array}$ & $\begin{array}{c}88 / 196 \\
45 \%\end{array}$ & $\begin{array}{c}59 / 224 \\
26 \%\end{array}$ & \\
\hline Genotyp & \multicolumn{2}{|c|}{$\begin{array}{c}110 / 308 \\
36 \%\end{array}$} & \multicolumn{2}{|c|}{$\begin{array}{c}104 / 392 \\
26.5 \%\end{array}$} & \multicolumn{2}{|c|}{$\begin{array}{c}124 / 308 \\
40 \%\end{array}$} & & \\
\hline & \multicolumn{3}{|c|}{$\begin{array}{c}\text { PrP Typ } 1 \\
170 / 504 \\
34 \%\end{array}$} & \multicolumn{3}{|c|}{$\begin{array}{c}\text { PrP Typ } 2 \\
168 / 504 \\
33 \%\end{array}$} & & \\
\hline
\end{tabular}

Tabelle 21: Semiquantitative prozentuale Darstellung der Bandenintensitäten im WB

Aus der Tabelle geht noch einmal deutlich hervor, dass $14-3-3-\gamma$ mit $74 \%$ die Isoform mit der stärksten Bandenintensität ist, gefolgt von den Isoformen $\varepsilon, \zeta$ und $\beta$. Außerdem zeigt der sCJK-Subtyp VV2 mit 45\% die stärksten Banden im Vergleich mit den anderen Subtypen. Auffällig ist die abweichende Stärke der Bandenintensitäten bei den Kontrollliquores insbesondere für die Isoformen $\beta(9 \%)$ und $\varepsilon(12,5 \%)$, die in diesem Patientenkollektiv vergleichsweise schwach ausfallen. Zusammenfassend ist im Folgenden für jeden Subtyp in abnehmender Reihenfolge die mittlere Bandenstärke jeder 14-3-3-Isoform dargestellt.

MM1: $\quad \gamma(89 \%)>\varepsilon(71 \%)>\zeta(61 \%)>\beta(39 \%)$

MM2: $\quad \gamma(62.5 \%)>\beta(56 \%)>\varepsilon(50 \%)>\zeta(44 \%)>\tau(19 \%)$

MV1: $\quad \gamma(68 \%)>\zeta(46 \%)>\varepsilon(43 \%)>\beta(39 \%)>\eta(7 \%)>\sigma(4 \%)$

MV2: $\quad \gamma(68 \%)>\varepsilon(46 \%)>\beta(43 \%)>\zeta(29 \%)>\tau(7 \%)$

VV1: $\quad \beta(62.5 \%)>\gamma(56 \%)>\varepsilon(50 \%)>\zeta(44 \%)>\tau(25 \%)$

VV2: $\quad \gamma(86 \%)>\zeta(71 \%)>\varepsilon(68 \%)>\beta(54 \%)>\tau(36 \%)$

Kontr: $\quad \gamma(84 \%)>\zeta(78 \%)>\varepsilon(12,5 \%)>\beta(9 \%)$ 


\subsection{Nachweis von Tau-Protein im Liquor von sCJK-Patienten}

Wie bereits im Methodenteil beschrieben, wurde von allen Patienten neben dem 143-3-Protein auch das Tau-Protein im Liquor als Marker bei neurodegenerativen Erkrankungen bestimmt.

Die jeweiligen Werte des Tau-Proteins im Liquor sind in folgender Tabelle 22 nach Subtypen unterteilt dargestellt:

\begin{tabular}{|c|cccccc|}
\hline $\begin{array}{c}\text { Tau- } \\
\text { Protein }\end{array}$ & MM1 & MM2 & MV1 & MV2 & VV1 & VV2 \\
\hline Pat. 1 & 1667 & 9504 & 30467 & 13153 & 1835 & 9016 \\
Pat. 2 & 7601 & 820 & 17007 & 876 & 4035 & 10607 \\
Pat. 3 & 13898 & 1970 & 4344 & 3678 & 2960 & 10635 \\
Pat. 4 & 10431 & 5404 & $<75$ & 3750 & 11500 & 21528 \\
Pat. 5 & 1517 & - & 6612 & 3963 & - & 1560 \\
\hline Pat. 6 & 19286 & - & 26880 & 1042 & - & 1783 \\
Pat. 7 & 9453 & - & 3789 & 3570 & - & 8809 \\
\hline MW & 9122 & 4425 & 12739 & 4290 & 5083 & 9188 \\
\hline Median & 9453 & 3687 & 6612 & 3678 & 3498 & 9016 \\
\hline SW & 17769 & 8684 & 30392 & 12277 & 9665 & 19968 \\
\hline SD & 6373 & 3906 & 12117 & 4124 & 4372 & 7341 \\
\hline
\end{tabular}

Tabelle 22: sCJK-Subtypen und Tau-Proteinbestimmung (in $\mathrm{pg} / \mathrm{ml}$ ) im Liquor Pat. $=$ Patient, MW $=$ Mittelwert, $S W=$ Spannweite,$S D=$ Standardabweichung

Die Abbildung 15 zeigt die zugehörige graphische Darstellung der Tau-Proteinwerte, wobei zu sehen ist, dass die 95\%-Konfidenzintervalle groß sind, was zum einen durch die geringe Probenanzahl sowie zum anderen durch die weite Streuung der Werte zu erklären ist. 


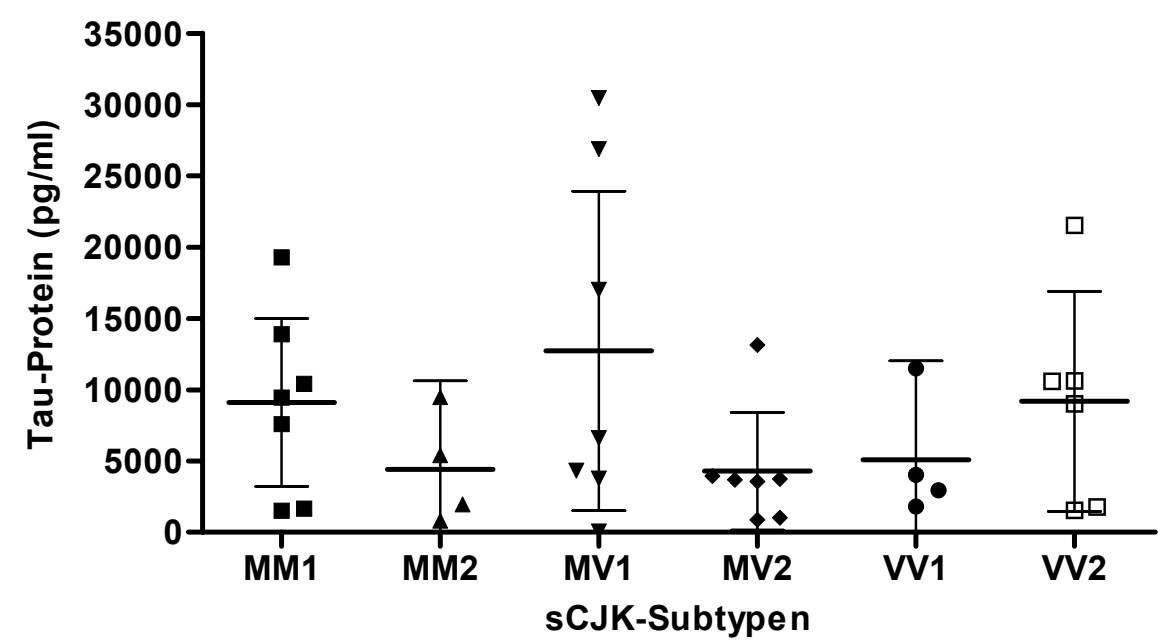

Abbildung 15: Tau-Proteinbestimmung im Liquor der sCJK-Subtypen

\subsection{Ergebnis der Korrelation der Bandenintensitäten für 14-3-3- Protein mit der Höhe des Tau-Proteins im Liquor cerebrospinalis}

Nach dem Nachweis von 14-3-3-Proteinisoformen und dem Tau-Protein im Liquor der SCJK-Patienten erfolgte die Korrelation dieser beiden Parameter für jede 14-3-3Isoform unabhängig von den Subtypen, um ein genügend großes Kollektiv zu erreichen. Ziel war es zu untersuchen, ob mit höherem Tau-Protein im Liquor auch höhere mittlere Bandenintensitäten der Isoformen bzw. einzelner Isoformen einhergehen.

Dafür wurden nicht-lineare Regressionskurven für jede einzelne 14-3-3-Isoform erstellt, deren Abszisse die Bandenintensitäten zeigt und die Ordinate die TauProteinkonzentrationen abbildet. In einer Graphik sind alle sCJK-Subtypen zusammengefasst und die jeweiligen im Western Blot ermittelten Bandenstärken nach bekanntem Schema dargestellt. Abbildung 16 zeigt die einzelnen Graphen nach 14-3-3-Isoformen. 
14-3-3- $\beta$

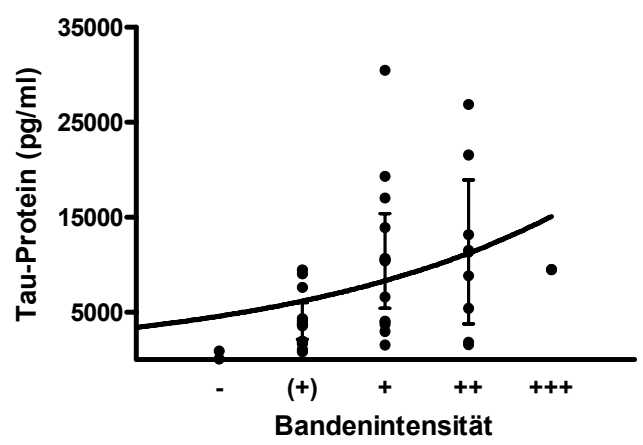

14-3-3-

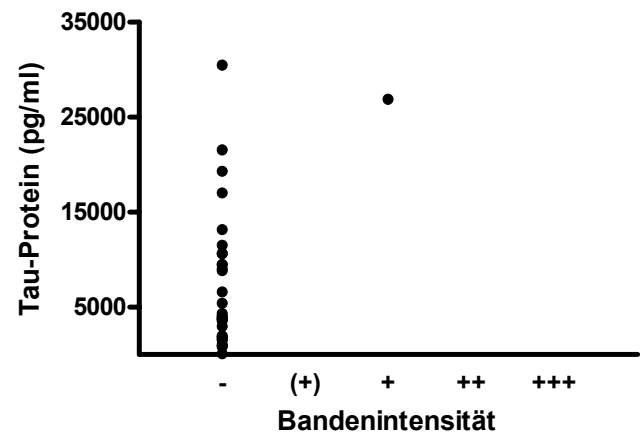

$14-3-3-\zeta$

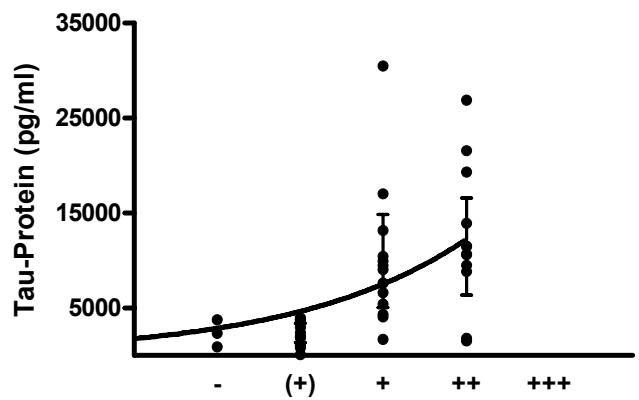

Bandenintensität $14-3-3-\gamma$

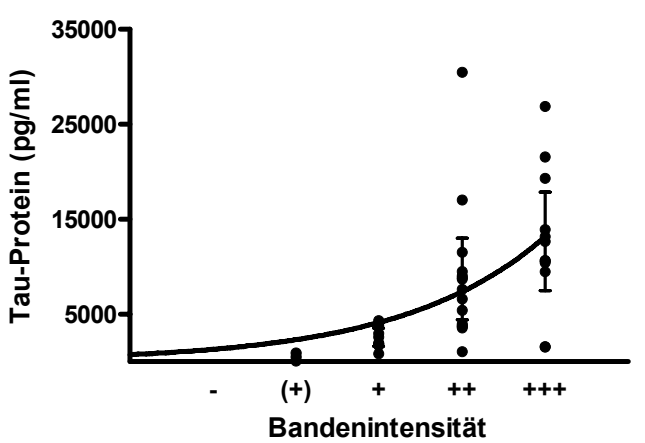

$14-3-3-\varepsilon$

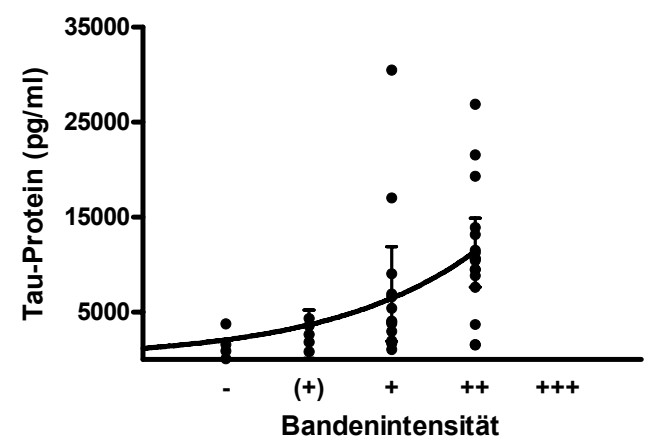

$14-3-3-\sigma$

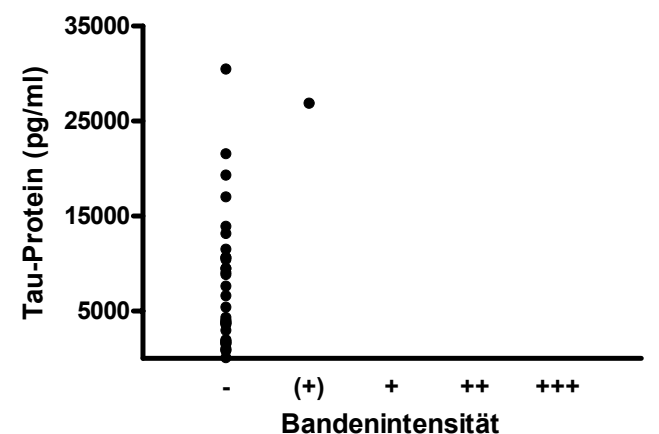

$14-3-3-\tau$

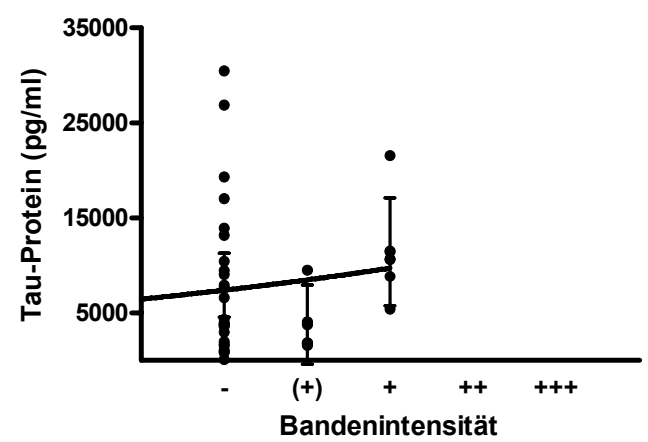

Abbildung 16: Regressionskurven für die Korrelation von Tau-Protein mit den Bandenstärken für jede 14-3-3-Isoform 
Die Abbildung lässt erkennen, dass für die Isoformen $\eta$ und $\sigma$ keine Regressionskurven zustande kommen, da diese Isoformen, wie bereits erwähnt, nur jeweils einmal überhaupt mittels Western Blot nachgewiesen werden konnten. Trotzdem kann man den Graphen die Information entnehmen, dass für 14-3-3- $\eta$ und 14-3-3- $\sigma$, unabhängig von der Höhe der Tau-Proteinwerte, keine Banden im WB zu sehen sind.

Für die Isoformen $\beta, \gamma, \varepsilon$ und $\zeta$ zeigen die Graphen, dass hier ein exponentieller Zusammenhang zwischen der Bandenintensität für die jeweilige 14-3-3-Isoform und der Höhe des Tau-Proteins besteht. Die 95\%-Konfidenzintervalle sind relativ schmal, was für eine hohe Wahrscheinlichkeit für die Lage des Mittelwertes in diesem Bereich spricht. Für die oben genannten Isoformen trifft daher im Mittel die Aussage zu: je höher der Tau-Proteinwert, desto stärker die Bandenintensität für diese Isoformen im Western Blot.

Bei der letzten Isoform $\tau$ ist diese Aussage bezüglich der Proportionalität nur partiell zutreffend. Bei dieser Isoform weisen viele Patienten gar keine Bande im WB auf, wobei die Tau-Proteinwerte bei diesen Patienten durchaus hoch sind, was zu einem relativ hohen Mittelwert führt. Die restlichen Patienten, die positiv, sei es schwach oder einfach, für 14-3-3- $\tau$ sind, zeigen einen Trend zur Abhängigkeit mit der Höhe des Tau-Proteins. Da der Mittelwert für die schwach positiven [(+)] Patienten unter dem der negativen [-] liegt, ist es schwierig, eine wahrhaftige Regressionskurve zu ermitteln. 


\section{Diskussion}

Auf Grund der ersten Fälle von varianter Creutzfeldt-Jakob-Krankheit beim Menschen, die in kausalen Zusammenhang mit dem BSE-Rindfleischskandal in England gebracht werden konnten, hat in den letzten Jahren das Interesse an der Prionforschung neuen Aufschwung erhalten. Pathophysiologie der Prionen, aber auch eine sichere prämortale Diagnose und Therapie dieser letal endenden Krankheitsgruppe ist Thema vieler Forschungsarbeiten.

Ziel dieser Arbeit war es, in dem Liquor cerebrospinalis von insgesamt 36 sCJKPatienten Isoformen des 14-3-3-Proteins nachzuweisen, darüber hinaus Subtypenspezifische Isoformmuster zu erkennen und von Kontrollpatienten abzugrenzen, um die Diagnose einer sCJK prämortal zu unterstützen, den Subtyp frühzeitig zu determinieren und somit möglicherweise zum Beispiel die subtypen-abhängige durchschnittliche Krankheitsdauer vorauszusagen (s. Tab. 2, z.B. MM1/MV1 4,4/4,6 Monate, MM2/VV1 14/17,4 Monate).

\subsection{Das Patientenkollektiv dieser Studie}

Die 36 Patienten des CJK-Studienkollektives weisen ein durchschnittliches Alter bei Krankheitsbeginn von 61 Jahren auf, wobei der VV1-Subtyp, auch als Early-OnsetTyp bezeichnet, mit einem mittleren Alter von 53 Jahren beim ersten Symptom deutlich abweicht. Dies deckt sich mit den Angaben der Literatur (Heinemann et al. 2007, Meissner et al. 2005), ebenso wie die mittleren Krankheitsdauern der einzelnen Subtypen, was die Schlussfolgerung zulässt, dass es sich bei dem Liquor dieser 36 Patienten um ein repräsentatives Studienkollektiv handelt. Abweichend davon ist das durchschnittliche Alter des Kontrollkollektivs mit 74 Jahren deutlich höher, was durch den allgemein späteren Erkrankungszeitpunkt der Diagnosen zu erklären und daher für die Studie durchaus repräsentativ ist (EROS 2009).

Hinsichtlich der Wahl des Zeitpunktes der Liquorpunktion im letzten Drittel des Krankheitsstadiums spielten hauptsächlich zwei Aspekte eine Rolle. Erstens konnte durch die Einteilung der Krankheitsdauer in drei Stadien die Variable der 
unterschiedlichen Krankheitsdauern der Subtypen eliminiert werden. Somit wurde vermieden, dass die Liquorpunktion, beispielsweise im vierten Krankheitsmonat durchgeführt, Patienten vom MM1-Subtyp im Endstadium ihrer Krankheit, MV2Patienten jedoch gerade im ersten Drittel erfasste. Der Liquor aller Subtypen entstammte folglich, unabhängig von der Krankheitsdauer, dem gleichen Krankheitsstadium. Zweitens wurde das dritte und letzte Krankheitsstadium für den Zeitpunkt der Liquoruntersuchung gewählt, da vorherige Studien Hinweise darauf geben, dass die Sensitivität für den Nachweis von 14-3-3 im Verlauf der Krankheit zunimmt, wobei ein endgültiger Abfall im terminalen Krankheitsstadium nicht auszuschließen ist (Sanchez-Juan et al. 2007, Van Everbroeck et al. 2003). Gmitterova et al. konnten mittels 14-3-3-ELISA zeigen, dass signifikant höhere 14-33-Konzentrationen im zweiten und dritten Krankheitsdrittel, verglichen mit dem ersten Drittel, nachgewiesen werden konnten, die höchsten Konzentrationen an 14-3-3Protein waren jedoch im zweiten Krankheitsdrittel im Liquor zu finden, mit einem leichten Abfall zum Ende der Erkrankung mit der Ausnahme des VV2-Subtyps, bei dem die höchsten 14-3-3-Konzentrationen im letzten Krankheitsdrittel gemessen wurden (Gmitterova et al. 2009). Die Vermutung, dass 14-3-3 auf Grund von neurodegenerativen Prozessen in den Liquor freigesetzt wird und diese im Laufe der Erkrankung zunehmen, hat die Wahl des dritten Krankheitsstadiums als Zeitpunkt der Liquoruntersuchung unterstützt.

\subsection{Antikörper}

Wie anfangs beschrieben, erfolgten bereits einige Studien zum Nachweis von 14-33-Isoformen im Liquor von Patienten mit Creutzfeldt-Jakob-Krankheit, aber auch anderen neurodegenerativen Erkrankungen, welche sehr unterschiedliche Ergebnisse hervorbrachten (s. Tab. 4). Lee und Harrington (1997), sowie Saiz et al. (1999) konnten zum Beispiel mit Hilfe von 14-3-3-Isoformantikörpern der Firma Santa Cruz Biotechnology 14-3-3- $\beta,-\gamma$ und $-\tau$ im Liquor nachweisen. Saiz et al. detektierten

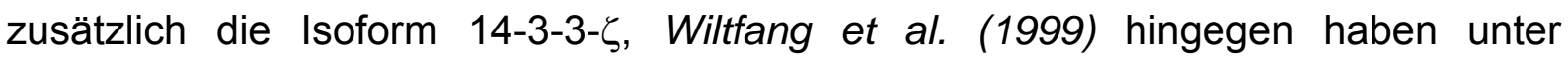
Verwendung derselben Antikörper der Firma Santa Cruz die Isoformen $\beta, \gamma, \eta$ und $\varepsilon$ im Liquor cerebrospinalis nachweisen können. Takahashi et al. (1999) haben mit selbst hergestellten 14-3-3-Antikörpern lediglich die Isoformen $\gamma$ und $\varepsilon$ nachgewiesen. Unter Verwendung von ebenfalls selbst hergestellten und später kommerzialisierten 
Antikörpern konnten Shiga et al. (2006) hingegen zeigen, dass die Isoformen 14-3-3$\beta,-\gamma,-\eta,-\varepsilon$ und $-\zeta$ im Liquor zu finden sind. Ein möglicher Grund dieser diskrepanten Ergebnisse könnten die unterschiedlichen Antikörper sein, die verwendet wurden und verschiedene Spezifitäten für die einzelnen Isoformen aufweisen. Bei den üblicherweise verwendeten Antikörpern (Lee und Harrington 1997, Saiz et al. 1999, Shiga et al. 2006, Wiltfang et al. 1999) handelte es sich um Produkte der Firma Santa Cruz Biotechnology. In anderen Studien wurden selbst hergestellte Antikörper verwendet, wobei diejenigen der japanischen Arbeitsgruppen (Wakabayashi et al. 2001, Shiga et al. 2006), unter der Prämisse höherer Spezifität, kommerzialisiert wurden und nun über die Firma IBL, Japan, vertrieben werden. Initial wurden auch in dieser Untersuchung 14-3-3-Antikörper der Firma Santa Cruz Biotechnology verwendet, mit Nachweis u.a. von 14-3-3- $\beta$ und $-\gamma$, aber auch von den Isoformen $\tau$ und $\sigma$. Da der Nachweis von 14-3-3- $\sigma$ bislang in der Literatur gar nicht und von 143-3- $\tau$ nur sporadisch beschrieben ist und lediglich in den Studien, in denen 14-3-3Antikörper der Firma Santa Cruz verwendet wurden, sowie vor dem Hintergrund der diskrepanten Studienergebnisse, kamen Zweifel an der Spezifität der verwendeten Antikörper auf und es ergab sich die Notwendigkeit 14-3-3-Antikörper mit einer hohen Spezifität für die einzelnen Isoformen zu finden. Vor diesem Hintergrund wurden in dieser Studie die Antikörper der beiden Firmen Santa Cruz und IBL verglichen, mit dem vorangehend beschriebenen Ergebnis einer höheren Spezifität der IBL-Antikörper, insbesondere für die Isoformen $\beta, \gamma, \eta, \sigma$ und $\tau$. Die Antikörper gegen die Isoformen $\varepsilon$ und $\zeta$ zeigen ähnlich hohe Spezifität (s. Abb. 6). Die Untersuchung auf Antikörperspezifität bei Shiga et al. (2006) zeigt ähnliche Ergebnisse mit einer deutlich höheren Spezifität der eigenen (später IBLkommerzialisierten) Antikörper, wobei z. B. Antikörper gegen die Isoform $\sigma$ nicht untersucht wurden, „SC“- $\varepsilon$ deutlich mehr Kreuzreaktionen aufweist als in unserem Dot Blot und "IBL"- $\gamma$ sowie $-\varepsilon$ andere und stärkere Kreuzreaktionen zeigten als wir nachweisen konnten. Abbildung 17 zeigt zum Vergleich den Dot Blot von Shiga et al. (2006): 
Antigen $14-3-3,10 \mathrm{ng}$

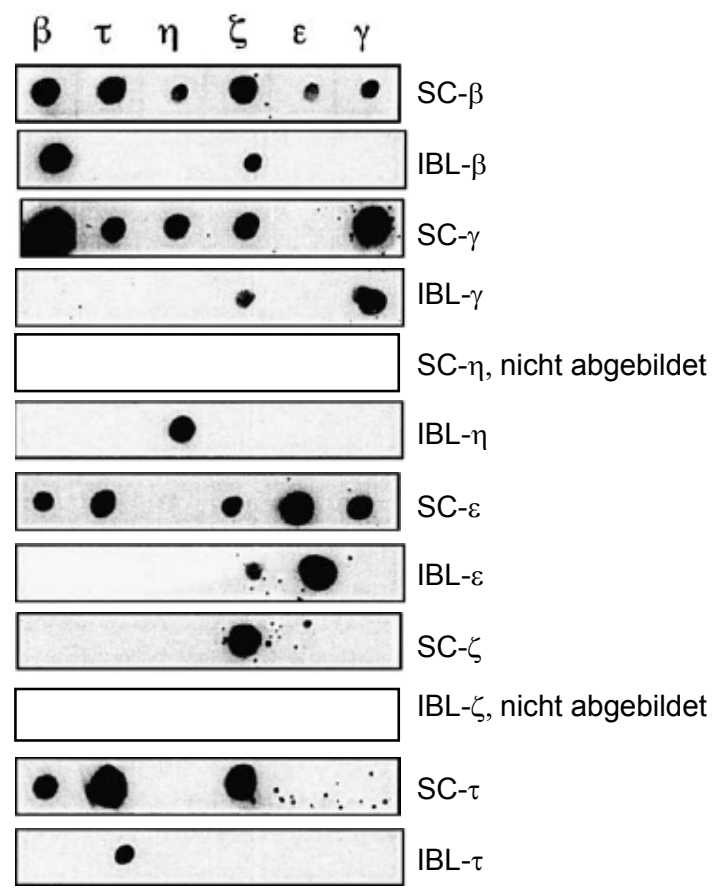

Abbildung 17: Dot Blot zum Nachweis der Antikörperspezifität nach Shiga et al. (2006)

Der dargestellte Dot Blot unterstützt die Ergebnisse unserer Untersuchung und daraus resultierend die Wahl der IBL-Antikörper als Primärantikörper der Western Blots, mit einer hohen Aussagekraft bezüglich des Vorhandenseins bzw. der Abwesenheit von 14-3-3-Isoformen im Liquor auf Grund der nachgewiesenen Spezifität.

\subsection{Vorhandensein von 14-3-3-Isoformen im Liquor von sCJK- Patienten}

14-3-3-Proteine haben vielfältige Funktionen und sind insbesondere in der Regulation von Zellzyklus, Signaltransduktion und Apoptose vornehmlich als Adapterproteine oder Chaperone involviert (Aitken et al. 1992, Berg et al. 2003, Fu et al. 2000, Vincenz und Dixit 1996). Im Rahmen dieser Studie konnte der Nachweis der Isoformen 14-3-3- $\beta,-\gamma,-\varepsilon$ und $-\zeta$ im Liquor von Patienten aller sechs Subtypen der sporadischen Creutzfeldt-Jakob-Krankheit erbracht werden. Aus den durchgeführten semiquantitativen und statistischen Analysen geht hervor, dass diese vier Isoformen über alle Subtypen gemittelt positive [+] oder, im Falle von 14-3-3- $\gamma$, 
sogar stark positive [++] Bandenintensitäten aufzeigen (s. Abb. 13). Die beiden Isoformen 14-3-3- $\gamma$ und - $\zeta$ weisen zum Teil deutliche „Doppelbanden“ auf, deren Muster, wie im Ergebnisteil beschrieben, leicht differieren und deren Ursache, gemäß Literaturangaben, entweder in der Kreuzreaktivität mit den leichten Ketten von Immunglobulinen liegt (Sanchez-Valle et al. 2002), möglicherweise aber auch durch Cleavage-Produkte des 14-3-3-Proteins selbst oder durch posttranslationale Modifikation zu erklären ist.

Die Tatsache des Nachweises der Isoformen 14-3-3- $\beta,-\gamma,-\varepsilon$ und $-\zeta$ im Liquor aller Subtypen erlaubt einerseits die Vermutung, dass diese Isoformen, zumindest im letzten Krankheitsstadium, vermutlich aber auch früher, in relevanter Konzentration und durch massiven Untergang neuronalen Gewebes im Liquor von betroffenen Patienten vorliegen. Andererseits ist die transkriptionale Regulation der Expression von 14-3-3-Isoformen eine weitere mögliche pathophysiologische Erklärung für das Vorhandensein lediglich einiger Isoformen (s.o.) im Liquor und das Fehlen anderer. Die Expression von 14-3-3- $\sigma$ beispielsweise wird durch DNA-Schädigung massiv hochreguliert, 14-3-3- $\gamma$ wird durch Einfluss von PDGF (platelet-derived growth factor) vermehrt exprimiert und 14-3-3- $\varepsilon$ bei der Differenzierung mesenchymaler Zellen herunterreguliert (Autieri et al. 1996, Hermeking et al. 1997, McConnell et al. 1995). Ein gänzliches Fehlen von $14-3-3-\varepsilon$ in $14-3-3-\varepsilon^{-/-}-$Knockoutmäusen zeigte eine hohe perinatale Mortalität und massive Defekte der Hippokampusregion und des Kortex, hinweisend auf eine Rolle von 14-3-3- $\varepsilon$ in neuronaler Plastizität und Gehirnentwicklung (Toyo-oka et al. 2003). Satoh et al. legen darüber hinaus in ihrer Arbeit nahe, dass 14-3-3 nicht nur unspezifisch durch neuronalen Untergang oder Hochregulation einzelner Isoformen, sondern spezifisch durch Interaktion von Hsp60 ([engl.] Heat shock protein), Prionprotein und 14-3-3 in den Liquor freigesetzt wird; durch Konformationsänderung von $\mathrm{PrP}^{\mathrm{c}}$ in $\mathrm{PrP}^{\mathrm{sc}}$ wird der Komplex dieser drei Proteine destabilisiert und 14-3-3 in den Liquor freigesetzt. Dies konnte sowohl für die Isoform 14-3-3- $\gamma$ als auch $-\zeta$ nachgewiesen werden, sodass die Autoren o.g. Pathomechanismus als isoform-unspezifisch gedeutet haben, Untersuchungen mit den anderen 14-3-3-Isoformen fanden jedoch nicht statt (Satoh et al. 2005). Der Nachweis der oben genannten 14-3-3-Isoformen $(\beta, \gamma, \varepsilon, \zeta)$ in dieser Arbeit, teilweise einhergehend mit den Ergebnissen von Saiz et al. (1999), Shiga et al. (2006) und Wiltfang et al. (1999) (s. Tab. 4), bestärkt den Einsatz des Nachweises dieser vier 
Isoformen in der prämortalen Diagnose von sporadischer Creutzfeldt-JakobKrankheit unabhängig vom molekularen Subtyp.

Im Gegensatz zu Shiga et al. (2006) und Wiltfang et al. (1999) konnte jedoch in dieser Untersuchung die Isoform 14-3-3- $\eta$, trotz hoher Antikörperspezifität, wiederholt bei allen Subtypen nicht nachgewiesen werden. Eine eindeutige pathophysiologische Erklärung für dieses Ergebnis ist uns bisher nicht bekannt, da dieser Isoform keine auffälligen physiologischen oder strukturellen Merkmale zu Grunde liegen, die sie von den anderen 14-3-3-Isoformen abgrenzen würde. 14-3-3- $\eta$ ist genauso wie andere 14-3-3-Isoformen in verschiedene Zellzyklusmechanismen involviert, spielt jedoch eine spezifische Rolle durch Bindung an das A20-Zinkfingerprotein bei dem TNF (Tumornekrosefaktor)-assoziierten Apoptoseweg (Vincenz und Dixit 1996). Aus der Arbeit von Baxter et al. (2002) geht jedoch hervor, dass in Scrapie-infizierten Ratten die Isoformen $\beta, \gamma, \zeta$ und $\eta$ ein sehr ähnliches, die Kerngebiete der grauen Substanz betreffendes, Verteilungsmuster zeigten, wobei die Isoform $\eta$ zusätzlich vermehrt in den Purkinje-Zellen des Kleinhirns gefunden wurde. Bei Schädigung dieser Hirnareale im Verlauf der SCJK, was nicht typischerweise bei allen Subtypen der Fall ist, müsste es auf Grund von Neuronenverlust zu einem Freisetzen aller dort nachgewiesenen Isoformen $(\beta, \gamma, \zeta, \eta)$ in den Liquor kommen. Vorraussetzung für diese Hypothese ist die Vorstellung, dass die Isoformen des Proteins 14-3-3 tatsächlich auf Grund der neuronalen Läsion freigesetzt werden und kein anderer molekularbiologischer Mechanismus involviert ist. Der dennoch fehlende Nachweis

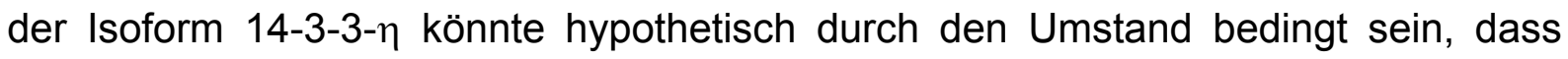
diese Isoform überdurchschnittlich häufig mit dem Prionprotein assoziiert gefunden wurde (Baxter et al. 2002). Eine mögliche Aggregation dieser beiden Proteine und darauffolgende geringe Liquorgängigkeit, eine fehlende Möglichkeit der Bindung von Antikörper auf Grund von Interaktionen oder sogar ein isoform-spezifischer Weg von 14-3-3-Protein in den Liquor sind spekulative Erklärungen für den fehlenden Nachweis der Isoform $\eta$ und bedürfen weiterer Untersuchung.

Das Ergebnis der ebenfalls in allen SCJK-Subtypen nicht nachweisbaren Isoform $\sigma$ ist kohärent mit den Angaben aus der Literatur. Die 14-3-3- $\sigma$-Isoform ist ebenfalls in Funktionen des Zellzyklus involviert, es konnte ihr jedoch auch ein isoformspezifischer biologischer Effekt nachgewiesen werden. Eine Überexpression von 14- 
3-3- $\sigma$ in kolorektalen Tumorzellen führte zum G2-Zellzyklusarrest und weist damit tumorsuppressive Eigenschaften auf (Hermeking et al. 1997). Im Liquor cerebrospinalis konnte diese Isoform in keiner der vorangegangenen Studien (s. Tab. 4) detektiert werden, einhergehend mit früheren Ergebnissen, die die Isoform $\sigma$ vornehmlich in epithelialen Zellen (Leffers et al. 1993) und nur in sehr geringer Konzentration im Gehirn (Di Fede et al. 2007) nachgewiesen haben. Vor dem Hintergrund der im Dot Blot ermittelten Antikörperspezifität kommen wir zu dem Schluss, dass die Isoform 14-3-3- $\sigma$ keine Rolle in der Diagnostik und noch weniger in der Differenzierung der Subtypen der sCJK spielt.

Hinsichtlich der siebten 14-3-3-Isoform, der $\tau$-Isoform, haben wir ein heterogenes Muster im Liquor der unterschiedlichen SCJK-Subtypen gefunden. Bei den Patienten mit Homozygotie für Valin an Codon-129 konnten wir diese Isoform im Liquor nachweisen, mit prozentualen Bandenintensitäten von 36\% für VV2 und $25 \%$ für VV1, genauso wie bei zwei Patienten vom MM2-Subtyp (19\%). Bei den anderen drei Subtypen MM1, MV1 und MV2, sowie für zwei der MM2-Patienten und bei den Kontrollpatienten konnte diese Isoform nicht detektiert werden. Wie einführend erwähnt, wurde die $\tau$-Isoform zunächst nur in T-Zellen des Menschen nachgewiesen (Nielsen 1991) und von Baxter et al. (2002) in geringer Konzentration nur im Hippokampus lokalisiert gefunden. Auch bezüglich des Auftretens dieser 14-3-3Isoform im Liquor finden sich, wie aus Tabelle 4 ersichtlich, differierende Angaben. So konnten die meisten Studien, einschließlich der Studie von Shiga et al. (2006), 14-3-3- $\tau$ nicht nachweisen. Allein Lee und Harrington (1997), sowie Saiz et al. (1999) lieferten den Nachweis von 14-3-3- $\tau$ unter Verwendung der Santa Cruz Biotechnology-Antikörper. Retrospektiv lässt sich auf Grund der Ergebnisse unseres Dot Blots und auch der Untersuchungen von Shiga et al. (2006) allerdings vermuten, dass es sich bei beiden oben genannten Studien um eine Kreuzreaktion des 14-3-3$\tau$-Antikörpers von Santa Cruz Biotechnology mit den 14-3-3-Isoformen $\beta$ und $\zeta$ gehandelt haben könnte. Weiterhin ist es möglich, dass in einigen o.g. Studien überhaupt keine VV-Subtypen untersucht worden sind und daher kein 14-3-3- $\tau$ im Liquor cerebrospinalis nachgewiesen wurde, da z.B. 93\% der japanischen Bevölkerung an Codon 129 homozygot für Methionin ist versus $37 \%$ in der kaukasischen Bevölkerung (Nozaki et al. 2010). 
Entgegen all dieser, das Vorhandensein von 14-3-3- $\tau$ im Liquor negierenden Ergebnisse, konnten wir in dieser Arbeit mit spezifischen Antikörpern 14-3-3- $\tau$ dennoch in einigen sCJK-Subtypen nachweisen. In Ermangelung fundierter Erklärungen für dieses Ergebnis, welches noch weitere Forschung erfordert, liefert die Studie von Di Fede et al. (2007) dennoch unterstützende Daten, die 14-3-3- $\tau$ als drittstärkste Isoform im Hirn mit einem homogenen Verteilungsmuster und nicht nur auf den Hippokampus lokalisiert (Baxter et al. 2002) nachweisen. Andererseits konnten Baxter et al. (2002) auch zeigen, dass bei Scrapie-infizierten Mäusen im terminalen Stadium der Erkrankung der Nachweis von 14-3-3- $\tau$ im Hippokampus nicht mehr gelingt, was die mögliche Hypothese unterstützt, dass in fortgeschrittenen Krankheitsstadien, nach starker Schädigung des Hirngewebes oder reaktiver Hochregulation von 14-3-3- $\tau$, auch diese Isoform in den Liquor freigesetzt wird und daher zu diesem Zeitpunkt detektiert werden kann.

Die Frage, die sich an dieser Stelle aufdrängt, ist, warum der Nachweis der $\tau$ Isoform, angesichts der vermuteten Hypothese und Untersuchung aller Patientenliquores im letzten Krankheitsdrittel, nicht bei allen Subtypen gelungen ist. Ein direkter Zusammenhang zwischen den unterschiedlich betroffenen Hirnarealen bei den molekularen Subtypen, dem damit assoziierten Freisetzen von 14-3-3- $\tau$ und somit dem Nachweis dieser Isoform im Liquor wäre denkbar, konnte bislang jedoch nicht gefunden werden. Geht man, nach Baxter et al. (2002), davon aus, dass 14-33- $\tau$ allein im Hippokampus nachgewiesen wird, so ist diese Hirnregion bei den MM1und MV1-Subtypen nicht betroffen (Parchi et al. 1996) und folglich scheint es erklärlich, dass 14-3-3- $\tau$ im Liquor bei diesen Subtypen nicht nachweisbar ist. Jedoch trifft diese Erklärung nicht für den MV2-Subtyp zu, bei dem 14-3-3- $\tau$ ebenfalls nicht im Liquor nachweisbar ist. Der MV2-Subtyp zeigt ein dem VV2-Subtypen sehr ähnliches histopathologisches Läsionsmuster, einschließlich des Hippokampus (Parchi et al. 1999), und dennoch konnten wir die Isoform $\tau$ nicht im Liquor bei MV2Patienten nachweisen.

Ein weiterer möglicher Aspekt, der mit dem Nachweis dieser Isoform bei den Subtypen MM2, VV1 und VV2 korrelieren könnte, ist die längere Krankheitsdauer der Patientin mit diesem Subtyp. Mit 8 Monaten (VV2-Subtyp), 10 bzw. 12 Monaten (MM2/VV1) weisen diese Subtypen besonders lange Krankheitszeiten auf, die 
möglicherweise mit stärkerem Neuronenverlust, Gliose und eventuell Hochregulation anti-apoptotischer 14-3-3-Proteine (Baxter et al. 2002), die dadurch vermehrt im Liquor zu finden sind, einhergehen. Diese Hypothese wird allerdings wiederholt durch den MV2-Subtyp entkräftet, der mit einer mittleren Krankheitsdauer von 14 Monaten alle anderen Subtypen übertrifft, dennoch kein 14-3-3- $\tau$ im Liquor nachzuweisen ist und daher Anlass zu weiteren Nachforschungen bezüglich der Rolle von 14-3-3- $\tau$ in der Diagnostik und Differenzierung der Subtypen gibt. Hypothetisch ist eine subtypen-spezifische verstärkte Expression der 14-3-3-Isoform $\tau$ z.B. bei VV1 und VV2 denkbar, die daher auch den Nachweis dieser Isoform im Liquor zulässt, grundlegende Daten liegen für diese Hypothese zum jetzigen Zeitpunkt jedoch nicht vor und bedürfen weiterer Studien.

\subsection{Differenzierung der sCJK-Subtypen anhand des 14-3-3- Isoformmusters im Liquor}

Wir sind bei dieser Arbeit zu dem Resultat gekommen, dass die Isoformen 14-3-3- $\beta$, $\gamma,-\varepsilon,-\zeta$ und $-\tau$ bei den verschiedenen sCJK-Subtypen im Liquor cerebrospinalis nachzuweisen sind. Bei näherer Betrachtung der mittleren Bandenintensitäten der einzelnen nachgewiesenen Isoformen abhängig vom sCJK-Subtyp ergeben sich leicht variierende Muster für jeden Subtyp, was aus der Tabelle 21 hervorgeht. Wie bereits oben erwähnt, ist zum Beispiel die Isoform 14-3-3- $\tau$ nicht bei allen Subtypen nachweisbar, aber auch die Reihenfolge der nach Bandenintensitäten sortierten Isoformen variiert von Subtyp zu Subtyp. So stellt die Isoform $\varepsilon$ zum Beispiel bei den Subtypen MM1, MV2, VV2 die zweitstärkste 14-3-3-Isoform dar, während sie bei den Subtypen MM2, MV1 und VV1 erst an dritter Stelle kommt. Besonders variabel ist auch die Position von 14-3-3- $\beta$ im Hinblick auf die Reihenfolge der Bandenintensitäten. So ist 14-3-3- $\beta$ bei dem VV1-Subtyp neben der $\gamma$-Isoform am stärksten nachzuweisen, beim MM1-Subtyp hingegen am schwächsten. Diese Unterschiede der mittleren Bandenstärken sind bislang nicht signifikant, jedoch durchaus vorhanden und möglicherweise in weiteren Untersuchungen mit größeren Patientenkollektiven und eventuell quantitativen Messverfahren für die Konzentration der einzelnen Isoformen im Liquor zu validieren. Wie bereits eingangs erwähnt, liefert die Literatur histopathologischen Anhalt für das Vorhandensein von Unterschieden im Isoformmuster bei den molekularen Subtypen der Creutzfeldt-Jakob-Krankheit 
zum einen auf Grund verschiedener subzellulärer Lokalisation der einzelnen 14-3-3Isoformen zum anderen durch die unterschiedlichen Hirnläsionsprofile bei den SCJKSubtypen. Beispielsweise sind bei den Subtypen MM1, MV1 und VV1 die Hirnstammkerne und das Kleinhirn von neuronaler, spongiformer Destruktion nicht betroffen im Gegensatz zu den Subtypen VV2, MV2 und MM2, wobei beim MM2Subtyp das Zerebellum ebenfalls nicht betroffen ist (Gambetti et al. 2003, Parchi et al. 1999). In Kombination mit dem Nachweis von 14-3-3- $\beta,-\gamma,-\eta$ und $-\zeta$ in lediglich bestimmten neuroanatomischen Kerngebieten gegenüber dem Vorhandensein von 14-3-3- $\varepsilon$ in der gesamten grauen Substanz oder von 14-3-3- $\tau$ vornehmlich im Hippokampus und der weißen Substanz, ergibt sich die Hypothese, dass aus den verschiedenen Hirnläsionsprofilen der sCJK-Subtypen und der unterschiedlichen Verteilung der 14-3-3-Isoformen durch neuronalen Untergang spezifische 14-3-3Isoformmuster im Liquor detektierbar sein könnten (Baxter et al. 2002, Gambetti et al. 2003, Parchi et al. 1999). Die Studie von Gmitterova et al. (2009) zeigt außerdem, dass sich auch die Konzentration von 14-3-3-Protein im Liquor bei den molekularen Subtypen der sCJK unterscheiden. 14-3-3-Konzentrationen waren signifikant höher bei homozygoten Subtypen (MM/VV), als bei den heterozygoten Subtypen (MV). Weiterhin hatten Patientin mit $\operatorname{PrP}^{\mathrm{sc}}$ Typ 1 höhere 14-3-3-Proteinkonzentrationen im Liquor als Patientin mit PrP ${ }^{\mathrm{sc}}$ Typ 2 (Gmitterova et al. 2009). Diese Arbeit zeigt zunächst eine Tendenz der unterschiedlichen Isoformmuster bzw. Isoformkonzentrationen abhängig vom sCJK-Subtyp, wobei eindeutige Zuordnungen zu den Hirnläsionsprofilen in der Literatur nicht gefunden werden konnten, was zum einen darin begründet liegt, dass die zitierte Studie 14-3-3-Isoformen in Rattenhirnen lokalisiert hat und möglicherweise ein Unterschied zur Verteilung im menschlichen Gehirn vorliegt (Baxter et al. 2002), zum anderen könnte neben der These der 14-33-Freisetzung in den Liquor allein durch neuronalen Untergang, auch eine Hochoder Herunterregulation der Expression verschiedener Isoformen eine Rolle spielen und dadurch eine strenge Korrelation zu den betroffenen Hirnläsionen erschweren.

\subsection{Isoformmuster des Kontrollkollektivs - 14-3-3- - als Differenzierungsmarker}

Ein deutlich abweichendes Isoformmuster zeigt bereits in dieser Arbeit das Kollektiv der Kontrollpatienten, bei dem die Isoformen $\gamma$ und $\zeta$ dominierend sind, die Isoformen 
$\beta$ und $\varepsilon$ mit 9 bzw. 12,5\% verschwindend geringe durchschnittliche Bandenintensitäten aufweisen und sich damit deutlich von den sCJK-Subtypen unterscheiden (s. Abb. 12 und Tab. 21). Wie aus der Abbildung 12 hervorgeht sind auch in dem Liquor der Kontrollpatienten verschiedene 14-3-3-Isoformen nachweisbar. Tabelle 19 zeigt, dass die Isoformen 14-3-3- $\gamma,-\zeta,-\varepsilon$ und $-\beta$ zu 84\%, $78 \%, 12,5 \%$ bzw. 9\% im Liquor der Kontrollpatienten mit ischämischen oder entzündlichen Erkrankungen des Gehirns nachweisbar sind. Die Isoformen 14-3-3- $\eta$, $-\sigma$ und $-\tau$ sind bei diesem Patientenkollektiv ebenfalls, wie bei der Mehrheit der sCJKSubtypen, nicht nachweisbar. Bemerkenswert ist jedoch die niedrige Nachweisrate von 14-3-3- $\beta$ mit nur $9 \%$ bei den Kontrollpatienten, im Gegensatz zu dem sCJKKollektiv (mittlere Bandenintensität 46\% für 14-3-3- $\beta$, s. Tab 21). Aus der Tabelle 20 geht hervor, dass jeder sCJK-Subtyp positiv für 14-3-3- $\beta$ ist und zusätzlich in den meisten Fällen sogar eine relativ hohe Bandenintensität aufweist, wobei Abbildung 12 bei lediglich zwei der acht Kontrollpatienten schwach positive Banden für die $\beta$ Isoform zeigt. Aus diesem Ergebnis ergibt sich eventuell die Möglichkeit einer Differenzierung von falsch-positivem und richtig-positivem 14-3-3-Nachweis in der Diagnostik der sCJK. Die Kontrollpatienten dieser Arbeit mit entzündlichem oder ischämischem Geschehen waren in der Routineuntersuchung initial positiv für 14-3-3 getestet worden, als Antikörper in der Routine diente hierbei der mit allen Isoformen kreuzreagierende SC- $\beta$-Antikörper (s. Abb. 6). Die genauere isoformspezifische Untersuchung zeigte im Folgenden jedoch den fehlenden Nachweis von 14-3-3- $\beta$, im Gegensatz zu den sCJK-Patienten. Man kann also die Hypothese aufstellen, dass der Nachweis von 14-3-3- $\beta$ herangezogen werden kann, um zwischen falsch- und richtig-positivem Nachweis von 14-3-3 in der Diagnostik der sporadischen Creutzfeldt-Jakob-Krankheit zu differenzieren.

\subsection{Rolle des Tau-Proteins im Liquor von sCJK-Patienten}

Bei den untersuchten Western Blots ist aufgefallen, dass Patienten vom gleichen Subtyp unterschiedlich starke Bandenintensitäten bei derselben 14-3-3-Isoform aufweisen. Weiterhin ergab eine nähere Betrachtung, dass Patienten eine Tendenz zeigten, bei allen Isoformen entweder stetig schwache oder stetig starke Bandenintensitäten aufzuweisen. Als Beispiel kann hier der Vergleich der Patienten 3 und 6 vom MV1-Subtyp dienen, wobei Patient 3 durchweg schwächere 
Bandenintensitäten aufweist als Patient 6 (s. Abb. 8 und Tab. 14). Wir haben versucht, für diese Beobachtung eine Erklärung zu finden und konnten feststellen, dass die Höhe des Tau-Proteins mit der Stärke der Bandenintensitäten korreliert (Bsp: MV1-Pat. 3: Tau-Protein = 4344 pg/ml, MV1-Pat. 6: Tau-Protein $=26880$ $\mathrm{pg} / \mathrm{ml}$ ), einhergehend mit den Studieninhalten von Otto et al. (2002). Diese Korrelation konnten wir für alle Isoformen, ausgenommen 14-3-3- $\eta$ und $-\sigma$, nachweisen (s. Abb. 17).

Die Überlegungen, die sich aus diesen Daten ergeben, betreffen den Nutzen des Tau-Proteins als Korrelationsmarker in der Diagnose der sCJK bzW. liefern eine mögliche Erklärung für das Auftreten von 14-3-3-Protein im Liquor. Hinsichtlich des Nutzens des Tau-Proteins als alleinigem neurodegenerativen Marker ist anzumerken, dass dieses Protein unspezifisch ist und auch bei anderen neurodegenerativen Erkrankungen, insbesondere der Alzheimer-Krankheit als diagnostisches Mittel validiert eingesetzt wird (Hampel et al. 2010). Dennoch könnte die gemeinsame Bestimmung von Tau-Protein und 14-3-3-Isoformen insofern diagnostisch wertvoll sein, als dass beispielsweise leicht erhöhte Konzentrationen des Tau-Proteins einhergehend mit geringen Bandenintensitäten von 14-3-3-Protein ein sehr frühes Stadium der SCJK-Krankheit bedeuten könnten, während hohe TauProteinkonzentrationen einhergehend mit fehlendem Nachweis von 14-3-3 dieses ausschließen. Otto et al. (2002) zum Beispiel fanden in ihrer Studie, dass sechs Patienten, später neuropathologisch definitiv als CJK-Patienten diagnostiziert, klinisch initial in die Gruppe anderer Demenzen klassifiziert wurden. Alle Patienten hatten Tau-Proteinkonzentrationen über 1300 pg/ml (diagnostischer Cut-Off für CJK), was für den Einsatz von Tau-Protein als Marker in der frühen Diagnose von Creutzfeldt-Jakob-Krankheit spricht. Andererseits bleibt die Frage, warum bei starker Neurodegeneration und Nachweis von hohen Tau-Proteinwerten dennoch die Isoformen 14-3-3- $\eta$ und $-\sigma$ nicht im Liquor erscheinen. Von den anderen Isoformen differierende funktionelle Eigenschaften, Interaktionen und Liquorgängigkeit, unabhängig vom Grad der Neurodegeneration, sowie unterschiedliche Regulation einzelner Isoformen, wie bereits oben erwähnt, sind mögliche Aspekte, die bei der Lösung dieser Frage berücksichtigt werden sollten. Andererseits deutet der Nachweis der Korrelation von Tau-Protein mit dem Vorhandensein von 14-3-3- $\tau$ im Liquor darauf hin, dass es einen Zusammenhang zwischen der Stärke der 
Hirnschädigung und dem Erscheinen von 14-3-3- $\tau$ im Liquor gibt und diese Isoform bei starker Schädigung des Gehirns nachzuweisen ist.

\subsection{Schlussfolgerung}

Aus den dargestellten Ergebnissen und den daraus folgenden Überlegungen lässt sich die eingangs formulierte Fragestellung abschließend relativ gut beantworten. Ziel dieser Studie war die Untersuchung der 14-3-3-Isoformen im Liquor von sCJKSubtypen, der Nachweis bestimmter Isoformmuster für die einzelnen Subtypen und Darstellung eines Zusammenhangs zu dem Tau-Protein, als weiterem neurodegenerativen Marker. Diese Ziele verfolgend sind wir in der Lage festzustellen, dass nur fünf der sieben Isoformen, nämlich 14-3-3- $\beta,-\gamma,-\varepsilon,-\zeta$ und $-\tau$, überhaupt im Liquor nachzuweisen sind. Die anderen beiden Isoformen $\eta$ und $\sigma$ konnten weder bei einem der sechs Subtypen noch dem Kontrollkollektiv nachgewiesen werden.

Weiterhin konnten wir beobachten, dass einige Isoformen stärkere Banden im Western Blot aufweisen als andere und dies auch in den differierenden Isoformmustern der Subtypen zum tragen kommt, insbesondere im Hinblick auf die Isoform $\tau$ zum einen und auf das Kollektiv der Kontrollpatienten zum anderen. Diese Beobachtungen sind nicht signifikant, zeigen jedoch die Tendenz heterogener Isoformmuster bzw. Isoformkonzentrationen im Liquor der verschiedenen Subtypen. Wir vermuten, dass sich hinter diesen Unterschieden und auch hinter dem fehlenden Nachweis von 14-3-3- $\eta$ und $-\sigma$ multiple Erklärungsmöglichkeiten verbergen. Zum einen könnten unterschiedliche histopathologische Profile eine Erklärung bieten, wobei wir nach eingehender Literaturrecherche keinen eindeutigen Zusammenhang finden konnten. Zum anderen könnten definierte, isoform-abhängige funktionelle oder pathophysiologische Aspekte eine Rolle spielen, die entweder den Weg dieser Isoform in den Liquor verhindern oder aber von weiteren, z. Zt. unbekannten, Faktoren, wie z.B. der Krankheitsdauer, abhängig sind. Um diese Zusammenhänge näher zu bestimmen, sind umfangreichere Untersuchungen hinsichtlich der Gemeinsamkeiten und Unterschiede der histopathologischen Läsionen, der Funktion, Lokalisation und Regulation der 14-3-3-Isoformen und deren Mechanismus der Liquorgängigkeit notwendig. 
Wir konnten jedoch zeigen, dass es einen Zusammenhang zwischen zunehmender Neurodegeneration und dem Erscheinen von 14-3-3-Isoformen in größerer Intensität im Liquor gibt. Das Tau-Protein diente dazu als Surrogatmarker, da es sich hierbei um einen weiteren neurodegenerativen Marker handelt, dessen Konzentration im Liquor bei starker Hirnschädigung zunimmt. Wir konnten für alle fünf im Liquor nachgewiesenen 14-3-3-Isoformen eine Korrelation mit der Höhe des Tau-Proteins nachweisen.

Resümierend können wir festhalten, dass es uns gelungen ist mit spezifischen Antikörpern bestimmte 14-3-3-Isoformen im Liquor nachzuweisen und damit die in der Literatur bestehenden Unklarheiten zu beseitigen. Weiterhin konnten wir erfolgreich tendenzielle Unterschiede in dem Isoformmuster für die verschiedenen sCJK-Subtypen und eine Korrelation der Bandenintensität im Western Blot aller Isoformen mit der Höhe des Tau-Proteins im Liquor aufzeigen. Diese Ergebnisse liefern zum Teil Hinweise für die Erklärung des Erscheinens von 14-3-3-Isoformen im Liquor, zum Teil dienen sie diagnostischen Zwecken. So können die nachgewiesenen Isoformen die Diagnose der sporadischen Creutzfeldt-JakobKrankheit bestätigen. Insbesondere der Nachweis der Isoform 14-3-3- $\beta$ bei Patienten mit SCJK und der fehlende Nachweis dieser Isoform bei den Kontrollpatienten lässt einen diagnostisch wegweisenden Unterschied zwischen diesen beiden Kollektiven erwarten.

Das einleitende Ziel einer prämortalen Diagnose einzelner Subtypen anhand spezifischer Isoformmuster kann durch diese Arbeit bislang nicht erreicht werden, jedoch zeigt sie eine Tendenz bezüglich unterschiedlich hoher Konzentrationen der 14-3-3-Isoformen im Liquor. Diese Beobachtung bedarf weiterer Forschung, wobei wir ein solch spezifisches, die Konzentration der einzelnen 14-3-3-Isoform betreffendes Muster für die Diagnose von sCJK-Subtypen nicht ausschließen würden, die alltagsrelevante Methode des Western Blots jedoch für nähere quantitative Untersuchungen nicht geeignet erscheint. 


\subsection{Limitationen}

Limitierend an dieser Studie ist die Tatsache, dass das verwendete Patientenkollektiv naturgemäß klein ausfällt, was sich auf nahezu alle Ergebnisbereiche auswirkt. Mit sieben bzw. zum Teil nur vier Patienten pro Subtyp war es schwierig, aus den Ergebnissen allgemein gültige Thesen zu formulieren. Dennoch war es uns auf Grund eingangs erwähnter limitierter Inzidenz einiger Subtypen nicht möglich, das Kollektiv zu vergrößern. Wir können daher nichtsdestotrotz die hier gewonnenen Ergebnisse als valide Tendenzen für die einzelnen Subtypen annehmen und müssen die ermittelten Daten prospektiv an einem größeren Patientenkollektiv zielgerichtet prüfen.

Des Weiteren ist die Methode des Western Blots auf den qualitativen und semiquantitativen Nachweis von Proteinen limitiert. Eine quantitative Bestimmung der 14-3-3-Isoformen würde möglicherweise eine genauere Differenzierung der Isoformmuster im Liquor der Subtypen zulassen. Wir haben jedoch den Western Blot als Methode der Wahl genutzt, da, wie eingangs beschrieben, diese Methode höhere Sensitivität und Spezifität als beispielweise ein ELISA zeigt. Außerdem wird der Western Blot als Methode in der täglichen Routine zur Diagnose der SCJK verwendet und sollte daher auch in unserer Studie alltagsrelevant angewandt werden. Die Subjektivität der semiquantitativen Auswertung der Western Blots wurde durch geblindete Auswertung durch zwei Betrachter so weit wie möglich minimiert.

Hinsichtlich des fehlenden Nachweises der Isoform 14-3-3- $\eta$ im Liquor oder des differierenden Auftretens von 14-3-3- $\tau$ bei den unterschiedlichen Subtypen konnten wir bislang leider keinen kausal erklärenden Zusammenhang finden. Wir konnten jedoch eindeutige Ergebnisse über das Vorhandensein und Fehlen verschiedener 14-3-3-Isoformen im Liquor von SCJK-Subtypen liefern und mögliche Erklärungen bzw. erklärende Aspekte formulieren. Es ergeben sich weitere Forschungsgebiete aus den hier aufgeworfenen Fragen, deren Klärung zu dem initial formulierten Ziel einer prämortalen, subtypen-spezifischen Diagnose beitragen könnte. 


\section{Zusammenfassung}

Die sporadische Creutzfeldt-Jakob-Krankheit gehört mit einer Inzidenz von 1-2/1 Millionen Einwohner $\mathrm{zu}$ den seltenen Transmissiblen Spongiformen Enzephalopathien, die, durch Prionen hervorgerufen, zu einer spongiformen Degeneration des Gehirns und konsekutiv immer zum Tode führen. Neben typischen Symptomkonstellationen, MRT- und EEG-Mustern ist der Nachweis des Proteins 143-3 im Liquor von Patienten mit sporadischer Creutzfeldt-Jakob-Krankheit in die prämortalen Diagnosekriterien der WHO eingegangen. In der hier vorliegenden Arbeit sollte untersucht werden, welche der sieben beim Menschen vorkommenden 14-3-3-Isoformen $(\beta, \gamma, \eta, \varepsilon, \zeta, \sigma, \tau)$ im Liquor der Patienten nachzuweisen sind und ob sie in einem bestimmten Muster bei den sechs verschiedenen Subtypen der sporadischen Creutzfeldt-Jakob-Krankheit (MM1, MM2, MV1, MV2, VV1, VV2) vorliegen. Variierende Krankheitsverläufe und v. a. Krankheitszeiten von durchschnittlich 4,4 Monaten beim MM1-Subtyp und 17,4 Monaten beim VV1-Subtyp mit jeweils letalem Ausgang waren Motivation zu vorliegender Fragestellung und möglicher diagnostischer Differenzierung der Subtypen.

Es wurden jeweils sieben bzw. vier Patienten jedes Subtyps, sowie acht Kontrollpatienten mit ischämischen bzw. entzündlichen Erkrankungen des Gehirns, mittels SDS-PAGE und Western Blot auf das Vorhandensein der sieben 14-3-3Isoformen im Liquor untersucht. Die ausgewählten Patienten stammten aus dem Nationalen Referenzzentrum für die Surveillance Transmissibler Spongiformer Enzephalopathien Göttingen. Der Liquor wurde jeweils im letzten Drittel der gesamten Krankheitsdauer entnommen und die Diagnose postmortal histopathologisch gesichert. Die verwendeten Primärantikörper stammten von der Firma IBL (Japan) und zeigten eine hohe Spezifität für die einzelnen 14-3-3Isoformen. Die aus den Western Blots erhaltenen Ergebnisse wurden semiquantitativ nach ihren Bandenintensitäten ([-] negativ, $[(+)]$ schwach positiv, $[+]$ positiv, $[++]$ stark positiv, $\left[{ }^{+++}\right]$sehr stark positiv, je 0-4 Punkte) und prozentual für jede Isoform und jeden Subtyp von zwei Beobachtern unabhängig ausgewertet. Außerdem wurde der Zusammenhang eines weiteren neurodegenerativen Markers, dem Tau-Protein, zu den im Liquor cerebrospinalis nachgewiesenen 14-3-3-Isoformen untersucht. 
In dieser Arbeit konnte gezeigt werden, dass bei allen SCJK-Subtypen vier der sieben Isoformen (14-3-3- $\beta,-\gamma,-\varepsilon,-\zeta)$ im Liquor nachweisbar sind, zwei Isoformen ( $\eta$ und $\sigma$ ) gar nicht gefunden wurden und 14-3-3- $\tau$ vereinzelt bei einigen $s C J K-$ Subtypen vorkam. Es konnten Tendenzen von subtypen-spezifischen Isoformmustern gesehen werden, die sich vor allem im Vorhandensein oder Fehlen von 14-3-3- $\tau$ und den Isoformkonzentrationen widerspiegeln. Wir konnten zeigen, dass ausgeprägte Neurodegeneration mit stärkeren Bandenintensitäten der verschiedenen 14-3-3-Isoformen, inklusive 14-3-3- $\tau$, beim Western Blot einhergeht. Wir konnten im Einklang mit diesem Ergebnis auch eine Korrelation zwischen der Höhe des Tau-Proteins und der Bandenstärken von 14-3-3-Isoformen feststellen. Es konnte außerdem gezeigt werden, dass insbesondere der Nachweis der 14-3-3- $\beta$ Isoform für die Diagnose der sporadischen Creutzfeldt-Jakob-Krankheit spricht und möglicherweise zur Differenzierung bei falsch-positivem 14-3-3-Nachweis dienen könnte, da diese Isoform überraschenderweise im 14-3-3-positiven Kontrollkollektiv nahezu nicht nachweisbar war. Für eine valide subtypen-spezifische Diagnose der sCJK bedarf es jedoch noch weiterer Forschung. 


\section{Literaturverzeichnis}

Aitken A, Collinge DB, van Heusden BP, Isobe T, Roseboom PH, Rosenfeld G, Soll J (1992): 14-3-3 proteins: a highly conserved, widespread family of eukaryotic proteins. Trends Biochem Sci 17, 498-501

Aitken A, Howell S, Jones D, Madrazo J, Patel Y (1995): 14-3-3 $\alpha$ and $\delta$ are the phosphorylated forms of raf-activating 14-3-3 $\beta$ and $\zeta$. In vivo stoichiometric phosphorylation in brain at a Ser-Pro-Glu-Lys motif. J Biol Chem $\underline{270}$, 57065709

Alonso A, Zaidi T, Novak M, Grundke-lqbal I, Iqbal K (2001): Hyperphosporylation induces self-assembly of $\tau$ into tangles of paired helical filaments/straight filaments. Proc Natl Acad Sci USA $\underline{98}$, 6923-6928

Atarashi R, Satoh K, Sano K, Fuse T, Yamaguchi N, Ishibashi D, Matsubara T, Nahagaki T, Yamanaka H, Shirabe S et al. (2011): Ultrasensitive human prion detection in cerebrospinal fluid by real-time quaking-induced conversion. Nat Med 17, 175-178

Autieri MV, Haines DS, Romanic AM, Ohlstein EH (1996): Expression of 14-3-3 gamma in injured arteries and growth factor- and cytokine-stimulated human vascular smooth muscle cells. Cell Growth Differ $\underline{7}, 1453-1460$

Baxter HC, Liu WG, Forster JL, Aitken A, Fraser JR (2002): Immunolocalisation of 14-3-3 isoforms in normal and scrapie-infected murine brain. Neuroscience $\underline{109}$, $5-14$

Berg D, Riess O, Bornemann A (2003): Specification of 14-3-3 proteins in Lewy bodies. Ann Neurol $\underline{54}, 135$

Boston PF, Jackson P, Kynoch PA, Thompson RJ (1982a): Purification, properties, and immunohistochemical localisation of human brain 14-3-3 protein. $\mathrm{J}$ Neurochem $\underline{38}, 1466-1474$ 
Boston PF, Jackson P, Thompson RJ (1982b): Human 14-3-3 protein: radioimmunoassay, tissue distribution, and cerebrospinal fluid levels in patients with neurological disorders. J Neurochem $\underline{38}, 1475-1482$

Brandel JP, Delasnerie-Lauprêtre N, Laplanche JL, Hauw JJ, Alpérovitch A (2000): Diagnosis of Creutzfeldt-Jakob disease: effect of clinical criteria on incidence estimates. Neurology $\underline{54}, 1095-1099$

Brown P, Preece M, Brandel JP, Sato T, McShane L, Zerr I, Fletcher A, Will RG, Pocchiari M, Cashman NR, et al. (2000): latrogenic Creutzfeldt-Jakob disease at the millennium. Neurology $\underline{55}, 1075-1081$

Budka H, Aguzzi A, Brown P, Brucher JM, Bugiani O, Gullotta F, Haltia M, Hauw JJ, Ironside JW, Jellinger K, et al. (1995): Neuropathological diagnostic criteria for Creutzfeldt-Jakob disease (CJD) and other human spongiform encephalopathies (prion diseases). Brain Pathol $\underline{5}$, 459-466

Castellani RJ, Colucci M, Xie Z, Zou W, Li C, Parchi P, Capellari S, Pastore M, Rahbar MH, Chen SG, Gambetti P (2004): Sensitivity of 14-3-3 protein test varies in subtypes of sporadic Creutzfeldt-Jakob disease. Neurology $\underline{63}$, 436442

Creutzfeldt HG (1920): Über eine eigenartige herdförmige Erkrankung des Zentralnervensystems (vorläufige Mitteilung). Z Ges Neurol Psychiatr $\underline{57}, 1-18$

Di Fede G, Giaccone G, Limido L, Mangieri M, Suardi S, Puoti G, Morbin M, Mazzoleni G, Ghetti B, Tagliavini F (2007): The $\varepsilon$ isoform of 14-3-3 protein is a component of the prion protein amyloid deposits of Gerstmann-SträusslerScheinker disease. J Neuropathol Exp Neurol $\underline{66}, 124-130$

EROS (The European Registers of Stroke Investigators) (2009): Incidence of Stroke in Europe at the Beginning of the 21st Century. Stroke $\underline{40}, 1557-1563$ 
Ford JC, al-Khodairy F, Fotou E, Sheldrick KS, Griffiths DJ, Carr AM (1994): 14-3-3 protein homologs required for the DNA damage checkpoint in fission yeast. Science $\underline{265}, 533-535$

Fu H, Subramanian RR, Masters SC (2000): 14-3-3 proteins: structure, function, and regulation. Annu Rev Pharmacol Toxicol $\underline{40}$, 617-647

Gajdusek DC, Gibbs CJ Jr (1968): Slow, latent and temperate virus infections of the central nervous system. Res Publ Assoc Res Nerv Ment Dis 444, 254-280

Gambetti P, Kong Q, Zou W, Parchi P, Chen SG (2003): Sporadic and familial CJD: classification and characterisation. Br Med Bull $\underline{66}$, 213-239

Gibbs CJ Jr, Gajdusek DC (1971): Transmission and characterization of the agents of spongiform virus encephalopathies: kuru, Creutzfeldt-Jakob disease, scrapie and mink encephalopathy. Res Publ Assoc Res Nerv Ment Dis $\underline{49}$, 383-410

Gmitterova K, Heinemann U, Bodemer M, Krasnianski A, Meissner B, Kretzschmar HA, Zerr I (2009): 14-3-3 CSF levels in sporadic Creutzfeldt-Jakob disease differ across molecular subtypes. Neurobiol Aging $\underline{30}$, 1842-1850

Hampel H, Blennow K, Shaw LM, Hoessler YC, Zetterberg H, Trojanowski JQ (2010): Total and phosphorylated tau protein as biological markers of Alzheimer's disease. Exp Gerontol 4도 $30-40$

Harrington MG, Merril CR, Asher DM, Gajdusek DC (1986): Abnormal proteins in the cerebrospinal fluid of patients with Creutzfeldt-Jakob disease. N Engl J Med $\underline{315}, 279-283$

Heinemann U, Krasnianski A, Meissner B, Varges D, Kallenberg K, Schulz-Schaeffer WJ, Steinhoff BJ, Grasbon-Frodl EM, Kretzschmar HA, Zerr I (2007): Creutzfeldt-Jakob disease in Germany: a prospective 12-year surveillance. Brain 130, 1350-1359 
Hermeking H, Benzinger A (2006): 14-3-3 proteins in cell cycle regulation. Semin Cancer Biol $\underline{16}$, 183-192

Hermeking H, Lengauer C, Polyak K, He TC, Zhang L, Thiagalingam S, Kinzler KW, Vogelstein B (1997): 14-3-3 sigma is a p53-regulated inhibitor of G2/M progression. Mol Cell $1,3-11$

Hill AF, Zeidler M, Ironside J, Collinge J (1997): Diagnosis of new variant CreutzfeldtJakob disease by tonsil biopsy. Lancet $\underline{349}, 99-100$

Hsich G, Kenney K, Gibbs CJ, Lee KH, Harrington MG (1996): The 14-3-3 brain protein in cerebrospinal fluid as a marker for transmissible spongiform encephalopathies. N Engl J Med $\underline{335}$, 924-930

Huang N, Marie SK, Livramento JA, Chammas R, Nitrini R (2003): 14-3-3 protein in the CSF of patients with rapidly progressive dementia. Neurology $\underline{61}, 354-357$

Ichimura T, Isobe T, Okuyama T, Yamauchi T, Fujisawa H (1987): Brain 14-3-3 protein is an activator protein that activates tryptophan 5-monooxygenase and tyrosine 3-monooxygenase in the presence of $\mathrm{Ca}^{2+}$, calmodulin-dependent protein kinase II. FEBS Lett $\underline{219}$, 79-82

Ichimura T, Isobe T, Okuyama T, Takahashi N, Araki K, Kuwano R, Takahashi Y (1988): Molecular cloning of cDNA coding for brain-specific 14-3-3 protein, a protein kinase-dependent activator of tyrosine and tryptophan hydroxylases. Proc Natl Acad Sci USA $\underline{85}, 7084-7088$

Isobe T, Ichimura T, Okuyama T (1989): Chemistry and cell biology of neuron- and

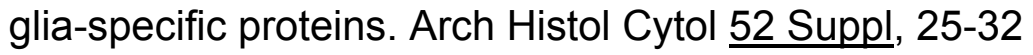

Jakob A (1921): Über eigenartige Erkrankungen des Zentralnervensystems mit bemerkenswertem anatomischen Befunde (Spastische PseudoskleroseEncephalomyelopathie mit disseminierten Degenerationsherden). Z Ges Neurol Psychiatr $\underline{64}, 147-228$ 
Jones DH, Ley S, Aitken A (1995): Isoforms of 14-3-3 protein can form homo- and heterodimers in vivo and in vitro: implications for function as adapter proteins. FEBS Lett $\underline{368}$, 55-58

Kallenberg K, Schulz-Schaeffer WJ, Jastrow U, Poser S, Meissner B, Tschampa HJ, Zerr I, Knauth M (2006): Creutzfeldt-Jakob disease: comparative analysis of MR imaging sequences. AJNR Am J Neuroradiol 27, 1459-1462

Kenney K, Brechtel C, Takahashi H, Kurohara K, Anderson P, Gibbs CJ Jr (2000): An enzyme-linked immunosorbent assay to quantify 14-3-3 proteins in the cerebrospinal fluid of suspected Creutzfeldt-Jakob disease patients. Ann Neurol 48, 395-398

Komori T, Ishizawa K, Arai N, Hirose T, Mizutani T, Oda M (2003): Immunoexpression of 14-3-3 proteins in glial cytoplasmic inclusions of multiple system atrophy. Acta Neuropathol 106, 66-70

Krasnianski A, Meissner B, Schulz-Schaeffer W, Kallenberg K, Bartl M, Heinemann U, Varges D, Kretzschmar HA, Zerr I (2006a): Clinical features and diagnosis of the MM2 cortical subtype of sporadic Creutzfeldt-Jakob disease. Arch Neurol $\underline{63}, 876-880$

Krasnianski A, Schulz-Schaeffer WJ, Kallenberg K, Meissner B, Collie DA, Roeber S, Bartl M, Heinemann U, Varges D, Kretzschmar HA, Zerr I (2006b): Clinical findings and diagnostic tests in the MV2 subtype of sporadic CJD. Brain $\underline{129}$, 2288-2296

Kretzschmar HA, Ironside JW, DeArmond SJ, Tateishi J (1996): Diagnostic criteria for sporadic Creutzfeldt-Jakob disease. Arch Neurol $\underline{53}, 913-920$

Ladogana A, Puopolo M, Croes EA, Budka H, Jarius C, Collins S, Klug GM, Sutcliffe T, Giulivi A, Alperovitch A, et al. (2005): Mortality from Creutzfeldt-Jakob disease and related disorders in Europe, Australia, and Canada. Neurology $\underline{64}$, 1586-1591 
Layfield R, Fergusson J, Aitken A, Lowe J, Landon M, Mayer RJ (1996): Neurofibrillary tangles of Alzheimer's disease brains contain 14-3-3 proteins. Neurosci Lett $\underline{209}$, 57-60

Lee KH, Harrington MG (1997): The assay development of a molecular marker for transmissible spongiform encephalopathies. Electrophoresis $\underline{18}, 502-506$

Leffers $H$, Madsen $P$, Rasmussen $H H$, Honoré $B$, Andersen $A H$, Walbum $E$, Vandekerckhove J, Celis JE (1993): Molecular cloning and expression of the transformation sensitive epithelial marker stratifin. A member of a protein family that has been involved in the protein kinase $C$ signalling pathway. J Mol Biol $\underline{231}, 982-998$

Maccioni RB, Cambiazo V (1995): Role of microtubule-associated proteins in the control of microtubule assembly. Physiol Rev $\underline{75}, 835-864$

Martin H, Patel Y, Jones D, Howell S, Robinson K, Aitken A (1993): Antibodies against the major brain isoforms of 14-3-3 protein. An antibody specific for the $\mathrm{N}$-acetylated amino-terminus of a protein. FEBS Lett $\underline{331}, 296-303$

Martin H, Rostas J, Patel Y, Aitken A (1994): Subcellular localisation of 14-3-3 isoforms in rat brain using specific antibodies. J Neurochem $\underline{63}, 2259-2265$

McConnell JE, Armstrong JF, Hodges PE, Bard JB (1995): The mouse 14-3-3 epsilon isoform, a kinase regulator whose expression pattern is modulated in mesenchyme and neuronal differentiation. Dev Biol 169, 218-228

Meissner B, Westner IM, Kallenberg K, Krasnianski A, Bartl M, Varges D, Bösenberg C, Kretzschmar HA, Knauth M, Schulz-Schaeffer WJ, et al. (2005): Sporadic Creutzfeldt-Jakob disease: clinical and diagnostic characteristics of the rare VV1 type. Neurology $\underline{65}, 1544-1550$ 
Meyer RK, McKinley MP, Bowman KA, Braunfeld MB, Barry RA, Prusiner SB (1986): Separation and properties of cellular and scrapie prion proteins. Proc Natl Acad Sci USA $\underline{83}, 2310-2314$

Mils V, Baldin V, Goubin F, Pinta I, Papin C, Wae M, Eychene A, Ducommun B (2000): Specific interaction between 14-3-3 isoforms and the human CDC25B phosphatase. Oncogene $\underline{19}, 1257-1265$

Mollenhauer B, Serafin S, Zerr I, Steinhoff BJ, Otto M, Scherer M, Schulz-Schaeffer WJ, Poser S (2003): Diagnostic problems during late course in CreutzfeldtJakob disease. J Neurol 250, 629-630

Moore BW, Perez VJ. Specific acidic proteins of the nervous system; in: Physiological and Biochemical Aspects of Nervous Integration; hrsg. v. Carlson FD; Prentice Hall, Englewood Cliffs, New Jersey 1968, 343-359

Muslin AJ, Tanner JW, Allen PM, Shaw AS (1996): Interaction of 14-3-3 with signalling proteins is mediated by the recognition of phosphoserine. Cell $\underline{84}$, 889-897

Neve RL, Harris P, Kosik KS, Kurnit DM, Donlon TA (1986): Identification of cDNA clones for the human microtubule-associated protein tau and chromosomal localization of the genes for tau and microtubule-associated protein 2. Brain Res $\underline{387}, 271-280$

Nielsen PJ (1991): Primary structure of a human protein kinase regulator protein. Biochim Biophys Acta 1088, 425-428

Nozaki I, Hamaguchi T, Sanio N, Noguchi-Shinohara M, Sakai K, Nakamura Y, Sato T, Kitamoto T, Mizusawa H, Moriwaka F et al. (2010): Prospective 10-year surveillance of human prion diseases in Japan. Brain $\underline{133}$, 3043-3057. 
Oesch B, Westaway D, Wälchli M, McKinley MP, Kent SB, Aebersold R, Barry RA, Tempst P, Teplow DB, Hood LE, et al. (1985): A cellular gene encodes scrapie PrP 27-30 protein. Cell $\underline{40}$, 735-746

Otto M, Wiltfang J, Tumani H, Zerr I, Lantsch M, Kornhuber J, Weber T, Kretzschmar HA, Poser S (1997): Elevated levels of tau-protein in cerebrospinal fluid of patients with Creutzfeldt-Jakob disease. Neurosci Lett $\underline{225}, 210-212$

Otto M, Wiltfang J, Cepek L, Neumann M, Mollenhauer B, Steinacker P, Ciesielczyk B, Schulz-Schaeffer W, Kretzschmar HA, Poser S (2002): Tau protein and 14-33 protein in the differential diagnosis of Creutzfeldt-Jakob disease. Neurology $\underline{58}, 192-197$

Owen F, Poulter M, Collinge J, Crow TJ (1990): Codon 129 changes in the prion protein gene in Caucasians. Am J Hum Genet $\underline{46}, 1215-1216$

Pan KM, Baldwin M, Nguyen J, Gasset M, Serban A, Groth D, Mehlhorn I, Huang Z, Fletterick RJ, Cohen FE, et al. (1993): Conversion of alpha-helices into betasheets features in the formation of the scrapie prion proteins. Proc Natl Acad Sci USA $\underline{90}, 10962-10966$

Parchi P, Gambetti P (1995): Human prion diseases. Curr Opin Neurol $\underline{8}, 286-293$

Parchi P, Castellani R, Capellari S, Ghetti B, Young K, Chen SG, Farlow M, Dickson DW, Sima AA, Trojanowski JQ, et al. (1996): Molecular basis of phenotypic variability in sporadic Creutzfeldt-Jakob disease. Ann Neurol $\underline{39}, 767-778$

Parchi P, Giese A, Capellari S, Brown P, Schulz-Schaeffer W, Windl O, Zerr I, Budka H, Kopp N, Piccardo P, et al. (1999): Classification of sporadic CreutzfeldtJakob disease based on molecular and phenotypic analysis of 300 subjects. Ann Neurol 느, 224-233

Pocchiari M, Puopolo M, Croes EA, Budka H, Gelpi E, Collins S, Lewis V, Sutcliffe T, Guilivi A, Delasnerie-Laupretre N, et al. (2004): Predictors of survival in sporadic 
Creutzfeldt-Jakob disease and other human transmissible spongiform encephalopathies. Brain $\underline{127}$, 2348-2359

Pozuelo Rubio M, Geraghty KM, Wong BH, Wood NT, Campbell DG, Morrice N, Mackintosh C (2004): 14-3-3-affinity purification of over 200 human phosphoproteins reveals new links to regulation of cellular metabolism, proliferation and trafficking. Biochem J $\underline{379}, 395-408$

Prasad GL, Valverius EM, McDuffie E, Cooper HL (1992): Complementary DNA cloning of a novel epithelial cell marker protein, HME1, that may be downregulated in neoplastic mammary cells. Cell Growth Differ $\underline{3}, 507-513$

Prusiner SB (1982): Novel proteinaceous infectious particles cause scrapie. Science $\underline{216}, 136-144$

Prusiner SB (1989) : Scrapie prions. Annu Rev Microbiol 433, 345-374

Prusiner SB, Groth DF, Bolton DC, Kent SB, Hood LE (1984): Purification and structural studies of a major scrapie prion protein. Cell $\underline{38}, 127-134$

Saiz A, Graus F, Dalmau J, Pifarre A, Marin C, Tolosa E (1999): Detection of 14-3-3 brain protein in the cerebrospinal fluid of patients with paraneoplastic neurological disorders. Ann Neurol $\underline{46}, 774-777$

Sanchez-Juan P, Green A, Ladogana A, Cuadrado-Corrales N, Sáanchez-Valle R, Mitrováa E, Stoeck K, Sklaviadis T, Kulczycki J, Hess K, et al. (2006): CSF tests in the differential diagnosis of Creutzfeldt-Jakob disease. Neurology $\underline{67}, 637-643$

Sanchez-Juan P, Sánchez-Valle R, Green A, Ladogana A, Cuadrado-Corrales N, Mitrová E, Stoeck K, Sklaviadis T, Kulczycki J, Hess K, et al. (2007): Influence of timing on CSF tests value for Creutzfeldt-Jakob disease diagnosis. J Neurol 254, 901-906 
Sanchez-Valle R, Saiz A, Graus F (2002): 14-3-3 protein isoforms and atypical patterns of the 14-3-3 assay in the diagnosis of Creutzfeldt-Jakob disease. Neurosci Lett $\underline{320}, 69-72$

Satoh J, Onoue H, Arima K, Yamamura T (2005): The 14-3-3 protein forms a molecular complex with heat shock protein Hsp60 and cellular prion protein. $J$ Neuropathol Exp Neurol $\underline{64}, 858-868$

Shiga Y, Wakabayashi H, Miyazawa K, Kido H, Itoyama Y (2006): 14-3-3 protein levels and isoform patterns in the cerebrospinal fluid of Creutzfeldt-Jakob disease patients in the progressive and terminal stages. J Clin Neurosci $\underline{13}$, 661-665

Sparkes RS, Simon M, Cohn VH, Fournier RE, Lem J, Klisak I, Heinzmann C, Blatt C, Lucero M, Mohandas T, et al. (1986): Assignment of the human and mouse prion protein genes to homologous chromosomes. Proc Natl Acad Sci USA $\underline{83}$, 7358-7362

Steinacker P, Schwarz P, Reim K, Brechlin P, Jahn O, Kratzin H, Aitken A, Wiltfang J, Aguzzi A, Bahn E, et al. (2005): Unchanged survival rates of 14-3-3gamma knockout mice after inoculation with pathological prion protein. Mol Cell Biol $\underline{25}$, 1339-1346

Takahashi H, Iwata T, Kitagawa Y, Takahashi RH, Sato Y, Wakabayashi H, Takashima M, Kido H, Nagashima K, Kenney K, et al. (1999): Increased levels of epsilon and gamma isoforms of 14-3-3 proteins in cerebrospinal fluid in patients with Creutzfeldt-Jakob disease. Clin Diagn Lab Immunol $\underline{6}$, 983-985

Taylor DM, Fraser H, McConnell I, Brown DA, Brown KL, Lamza KA, Smith GRA (1994): Decontamination studies with the agents of bovine spongiform encephalopathy and scrapie. Arch Virol 139, 313-326

Toyo-oka K, Shionoya A, Gambello MJ, Cardoso C, Leventer R, Ward HL, Ayala R, Tsai LH, Dobyns W, Ledbetter D et al. (2003): 14-3-3epsilon is important for 
neuronal migration by binding to NUDEL: a molecular explanation for MillerDieker syndrome. Nat Genet $\underline{34}, 274-285$

Umahara T, Uchihara T, Tsuchiya K, Nakamura A, Ikeda K, Iwamoto T, Takasaki M (2004): Immunolocalization of 14-3-3 isoforms in brains with Pick body disease. Neurosci Lett $\underline{371}$, 215-219

Vandermeeren M, Mercken M, Vanmechelen E, van Six J, van de Voorde A, Martin JJ, Cras P (1993): Detection of tau proteins in normal and Alzheimer's disease cerebrospinal fluid with a sensitive sandwich enzyme-linked immunosorbent assay. J Neurochem $\underline{61}, 1828-1834$

Van Everbroeck B, Quoilin S, Boons J, Martin JJ, Cras P (2003): A prospective study of CSF markers in 250 patients with possible Creutzfeldt-Jakob disease. J Neurol Neurosurg Psychiatry $\underline{74}, 1210-1214$

Van Everbroeck B, Boons J, Cras P (2005): Cerebrospinal fluid biomarkers in Creutzfeldt-Jakob disease. Clin Neurol Neurosurg 107, 355-360

Van Hemert MJ, Steensma HY, van Heusden GP (2001): 14-3-3 proteins: key regulators of cell division, signalling and apoptosis. Bioessays $\underline{23}$, 936-946

Vigo-Pelfrey, Seubert P, Barbour R, Blomquist C, Lee M, Lee D, Coria F, Chang L, Miller B, Lieberburg I, et al. (1995): Elevation of microtubule-associated protein tau in the cerebrospinal fluid of patients with Alzheimer's disease. Neurology $\underline{45}$, 788-793

Vincenz C, Dixit VM (1996): 14-3-3 proteins associate with A20 in an isoform-specific manner and function both as chaperone and adapter molecules. J Biol Chem $\underline{271}, 20029-20034$

Wakabayashi H, Yano M, Tachikawa N, Oka S, Maeda M, Kido H (2001): Increased concentrations of 14-3-3 epsilon, gamma and zeta isoforms in cerebrospinal fluid of AIDS patients with neuronal destruction. Clin Chim Acta 312, 97-105 
Watanabe $M$, Isobe T, Ichimura T, Kuwano R, Takahashi $Y$, Kondo $H$, Inoue $Y$ (1994): Molecular cloning of rat cDNAs for the zeta and theta subtypes of 14-3-3 protein and differential distributions of their mRNAs in the brain. Brain Res Mol Brain Res $\underline{25}, 113-121$

WHO (1998): Human transmissible spongiform encephalopathies. Wkly Epidemiol $\operatorname{Rec} \underline{47}, 361-365$

Will RG, Ironside JW, Zeidler M, Cousens SN, Estibeiro K, Alperovitch A, Poser S, Pocchiari M, Hofmann A, Smith PG (1996): A new variant of Creutzfeldt-Jakob disease in the UK. Lancet $\underline{347}$, 921-925.

Wiltfang J, Otto M, Baxter HC, Bodemer M, Steinacker P, Bahn E, Zerr I, Kornhuber J, Kretzschmar HA, Poser S, et al. (1999): Isoform pattern of 14-3-3 proteins in the cerebrospinal fluid of patients with Creutzfeldt-Jakob disease. J Neurochem $\underline{73}, 2485-2490$

Windl O, Dempster M, Estibeiro JP, Lathe R, de Silva R, Esmonde T, Will R, Springbett A, Campbell TA, Sidle KC, et al. (1996): Genetic basis of CreutzfeldtJakob disease in the United Kingdom: a systematic analysis of predisposing mutations and allelic variation in the PRNP gene. Hum Genet $\underline{98}, 259-264$

Xiao B, Smerdon SJ, Jones DH, Dodson GG, Soneji Y, Aitken A, Gamblin SJ (1995): Structure of a 14-3-3 protein and implications for coordination of multiple signalling pathways. Nature $\underline{376}, 188-191$

Yaffe MB (2002): How do 14-3-3 proteins work? - Gatekeeper phosphorylation and the molecular anvil hypothesis. FEBS Lett $\underline{513}, 53-57$

Yamauchi T, Nakata H, Fujisawa H (1981): A new activator protein that activates tryptophan 5-monooxygenase and tyrosine 3-monooxygenase in the presence of Ca2+-, calmodulin-dependent protein kinase. Purification and characterization. J Biol Chem 256, 5404-5409 
Zerr I, Bodemer M, Otto M, Poser S, Windl O, Kretzschmar HA, Gefeller O, Weber T (1996): Diagnosis of Creutzfeldt-Jakob disease by two-dimensional gel electrophoresis of cerebrospinal fluid. Lancet $\underline{348}, 846-849$

Zerr I, Bodemer M, Gefeller O, Otto M, Poser S, Wiltfang J, Windl O, Kretzschmar HA, Weber T (1998): Detection of 14-3-3 protein in the cerebrospinal fluid supports the diagnosis of Creutzfeldt-Jakob disease. Ann Neurol $\underline{43}, 32-40$

Zerr I, Pocchiari M, Collins S, Brandel JP, de Pedro Cuesta J, Knight RS, Bernheimer H, Cardone F, Delasnerie-Lauprêtre N, Cuadrado Corrales N, et al. (2000a): Analysis of EEG and CSF 14-3-3 proteins as aids to the diagnosis of Creutzfeldt-Jakob disease. Neurology $\underline{55}, 811-815$

Zerr I, Schulz-Schaeffer WJ, Giese A, Bodemer M, Schröter A, Henkel K, Tschampa HJ, Windl O, Pfahlberg A, Steinhoff BJ, et al. (2000b): Current clinical diagnosis in Creutzfeldt-Jakob Disease: Identification of uncommon variants. Ann Neurol $\underline{48}, 323-329$

Zerr I, Kallenberg K, Summers DM, Romero C, Taratuto A, Heinemann U, Breithaupt M, Varges D, Meissner B, Ladogana A, et al. (2009): Updates clinical diagnostic criteris for sporadic Creutzfeldt-Jakob disease. Brain 132, 2659-2668 


\section{Danksagung}

Die Durchführung und Abfassung dieser Arbeit wäre nicht möglich gewesen ohne die Unterstützung und Förderung der im Folgenden genannten Personen, denen ich deshalb zu besonderem Dank verpflichtet bin.

Frau Prof. Dr. med. Inga Zerr, Leiterin der Prionforschungsgruppe Göttingen, danke ich für die Möglichkeit in ihrer Abteilung zu promovieren und in ihrer Arbeitsgruppe mitgearbeitet zu haben und für die konstruktive Kritik

Bei meiner Betreuerin Dr. med. Uta Heinemann möchte ich mich ganz herzlich für die gemeinsame Themenfindung, ihr lebhaftes Interesse, für ihre Anregungen und die motivierende Unterstützung während der gesamten Zeit dieser Arbeit bedanken.

Des Weiteren danke ich allen wissenschaftlichen Mitarbeitern der Prionforschungsgruppe Göttingen für die interessierte Hilfestellung und die sehr angenehme Arbeitsatmosphäre. Insbesondere bin ich loanna Gawinecka, Barbara Ciesielczyk und Monika Bodemer für ihr kontinuierliches Engagement, ihre Hilfe und freundschaftliche Unterstützung v. a. während der gesamten Laborphase zu außerordentlichem Dank verpflichtet. In diesem Zusammenhang danke ich KaiHenrik Peiffer für sein endloses Interesse, seinen Rückhalt und die Korrekturen an dieser Arbeit.

An dieser Stelle möchte ebenfalls ich dankend erwähnen die herrausragende Rolle meiner wunderbaren Eltern und Schwester, Dr. med. Smita R. Jategaonkar, die mir mit ihrer immerwährenden Unterstützung und Motivation während der gesamten Arbeit zur Seite gestanden haben und deren fortwährendes Interesse die Entstehung dieser Arbeit erst möglich gemacht hat. 


\section{Curriculum vitae}

Ich, Swati Ravindra Jategaonkar, wurde am 11. 11. 1984 als zweite Tochter meiner Eltern, Dr. Ravindra V. Jategaonkar und Padma R. Jategaonkar, in Bangalore, Indien geboren. Seit meinem zweiten Lebensjahr lebe ich mit meiner Familie in Deutschland, habe von 1990-1996 Grundschule und Orientierungsstufe in Braunschweig besucht, sowie von 1996-2003 das Gymnasium Neue Oberschule in Braunschweig, welches ich mit dem Abitur der Note 1,0 abschloss. Im Jahre 2003 immatrilulierte ich mich für das Medizinstudium an der Georg-August Universität in Göttingen, legte 2005 den ersten Abschnitt der Ärztlichen Prüfung mit der Note 2 ab und famulierte in den folgenden zwei Jahren in Österreich, den USA und der Schweiz. Ich absolvierte 2008/2009 regelrecht das Praktische Jahr, zunächst in England, dann in Oldenburg und abschließend in Bremen. Im Oktober/November 2009 absolvierte ich erfolgreich den zweiten Abschnitt der Ärztlichen Prüfung mit der Note 1,5. Während meines gesamten Studiums wurde ich als Stipendiatin durch die Studienstiftung des deutschen Volkes gefördert. Seit Januar 2010 arbeite ich als Assistenzärztin in der Frauenklinik der Universitätsklinik Frankfurt. 